Prepared for the U.S. Department of Energy under Contract DE-AC05-76RL01830

\title{
ANSI/ASHRAE/IESNA Standard 90.1-2007 Final Determination Quantitative Analysis
}
M Halverson
E Richman
B Liu
D Winiarski

May 2011

Pacific Northwest

NATIONAL LABORATORY

Proudly Operated by Battelle Since 1965 


\title{
DISCLAIMER
}

This report was prepared as an account of work sponsored by an agency of the United States Government. Neither the United States Government nor any agency thereof, nor Battelle Memorial Institute, nor any of their employees, makes any warranty, express or implied, or assumes any legal liability or responsibility for the accuracy, completeness, or usefulness of any information, apparatus, produet, or process disclosed, or represents that its use would not infringe privately owned rights. Reference herein to any specific commercial product, process, or service by trade name, trademark, manufacturer, or otherwise does not necessarily constitute or imply its endorsement, recommendation, or favoring by the United States Government or any agency thereof, or Battelle Memorial Institute. The views and opinions of authors expressed herein do not necessarily state or reflect those of the United States Government or any agency thereof

\author{
PACIFIC NORTHWEST NATIONAL LABORATORY \\ operated by \\ BATTELLE \\ for the \\ UNITED STATES DEPARTMENT OF ENERGY \\ under Contract DE-AC0 5-76RL01830 \\ Printed in the United States of America \\ Available to DOE and DOE contractors from the \\ Office of Scientific and Technical Information, \\ P.O. Box 62, Oak Ridge, TN 37831-0062; \\ ph: (865) 576-8401 \\ fax: $(865) 576-5728$ \\ email: reports@adonis.osti.gov \\ Available to the public from the National Technical Information Service, \\ U.S. Department of Commerce, 5285 Port Royal Rd., Springfield, VA 22161 \\ ph: (800) $553-6847$
fax: $(703) 605-6900$ \\ email: orders $(a$ ntis.fedworld.gov \\ online ordering: http://www.ntis.gov/ordering.htm
}

(

This document was printed on recycled paper.

$(9 / 2003)$ 


\title{
ANSI/ASHRAE/IESNA Standard 90.1-2007 Final Determination Quantitative Analysis
}

\author{
M Halverson \\ E Richman \\ B Liu \\ D Winiarski
}

May 2011

Prepared for the U.S. Department of Energy under Contract DE-AC05-76RL01830

Pacific Northwest National Laboratory

Richland, Washington 99352 



\section{Summary}

The United States (U.S.) Department of Energy (DOE) conducted a final quantitative analysis to assess whether buildings constructed according to the requirements of the American National Standards Institute (ANSI)/American Society of Heating, Refrigerating and Air-Conditioning Engineers (ASHRAE)/Illuminating Engineering Society of North America (IESNA) Standard 90.1-2007 would result in energy savings compared with buildings constructed to ANSI/ASHRAE/IESNA Standard 90.12004. The final analysis considered each of the 44 addenda to ANSI/ASHRAE/IESNA Standard 90.12004 that were included in ANSI/ASHRAE/IESNA Standard 90.1-2007. All 44 addenda processed by ASHRAE in the creation of Standard 90.1-2007 from Standard 90.1-2004 were reviewed by DOE, and their combined impact on a suite of 15 building prototype models in 15 ASHRAE climate zones was considered. Most addenda were deemed to have little quantifiable impact on building efficiency for the purpose of DOE's final determination. However, out of the 44 addenda, 9 were preliminarily determined to have measureable and quantifiable impact.

A suite of 225 computer energy simulations for building prototypes complying with ASHRAE 90.12004 was developed. These prototypes were then modified in accordance with these 9 addenda to create a second suite of corresponding building simulations reflecting the same buildings compliant with Standard 90.1-2007. The building simulations were conducted using the DOE EnergyPlus building simulation software. The resulting energy use from the complete suite of 450 simulation runs was then converted to energy use intensity (EUI, or energy use per unit floor area) metrics (Site EUI, Primary EUI, and energy cost intensity (ECI)) results for each simulation. For each version of the Standard, these energy use intensities were then aggregated to a national basis for each prototype using construction-floor-area based weighting factors developed for each of the 15 U.S. climate zones using commercial construction data. When compared, the resulting weighted energy use intensities showed that each of the 15 building prototypes used less energy under Standard 90.1-2007 than under Standard 90.1-2004 on a national basis when considering site energy, primary energy, or energy cost. The energy use intensities were also aggregated across building types to a national commercial building basis using the same weighting data. On a national basis, the final quantitative analysis estimated a floor-space-weighted national average reduction in new building energy consumption of 3.9 percent for source energy and 4.6 percent when considering site energy. A 3.9 percent savings in energy cost, based on national average commercial energy costs for electricity and natural gas, was also estimated. These final results support a positive determination of energy savings for Standard 90.1-2007. 



\section{Acronyms and Abbreviations}

AFUE

ANSI

ARI

ASHRAE

ASTM

BECP

Btu

CAV

$\mathrm{cfm}$

CBECS

DOE

$\mathrm{ECB}$

ECI

EIA

EPCA

EPACT

EUI

FCU

$\mathrm{ft}^{2}$

hp

$\mathrm{h}$

in. wc

HVAC

IESNA

kBtu

$\mathrm{kW}$

$\mathrm{kWh}$

LPD

PBA

PNNL

PTAC

PTHP

SHGC

SRI

SSPC

TMY

U.S.

VAV

W annual fuel utilization efficiency

American National Standards Institute

Air-Conditioning and Refrigeration Institute

American Society of Heating, Refrigerating and Air-Conditioning Engineers

American Society for Testing and Materials

Building Energy Codes Program

British thermal units

constant air volume

cubic feet per minute

Commercial Building Energy Consumption Survey

U.S. Department of Energy

energy cost budget

energy cost intensity

Energy Information Administration

Energy Policy and Conservation Act

Energy Policy Act (of 1992)

energy use intensity

fan coil unit

square feet

horsepower

hour(s)

inches water column

heating, ventilating, and air conditioning

Illuminating Engineering Society of North America

kilo British thermal unit

kilowatt(s)

kilowatt hour(s)

lighting power density

principal building activity

Pacific Northwest National Laboratory

packaged terminal air conditioner

packaged terminal heat pump

solar heat gain coefficient

Solar Reflectance Index

Standing Standards Product Committee

typical meteorological year

United States

variable air volume

watt(s) 



\section{Contents}

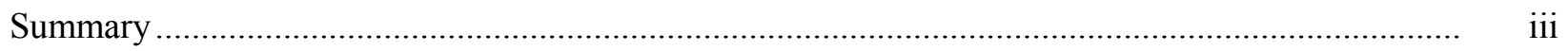

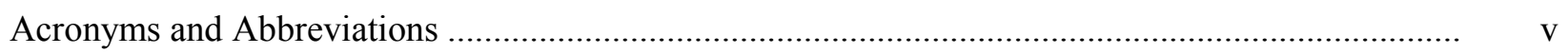

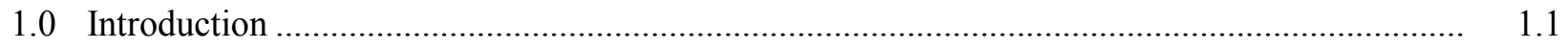

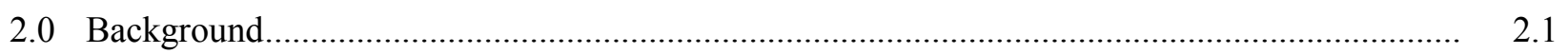

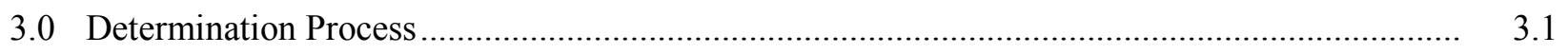

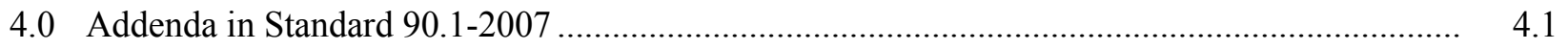

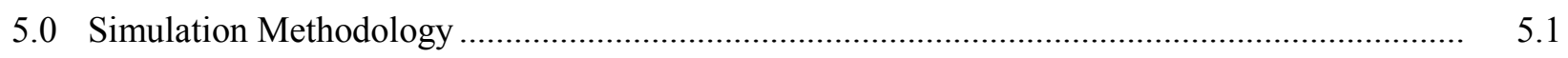

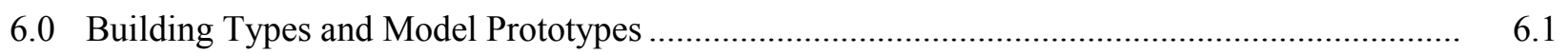

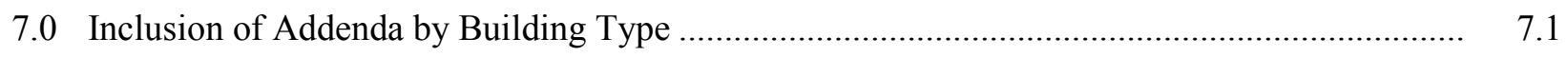

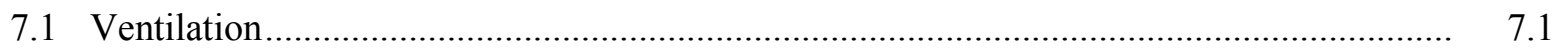

7.2 Equipment Efficiency and Mandatory Federal Efficiency Standards ............................... 7.2

8.0 Modeling of Specific Addenda ........................................................................................ 8.1

8.1 Addendum 90.1-04c - Vestibules .......................................................................... 8.1

8.2 Addendum 90.1-04q - Off-Hour Controls Exception for Hotel/Motel Removed .............. 8.3

8.3 Addendum 90.1-04v - Update for Demand-Controlled Ventilation Requirements............ 8.4

8.4 Addendum 90.1-04ac - Fan Power Requirements ........................................................ 8.5

8.5 Addendum 90.1-04ai - Lighting in Retail Buildings .................................................... 8.7

8.6 Addendum 90.1-04an - Boiler Efficiency Change ...................................................... 8.9

8.7 Addendum 90.1-04ar - Part Load Fan Power Limitation Modification .............................. 8.10

8.8 Addendum 90.1-04as - Opaque Envelope U-Factors Updates ........................................ 8.11

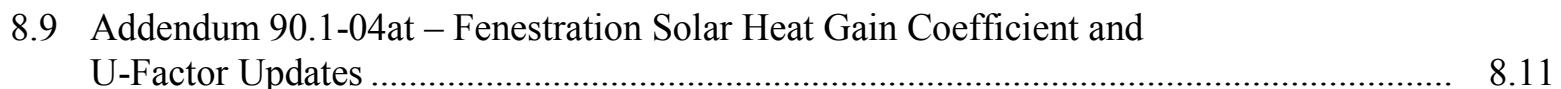

9.0 Simulation of Prototypes and Extraction of Results ......................................................... 9.1

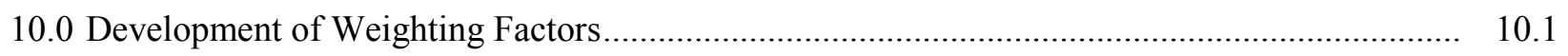

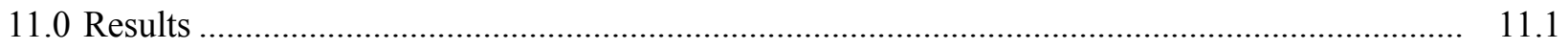

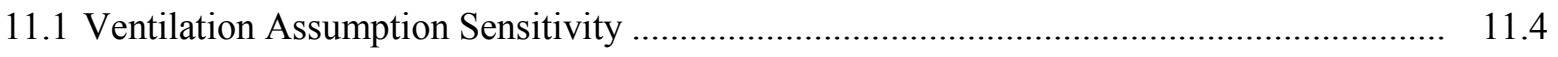

Appendix A - Vestibule Requirement and Door Infiltration Modeling ............................................ A.1

Appendix B - Development of Additional Lighting Power for the Strip Mall Prototype................... B.1 


\section{Tables}

4.1 Addenda to ASHRAE Standard 90.1-2004, Changes Identified.............................................. 4.2

6.1 ASHRAE Commercial Reference Building Models ............................................................ 6.1

7.1 Addenda Included in Quantitative Analysis and Affected Building Models ............................ 7.4

8.1 Special Consideration Addenda ..................................................................................... 8.1

8.2 ASHRAE 90.1-2004 Vestibule Requirement for All Prototypes in Each Zone*..................... 8.3

8.3 ASHRAE 90.1-2007 Vestibule Requirement for All Prototypes in Each Zone*...................... 8.3

8.4 Rules for Establishing Fan Power in Quantitative Analysis Simulations ................................. 8.6

8.5 Internal Lighting Power Density Used in Building Models ................................................. 8.8

8.6 Boiler Efficiency Assumptions Used in Quantitative Analysis ............................................ 8.10

8.7 Coefficients for VAV Part-Load Curves.......................................................................... 8.11

10.1 Relative Construction Volume Weights for 15 ASHRAE Building Prototypes

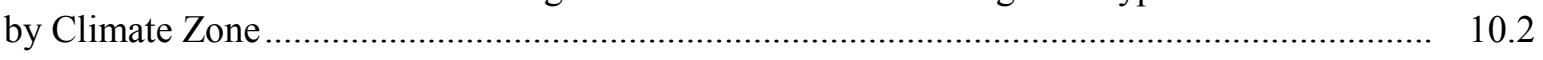

11.1 Estimated Energy Use Intensity by Building Type - 2004 Edition ...................................... 11.1

11.2 Estimated Energy Use Intensity by Building Type - 2007 Edition ...................................... 11.2

11.3 Estimated Percent Energy Savings with 2007 Edition - by Building Type............................. 11.3

11.4 Estimated Energy Use Intensity by Building Type - 2004 Edition ...................................... 11.4

11.5 Estimated Energy Use Intensity by Building Type - 2007 Edition ....................................... 11.5

11.6 Estimated Percent Energy Savings with 2007 Edition - by Building Type.............................. 11.5 


\subsection{Introduction}

In support of the United States (U.S.) Department of Energy's (DOE) determination of energy savings of American National Standards Institute (ANSI)/American Society of Heating, Refrigerating and Air-Conditioning Engineers (ASHRAE)/Illuminating Engineering Society of North America (IESNA) Standard 90.1-2007 (ASHRAE 90.1-2007), staff from Pacific Northwest National Laboratory's (PNNL) Building Energy Codes Program (BECP) prepared an assessment of the relative energy use for commercial buildings designed to meet building design requirements found in ASHRAE 90.1-2007 as opposed to meeting design requirements found in ASHRAE 90.1-2004.

This document provides an evaluation of the energy savings achieved from use of ANSI/ASHRAE/IESNA Standard 90.1-2007 over its predecessor, ANSI/ASHRAE/IESNA Standard 90.1-2004. The evaluation was carried out using computer simulations of prototype buildings constructed to both Standard 90.1-2004 and Standard 90.1-2007 across a range of U.S. climates. Each building prototype used in the simulation analysis was first developed as a computer model in accordance with design and construction requirements found in Standard 90.1-2004. Changes to the building model, consistent with addenda published to Standard 90.1-2004 in the development of Standard 90.1-2007, were made to reflect the building as constructed under the requirements of Standard 90.1-2007. The set of Standard 90.1-2004 buildings and Standard 90.1-2007 buildings were simulated and energy use statistics were extracted from each building model in the form of annual energy use by fuel type. The annual energy use was then converted to energy use intensity (EUI) figures expressed in energy use per square foot $\left(\mathrm{ft}^{2}\right)$. Using weighting factors by building type and geographic area developed from 5 years of recent construction data, these energy use statistics were then aggregated to national levels for each revision of the Standard 90.1, both by building prototype and weighted across building type. DOE used this data to assess whether a positive determination can be made for ASHRAE Standard 90.1-2007.

The document describes

- characterization of the building models,

- characterization of the addenda to be modeled for ASHRAE 90.1-2007,

- the simulation tool used,

- translation of the addendum into engineering parameters used in the computer simulations,

- use of Building Construction weights to aggregate results from simulations across building types and locations into national results, and,

- results of the analysis with regard to the overall EUI for buildings under both Standards and the energy and energy cost savings of the standard (expressed as a percentage change in EUI). 



\subsection{Background}

The Energy Policy and Conservation Act (EPCA), as amended by the Energy Policy Act (EPACT) of 1992, requires individual States to adopt commercial building energy standards that meet or exceed the energy performance of ANSI/ASHRAE/IESNA Standard 90.1-1989. When this standard or any later version of ASHRAE Standard 90.1 is amended, DOE is required to do a determination of energy savings comparing the amended version and previous version of the standard to determine if the amended version provides greater energy efficiency than the previous version and would therefore save energy in commercial buildings. If DOE makes a positive determination of energy savings, individual States have 2 years after publication of such a determination to certify to DOE that they have updated their State commercial building energy codes to meet or exceed the efficiency of the modified ASHRAE Standard 90.1. EPACT specifies that DOE has 12 months to make this determination from the time the ASHRAE Standard 90.1 is amended. DOE has determined that amendment, in this context, is the publication of a revised version of ASHRAE Standard 90.1 incorporated one or more addenda to Standard 90.1.

On December 30, 2008, DOE issued a positive determination of energy savings for Standard 90.12004 that concluded that Standard 90.1-2004 "would achieve greater energy efficiency in buildings subject to the code, than the 1999 edition (Standard 90.1-1999 or the 1999 edition)." 73 FR 79868. Consequently, DOE has determined that Standard 90.1-2004 represents the baseline to which Standard 90.1-2007 requirements are compared for the purpose of a determination of energy savings for Standard 90.1-2007.

On September 3, 2010, DOE issued a preliminary determination that Standard 90.1-2007 would achieve greater energy efficiency in buildings subject to the code, than the 2004 edition (Standard 90.12004 or the 2004 edition). Accompanying that determination were two PNNL documents detailing the qualitative $^{1}$ and quantitative ${ }^{2}$ analyses that fed into the determination. Comments were accepted on the preliminary determination until October 4, 2010. No comments were received on qualitative or quantitative reports. The preliminary quantitative (numerical) savings report provided the basis of this report.

This document provides the quantitative (numerical) savings estimate used for DOE's final determination of energy savings for Standard 90.1-2007. The quantitative savings estimate is obtained by simulating a set of prototypical buildings under the requirements of Standard 90.1-2004, then again under Standard 90.1-2007, and then comparing the results. Results are weighted by building type and climate zone to obtain national average estimates.

\footnotetext{
${ }^{1}$ Halverson, M, B Liu, E Richman, and D Winiarski. May 2010. ANSI/ASHRAE/IESNA Standard 90.1-2007 Preliminary Qualitative Determination. Pacific Northwest National Laboratory. PNNL-19791

${ }^{2}$ Halverson, M, B Liu, E Richman, and D Winiarski. May 2010. ANSI/ASHRAE/IESNA Standard 90.1-2007

Preliminary Determination Quantitative Analysis. Pacific Northwest National Laboratory. PNNL-19789
} 



\subsection{Determination Process}

DOE typically requests two types of analysis from the BECP in a determination of energy savings for a revised Standard 90.1. The first is a qualitative analysis that attempts to identify all the changes made to the baseline version of Standard 90.1 to create the revised standard and categorize the changes as having a positive, negative, or neutral impact on energy efficiency in Standard 90.1. No attempt is made to estimate the numerical energy savings either in absolute terms or as a percentage of baseline energy use in the qualitative analysis. Rather, the qualitative analysis discusses qualitatively the significance of each addendum in terms of energy consumption in buildings and whether it appears that the addenda will likely save energy, result in higher energy use, or be largely neutral with regard to energy efficiency. Three steps are typically undertaken in the qualitative analysis. The first step is to identify all changes made to Standard 90.1. The second step is to estimate qualitatively the impact of each change on the energy efficiency of Standard 90.1. The third step is to look at the changes and categorize them into those that have a clear impact on stringency of requirements in the standard, and of these, those that can or cannot be incorporated in DOE's quantitative analysis.

The second type of analysis that BECP performs for DOE is the quantitative analysis of energy savings on Standard 90.1. This analysis uses the results of the qualitative analysis to identify what addenda should be incorporated into the building models used for whole building simulation. These addenda are then reflected as changes in the particular building models to represent compliance with Standard 90.1-2007. 



\subsection{Addenda in Standard 90.1-2007}

DOE prepared a qualitative assessment of the addenda to Standard 90.1-2007 and published it as a web document in support of a final assessment of energy savings. ${ }^{1}$ The qualitative analysis contains the complete list of addenda processed by ASHRAE for ANSI/ASHRAE/IESNA Standard 90.1-2007. A total of 44 addenda to 90.1-2004 exist. All addenda were applied to ASHRAE Standard 90.1-2004 to create ASHRAE Standard 90.1-2007. ASHRAE/IESNA Standard 90.1-2007 incorporates ASHRAE Standard 90.1-2004 and addenda a, b, c, d, e, f, g, h, i, j, k, 1, m, n, o, p, q, r, s, t, u, v, x, y, aa, ab, ac, ad, ae, af, ag, ah, ai, aj, ak, al, am, an, ap, aq, ar, as, at, and av to ASHRAE Standard 90.1-2004. The qualitative analysis lists each addendum and describes how the text of the standard is affected by the change and how that will likely impact the efficiency of new buildings constructed to the standard in the United States. The qualitative analysis also identifies what portion of the standard is affected by the change. ASHRAE Standard 90.1-2004 includes addenda that

- are purely editorial in nature,

- update prescriptive design and construction requirements for the envelope, lighting, and mechanical sections of the Standard,

- update references to other documents,

- update the performance path option to compliance (the energy cost budget or ECB section of Standard 90.1), and

- affect informative appendix material provided in Standard 90.1-2004 but are not part of the construction and design requirements of the Standard.

For the quantitative analysis, DOE incorporated only addenda that modified the prescriptive requirements of the Standard. In specific circumstances, particularly with regard to requirements for certain heating, ventilation, and air conditioning (HVAC) equipment, addenda to Standard 90.1-2007 reflect changes to national manufacturing standards previously developed by DOE or enacted independently through Federal legislation. Because the energy savings that are attributable to these national manufacturing standards would accrue no matter what version of Standard 90.1 is considered and regardless of whether they are reflected in the text of the Standards, DOE has not incorporated these as changes contributing to energy savings for the purpose of the Determination. Table 4.1 shows all addenda to Standard 90.1-2004.

\footnotetext{
${ }^{1}$ Pacific Northwest National Laboratory. ANSI/ASHRAE/IESNA Standard 90.1-2007 Determination Qualitative Analysis. 2010.
} 
Table 4.1. Addenda to ASHRAE Standard 90.1-2004, Changes Identified

\begin{tabular}{|c|c|c|c|c|c|c|}
\hline \multirow{2}{*}{$\begin{array}{c}\text { Addenda } \\
\text { to } \\
90.1-2004\end{array}$} & \multirow[t]{2}{*}{ Section(s) Affected } & \multirow[t]{2}{*}{ Description of Changes } & \multicolumn{4}{|c|}{ Approval Date } \\
\hline & & & $\begin{array}{l}\text { ASHRAE } \\
\text { Standards } \\
\text { Committee }\end{array}$ & $\begin{array}{l}\text { ASHRAE } \\
\text { Board of } \\
\text { Directors }\end{array}$ & IESNA & ANSI \\
\hline $90.1-04 a$ & $\begin{array}{l}\text { Informative } \\
\text { Appendix G }\end{array}$ & $\begin{array}{l}\text { This addendum clarifies how windows should be distributed in the baseline simulation } \\
\text { model, clarifies how uninsulated assemblies should be treated in the baseline } \\
\text { simulation model, increases the size range for the use of packaged variable air volume } \\
\text { (VAV) systems in the baseline model, and provides more detail on how service hot- } \\
\text { water systems should be modeled. Many of these changes may affect the ultimate } \\
\text { performance rating of buildings using Appendix G. In addition, a reference was added } \\
\text { to ASHRAE Standard } 140 \text { establishing the method of testing of building energy } \\
\text { simulation software. }\end{array}$ & $1 / 21 / 06$ & $1 / 26 / 06$ & $1 / 18 / 06$ & $4 / 10 / 06$ \\
\hline $90.1-04 b$ & $\begin{array}{l}\text { 6. Heating, } \\
\text { Ventilating, and Air } \\
\text { Conditioning }\end{array}$ & $\begin{array}{l}\text { Revises Table 6.8.1D and adds a definition for single-package vertical air-conditioner } \\
\text { and single-package vertical heat pump. }\end{array}$ & $6 / 25 / 05$ & $6 / 30 / 05$ & $8 / 3 / 05$ & $8 / 3 / 05$ \\
\hline $90.1-04 \mathrm{c}$ & $\begin{array}{l}\text { 5. Building } \\
\text { Envelope }\end{array}$ & $\begin{array}{l}\text { This addendum revises the definition of building entrance to include vestibules and } \\
\text { clarifies the requirements and exceptions for vestibules in Section 5.4.3.4. }\end{array}$ & $6 / 25 / 05$ & $6 / 30 / 05$ & $8 / 3 / 05$ & $8 / 3 / 05$ \\
\hline $90.1-04 d$ & $\begin{array}{l}\text { 12. Normative } \\
\text { References }\end{array}$ & $\begin{array}{l}\text { This addendum updates the references applicable to the building envelope and deletes } \\
\text { references that are not cited in the standard. }\end{array}$ & $6 / 25 / 05$ & $6 / 30 / 05$ & $8 / 3 / 05$ & $8 / 3 / 05$ \\
\hline $90.1-04 \mathrm{e}$ & 9. Lighting & $\begin{array}{l}\text { This addendum recognizes that track and busway type lighting systems can be limited } \\
\text { by circuit breakers and permanently installed current limiters in Section 9.1.4. }\end{array}$ & $6 / 25 / 05$ & $6 / 30 / 05$ & $8 / 3 / 05$ & $8 / 3 / 05$ \\
\hline $90.1-04 f$ & $\begin{array}{l}\text { 6. Heating, } \\
\text { Ventilating, and Air } \\
\text { Conditioning }\end{array}$ & $\begin{array}{l}\text { This addendum modifies Tables } 6.8 .1 \mathrm{~A} \text { and } 6.8 .1 \mathrm{~B} \text { by raising the minimum efficiency } \\
\text { for three-phase air-cooled central conditioners and heat pumps to be consistent with } \\
\text { Federal minimum standards effective } 1 / 1 / 2008 \text {. }\end{array}$ & $1 / 21 / 06$ & $1 / 26 / 06$ & $1 / 18 / 06$ & $4 / 10 / 06$ \\
\hline $90.1-04 \mathrm{~g}$ & $\begin{array}{l}\text { 6. Heating, } \\
\text { Ventilating, and Air } \\
\text { Conditioning }\end{array}$ & $\begin{array}{l}\text { This addendum amends the minimum efficiency levels of air-cooled air conditioners } \\
\text { and heat pumps in Tables } 6.8 .1 \mathrm{~A} \text { and } 6.8 .1 \mathrm{~B} \text { greater than } 65,000 \mathrm{k} \text { British thermal } \\
\text { units (Btu)/hour }(\mathrm{h}) \text { cooling capacity to be consistent with Federal minimum } \\
\text { standards effective } 1 / 1 / 2010 \text {. }\end{array}$ & $1 / 21 / 06$ & $1 / 26 / 06$ & $1 / 18 / 06$ & $4 / 10 / 06$ \\
\hline $90.1-04 h$ & $\begin{array}{l}\text { 6. Heating, } \\
\text { Ventilating, and Air } \\
\text { Conditioning }\end{array}$ & $\begin{array}{l}\text { This addendum revises the exceptions to Sections } 6.4 .3 .1 .2 \text { and } 6.4 .3 .6 \text { by removing } \\
\text { specific exceptions on temperature and humidification dead bands for data processing } \\
\text { centers. }\end{array}$ & $1 / 21 / 06$ & $1 / 26 / 06$ & $1 / 18 / 06$ & $4 / 10 / 06$ \\
\hline $90.1-04 \mathrm{i}$ & 9. Lighting & $\begin{array}{l}\text { This addendum adds language to Section 9.1.4(b) that allows additional flexibility in } \\
\text { assigning wattage to luminaires with multi-level ballasts where other luminaire } \\
\text { components would restrict lamp size. }\end{array}$ & $1 / 21 / 06$ & $1 / 26 / 06$ & $1 / 18 / 06$ & $4 / 10 / 06$ \\
\hline $90.1-04 \mathrm{j}$ & 9. Lighting & $\begin{array}{l}\text { This addendum to Section 9.4.1.3 allows additional flexibility in complying with the } \\
\text { controls requirements by allowing additional combinations of commonly available } \\
\text { control equipment. }\end{array}$ & $1 / 21 / 06$ & $1 / 26 / 06$ & $1 / 18 / 06$ & $4 / 10 / 06$ \\
\hline $90.1-04 \mathrm{k}$ & $\begin{array}{l}\text { Informative } \\
\text { Appendix A }\end{array}$ & $\begin{array}{l}\text { This addendum revises Table A2.3 to add U-factors for screw-down roofs with R-19 } \\
\text { insulation. }\end{array}$ & $1 / 21 / 06$ & $1 / 26 / 06$ & $1 / 18 / 06$ & $4 / 10 / 06$ \\
\hline
\end{tabular}


Table 4.1. contd

\begin{tabular}{|c|c|c|c|c|c|c|}
\hline \multirow{2}{*}{$\begin{array}{l}\text { Addenda } \\
\text { to } \\
90.1-2004\end{array}$} & \multirow[t]{2}{*}{ Section(s) Affected } & \multirow[t]{2}{*}{ Description of Changes } & \multicolumn{4}{|c|}{ Approval Date } \\
\hline & & & $\begin{array}{l}\text { ASHRAE } \\
\text { Standards } \\
\text { Committee }\end{array}$ & $\begin{array}{l}\text { ASHRAE } \\
\text { Board of } \\
\text { Directors }\end{array}$ & IESNA & ANSI \\
\hline $90.1-041$ & $\begin{array}{l}\text { 12. Normative } \\
\text { References }\end{array}$ & This addendum updates the reference to ASHRAE Standard 140. & $1 / 21 / 06$ & $1 / 26 / 06$ & $1 / 18 / 06$ & $4 / 10 / 06$ \\
\hline $90.1-04 \mathrm{~m}$ & 9. Lighting & $\begin{array}{l}\text { This addendum revises the exception to Section 9.2.2.3 to provide an option for } \\
\text { compliance that exempts the commonly used furniture mounted track lighting if it } \\
\text { incorporates automatic shutoff. }\end{array}$ & $1 / 21 / 06$ & $1 / 26 / 06$ & $1 / 18 / 06$ & $4 / 10 / 06$ \\
\hline $90.1-04 n$ & $\begin{array}{l}\text { 5. Building } \\
\text { Envelope }\end{array}$ & $\begin{array}{l}\text { This addendum revises Section 5.5.4.4.1 to provide an exception to allow a user to } \\
\text { take credit for partially opaque overhangs towards compliance with the maximum } \\
\text { SHGC requirements. }\end{array}$ & $1 / 21 / 06$ & $1 / 26 / 06$ & $1 / 18 / 06$ & $4 / 10 / 06$ \\
\hline $90.1-040$ & $\begin{array}{l}\text { Normative Appendix } \\
\text { D }\end{array}$ & This addendum increases the amount of international climatic data in Appendix D. & $1 / 21 / 06$ & $1 / 26 / 06$ & $1 / 18 / 06$ & $4 / 10 / 06$ \\
\hline $90.1-04 \mathrm{p}$ & 9. Lighting & $\begin{array}{l}\text { This addendum modifies Exception ( } \mathrm{g} \text { ) to Section 9.2.2.3 to allow for increased } \\
\text { lighting for medical- and age-related issues in addition to visual impairment. }\end{array}$ & $1 / 21 / 06$ & $1 / 26 / 06$ & $1 / 18 / 06$ & $4 / 10 / 06$ \\
\hline $90.1-04 q$ & $\begin{array}{l}\text { 6. Heating, } \\
\text { Ventilating, and Air } \\
\text { Conditioning }\end{array}$ & $\begin{array}{l}\text { This addendum removes Exception (a) to Section 6.4.3.2 for HVAC systems serving } \\
\text { hotel/motel rooms and guest rooms. }\end{array}$ & $1 / 21 / 06$ & $1 / 26 / 06$ & $1 / 18 / 06$ & $4 / 10 / 06$ \\
\hline $90.1-04 \mathrm{r}$ & $\begin{array}{l}\text { 12. Normative } \\
\text { References }\end{array}$ & $\begin{array}{l}\text { This addendum updates the reference to Air Conditioning and Refrigeration Institute } \\
\text { (ARI) } 340 / 260 \text { from the } 2000 \text { edition to the } 2004 \text { edition. }\end{array}$ & $1 / 21 / 06$ & $1 / 26 / 06$ & $1 / 18 / 06$ & $4 / 10 / 06$ \\
\hline $90.1-04 \mathrm{~s}$ & $\begin{array}{l}\text { 6. Heating, } \\
\text { Ventilating, and Air } \\
\text { Conditioning and } \\
\text { 12. Normative } \\
\text { References } \\
\end{array}$ & $\begin{array}{l}\text { This addendum updates language in the standard based on differences between } \\
\text { Standard 62-1999 and 62.1-2004. The reference has also been updated. }\end{array}$ & $1 / 21 / 06$ & $1 / 26 / 06$ & $1 / 18 / 06$ & $4 / 10 / 06$ \\
\hline $90.1-04 t$ & $\begin{array}{l}\text { 6. Heating, } \\
\text { Ventilating, and Air } \\
\text { Conditioning and } \\
\text { 12. Normative } \\
\text { References } \\
\end{array}$ & $\begin{array}{l}\text { This addendum changes Table } 6.8 .1 \mathrm{~F} \text { to add an additional requirement of combustion } \\
\text { efficiency to the current requirement of thermal efficiency for boilers, which will } \\
\text { increase minimum efficiency. The reference in Section } 12 \text { has also been changed to } \\
\text { reflect the change in the table. }\end{array}$ & $1 / 21 / 06$ & $1 / 26 / 06$ & $1 / 18 / 06$ & $4 / 10 / 06$ \\
\hline $90.1-04 \mathrm{u}$ & $\begin{array}{l}\text { Informative } \\
\text { Appendix G }\end{array}$ & $\begin{array}{l}\text { This addendum provides guidance for complying with the intent of the baseline } \\
\text { building design for HVAC systems } 5,6,7 \text {, and } 8 \text {, which shall be modeled as floor-by- } \\
\text { floor HVAC systems. }\end{array}$ & $1 / 21 / 06$ & $1 / 26 / 06$ & $1 / 18 / 06$ & $4 / 10 / 06$ \\
\hline $90.1-04 \mathrm{v}$ & $\begin{array}{l}\text { 6. Heating, } \\
\text { Ventilating, and Air } \\
\text { Conditioning }\end{array}$ & $\begin{array}{l}\text { This addendum modifies the provisions of Section 6.4.3.8 to allow for demand control } \\
\text { ventilation. }\end{array}$ & $1 / 21 / 06$ & $1 / 26 / 06$ & $1 / 18 / 06$ & $5 / 10 / 06$ \\
\hline $90.1-04 x$ & $\begin{array}{l}\text { 12. Normative } \\
\text { References and } \\
\text { Informative } \\
\text { Appendix G }\end{array}$ & $\begin{array}{l}\text { This addendum updates the normative references in Section } 12 \text { and Informative } \\
\text { Appendix G for ATM- } 02 \text { to ATM- } 04 \text {. }\end{array}$ & $1 / 21 / 06$ & $1 / 26 / 06$ & $1 / 18 / 06$ & 4/10/06 \\
\hline
\end{tabular}


Table 4.1. contd

\begin{tabular}{|c|c|c|c|c|c|c|}
\hline \multirow{2}{*}{$\begin{array}{l}\text { Addenda } \\
\text { to } \\
90.1-2004\end{array}$} & \multirow{2}{*}{ Section(s) Affected } & \multirow{2}{*}{ Description of Changes } & \multicolumn{4}{|c|}{ Approval Date } \\
\hline & & & $\begin{array}{l}\text { ASHRAE } \\
\text { Standards } \\
\text { Committee }\end{array}$ & $\begin{array}{l}\text { ASHRAE } \\
\text { Board of } \\
\text { Directors }\end{array}$ & IESNA & ANSI \\
\hline $90.1-04 y$ & $\begin{array}{l}\text { 5. Envelope, } \\
\text { 12. Normative } \\
\text { References, and } \\
\text { Informative } \\
\text { Appendix G }\end{array}$ & $\begin{array}{l}\text { This addendum adds a reference and method of test for deriving Solar Reflectance } \\
\text { Index (SRI) (American Society for Testing and Materials (ASTM) Test Method E, } \\
\text { 1980) for high albedo roofs. The changes in the standard were in both Section } 5 \text { and } \\
\text { Informative Appendix G. }\end{array}$ & $6 / 24 / 06$ & $6 / 29 / 06$ & $6 / 18 / 06$ & $3 / 3 / 07$ \\
\hline 90.1-04aa & 9. Lighting & This addendum modifies Section 9.1 to clarify some lighting requirements. & $6 / 24 / 06$ & $6 / 29 / 06$ & $6 / 18 / 06$ & $3 / 3 / 07$ \\
\hline $90.1-04 a b$ & $\begin{array}{l}\text { 11. Energy Cost } \\
\text { Budget Method and } \\
\text { Informative } \\
\text { Appendix G }\end{array}$ & $\begin{array}{l}\text { This addendum corrects the referenced section in Tables } 11.3 .1 \text { and G3.1; Heating, } \\
\text { Ventilating, and Air Conditioning to Sections 9.1.3, 9.1.4, and 9.2. }\end{array}$ & $6 / 24 / 06$ & $6 / 29 / 06$ & $6 / 18 / 06$ & $3 / 3 / 07$ \\
\hline $90.1-04 \mathrm{ac}$ & $\begin{array}{l}\text { 3. Definitions and } \\
\text { 6. Heating, } \\
\text { Ventilating, and Air } \\
\text { Conditioning }\end{array}$ & This addendum modifies the fan power limitation requirements in Section 6.5.3. & $1 / 27 / 07$ & $3 / 2 / 07$ & $1 / 18 / 07$ & $3 / 27 / 07$ \\
\hline $90.1-04 \mathrm{ad}$ & $\begin{array}{l}\text { 5. Building } \\
\text { Envelope }\end{array}$ & $\begin{array}{l}\text { This addendum changes the exception to Section 5.3.1.1 to add a requirement that the } \\
\text { values for solar reflectance and thermal emittance be determined by a laboratory } \\
\text { accredited by a nationally recognized accreditation organization, such as the Cool } \\
\text { Roof Rating Council. }\end{array}$ & $2 / 5 / 05$ & $2 / 10 / 05$ & $2 / 3 / 05$ & $3 / 14 / 05$ \\
\hline $90.1-04 \mathrm{ae}$ & $\begin{array}{l}\text { 11. Energy Cost } \\
\text { Budget Method and } \\
\text { Informative } \\
\text { Appendix G }\end{array}$ & $\begin{array}{l}\text { This addendum clarifies that average lighting power density (LPD) for each thermal } \\
\text { block should be modeled (originally listed as "Change to Section 9.2.1.1, Space } \\
\text { Control" in Appendix F). }\end{array}$ & $1 / 27 / 07$ & $3 / 2 / 07$ & $1 / 18 / 07$ & $3 / 27 / 07$ \\
\hline $90.1-04 \mathrm{ag}$ & $\begin{array}{l}\text { Informative } \\
\text { Appendix G }\end{array}$ & $\begin{array}{l}\text { This addendum clarifies that only HVAC fans that provide outdoor air for ventilation } \\
\text { need to be modeled as running continuously. }\end{array}$ & $6 / 24 / 06$ & $6 / 29 / 06$ & $6 / 18 / 06$ & $3 / 3 / 07$ \\
\hline 90.1-04ah & $\begin{array}{l}\text { 11. Energy Cost } \\
\text { Budget Method }\end{array}$ & $\begin{array}{l}\text { This addendum modifies the requirements in Table } 11.3 .1 \text { for condenser heat } \\
\text { recovery. }\end{array}$ & $6 / 24 / 06$ & $6 / 29 / 06$ & $6 / 18 / 06$ & $3 / 3 / 07$ \\
\hline 90.1-04ai & 9. Lighting & $\begin{array}{l}\text { This addendum modifies the interior lighting power requirements for retail display } \\
\text { lighting in Section 9.6.2. }\end{array}$ & $1 / 27 / 07$ & $3 / 2 / 07$ & $1 / 18 / 07$ & $3 / 27 / 07$ \\
\hline 90.1-04aj & $\begin{array}{l}\text { 5. Building } \\
\text { Envelope }\end{array}$ & $\begin{array}{l}\text { This addendum modifies the exception to Section 5.5.3.1 by adding the ASTM Test } \\
\text { Method E } 1980 \text {-Standard Practice for Calculating SRI of Horizontal and Low } \\
\text { Sloped Opaque Surfaces. }\end{array}$ & $6 / 24 / 06$ & $6 / 29 / 06$ & $6 / 18 / 06$ & $3 / 3 / 07$ \\
\hline 90.1-04ak & $\begin{array}{l}\text { Table 6.2.1G, } \\
\text { Performance } \\
\text { Requirements for } \\
\text { Heat Rejection } \\
\text { Equipment, and } \\
\text { Section 6.2.1 }\end{array}$ & $\begin{array}{l}\text { This addendum changes Table } 6.2 .1 \mathrm{G} \text { to add requirements for cooling towers to } \\
\text { be tested to CTI test procedures and to update the corresponding references in } \\
\text { Section 6.2.1. }\end{array}$ & $6 / 24 / 06$ & $6 / 29 / 06$ & $6 / 18 / 06$ & $3 / 3 / 07$ \\
\hline
\end{tabular}


Table 4.1. contd.

\begin{tabular}{|c|c|c|c|c|c|c|}
\hline \multirow{2}{*}{$\begin{array}{c}\text { Addenda } \\
\text { to } \\
\mathbf{9 0 . 1 - 2 0 0 4}\end{array}$} & \multirow[t]{2}{*}{ Section(s) Affected } & \multirow[t]{2}{*}{ Description of Changes } & \multicolumn{4}{|c|}{ Approval Date } \\
\hline & & & $\begin{array}{l}\text { ASHRAE } \\
\text { Standards } \\
\text { Committee }\end{array}$ & $\begin{array}{l}\text { ASHRAE } \\
\text { Board of } \\
\text { Directors }\end{array}$ & IESNA & ANSI \\
\hline $90.1-04 \mathrm{al}$ & $\begin{array}{l}\text { Normative Appendix } \\
\text { A }\end{array}$ & $\begin{array}{l}\text { This addendum corrects the terminology used in Section A2.3 for metal building } \\
\text { roofs. }\end{array}$ & $6 / 24 / 06$ & $6 / 29 / 06$ & $6 / 18 / 06$ & $3 / 3 / 07$ \\
\hline 90.1-04am & $\begin{array}{l}\text { 11. Energy Cost } \\
\text { Budget Method and } \\
\text { Informative } \\
\text { Appendix G } \\
\end{array}$ & $\begin{array}{l}\text { This addendum modifies the VAV turndown requirements in Section } 11 \text { and } \\
\text { Informative Appendix } G \text { in accordance to the requirements in Section 6.5.2.1. }\end{array}$ & $6 / 24 / 06$ & $6 / 29 / 06$ & $6 / 18 / 06$ & $3 / 3 / 07$ \\
\hline $90.1-04 a n$ & $\begin{array}{l}\text { 6. Heating, } \\
\text { Ventilating, and Air } \\
\text { Conditioning }\end{array}$ & $\begin{array}{l}\text { This addendum modifies the equipment efficiency requirements for commercial } \\
\text { boilers in Table 6.8.1F. }\end{array}$ & $1 / 27 / 07$ & $3 / 2 / 07$ & $1 / 18 / 07$ & $3 / 27 / 07$ \\
\hline $90.1-04 a 0$ & $\begin{array}{l}\text { 6. Heating, } \\
\text { Ventilating, and Air } \\
\text { Conditioning } \\
\end{array}$ & $\begin{array}{l}\text { This addendum adds a footnote for increasing unit heater efficiency requirements } \\
\text { (requiring intermittent ignition devices, power venting, or flue dampers) to comply } \\
\text { with federal law. }\end{array}$ & $1 / 27 / 07$ & $3 / 2 / 07$ & $1 / 18 / 07$ & $3 / 27 / 07$ \\
\hline 90.1-04ap & 9. Lighting & This addendum clarifies the intent of a "sales area" space in Table 9.6.1. & $1 / 27 / 07$ & $3 / 2 / 07$ & $1 / 18 / 07$ & $3 / 3 / 07$ \\
\hline $90.1-04 \mathrm{aq}$ & $\begin{array}{l}\text { 12. Normative } \\
\text { References }\end{array}$ & This addendum updates the references to CTI documents. & $1 / 27 / 07$ & $3 / 2 / 07$ & $1 / 18 / 07$ & $3 / 3 / 07$ \\
\hline 90.1-04ar & 6. Mechanical & $\begin{array}{l}\text { This addendum lowers the part-load fan power limitation from } 15 \text { horsepower (hp) to } \\
10 \text { hp in Section 6.5.3.2.1. }\end{array}$ & $1 / 27 / 07$ & $3 / 2 / 07$ & $1 / 18 / 07$ & $3 / 3 / 07$ \\
\hline $90.1-04$ as & $\begin{array}{l}\text { 5. Building } \\
\text { Envelope }\end{array}$ & $\begin{array}{l}\text { This addendum modifies the opaque assembly requirements in Tables 5.5-1 through } \\
\text { 5.5-8. }\end{array}$ & $5 / 18 / 07$ & $6 / 4 / 07$ & $6 / 4 / 07$ & $12 / 18 / 07$ \\
\hline 90.1-04at & $\begin{array}{l}\text { 5. Building } \\
\text { Envelope }\end{array}$ & This addendum modifies the fenestration requirements in Tables 5.5-1 through 5.5-8. & $5 / 18 / 07$ & $6 / 4 / 07$ & $6 / 4 / 07$ & $12 / 18 / 07$ \\
\hline 90. 1-04av & $\begin{array}{l}\text { 5. Building } \\
\text { Envelope }\end{array}$ & $\begin{array}{l}\text { This addendum adds an exception to Section 5.5.4.4.1 to allow credit for overhangs } \\
\text { composed of open louvers toward compliance with the maximum SHGC } \\
\text { requirements. }\end{array}$ & $1 / 27 / 07$ & $3 / 2 / 07$ & $1 / 18 / 07$ & $3 / 3 / 07$ \\
\hline
\end{tabular}





\subsection{Simulation Methodology}

The purpose of the final quantitative analysis is to provide DOE with an evaluation of the relative energy efficiency of the two versions of ASHRAE Standard 90.1 when taken as a whole. To the degree that it can be considered representative of all commercial building construction, the final analysis provides an estimate of the energy impact of the change in standards on commercial building energy efficiency. The quantitative comparison of energy codes was based on whole building energy simulation of buildings built to either the ASHRAE Standard 90.1-2004 or 90.1-2007. It is not feasible to simulate all possible permutations of building design, nor are the data available to weigh correctly each possible permutation in each possible U.S. climate as a fraction of the national building construction mix. Hence, the quantitative analysis focuses on the use of prototype buildings that reflect typical construction practices.

For the purpose of the final determination, DOE used a set of 15 building commercial building prototypes based on DOE's published commercial reference building simulation models ${ }^{1}$ developed by DOE in support of the DOE Building Technologies Program Net Zero Energy Commercial Building Initiative. ${ }^{2,3}$ The prototypes are implemented as building models for use with the EnergyPlus ${ }^{4}$ wholebuilding energy simulation software. In addition, for the simulation work, each prototype building is assumed to be potentially situated in 1 of 15 climate zones, each corresponding to the 15 U.S. climate zones used in the Standard 90.1-2004 and Standard 90.1-2007 versions. For each climate zone, a mostrepresentative location and corresponding typical meteorological year (TMY) weather file is identified, ${ }^{5}$ which results in 225 climate/prototype combinations.

The individual building models for each climate are then modified as needed to correctly reflect the prescriptive requirements for Standard 90.1-2004 as required for each climate zone. DOE received input from the ASHRAE Standard 90.1 Simulation Working Group in support of this effort, resulting in some modifications to the DOE published commercial reference building models. In addition, for each of these Standard 90.1-2004 compliant building models, a second, corresponding building with the same basic design and use patterns, but which reflected the prescriptive requirements for Standard 90.1-2007, was developed. This latter process was completed by review of each addenda; first establishing whether that addenda would impact a given building prototype (based on the assumptions and descriptions of the benchmark building components) and in which climates.

Each of the 450 resulting building models was then simulated using EnergyPlus, and the resulting energy use was extracted by fuel type and by end use. The energy use data were then aggregated by fuel type and, using the floor space for each prototype, were converted to EUI metrics for each fuel by building prototype by climate and standard level.

1 Also referred to in previous literature as DOE's Commercial Benchmark Building Models

2. U.S. Department of Energy-Office of Public Affairs. DOE to Pursue Zero-Net Energy Commercial Buildings: National Renewable Energy Laboratory Announces Support for Clean Tech Open. August 5, 2008. Available at

http://apps1.eere.energy.gov/buildings/publications/pdfs/corporate/ns/commercial building initiative release 8 08.pdf

3. U.S. Department of Energy-Office of Energy Efficiency \& Renewable Energy. Net-Zero Energy Commercial Building Initiative: Commercial Building Benchmark Models. (Last accessed March 31, 2010.)

$<$ http://www1.eere.energy.gov/buildings/commercial initiative/benchmark models.html $>$

4. U.S. Department of Energy-Office of Energy Efficiency \& Renewable Energy. EnergyPlus Energy Simulation Software V3.0. Available at $<\underline{\text { http://apps1.eere.energy.gov/buildings }>}$

5. Wilcox, S. and W. Marion. Users Manual for TMY3 Data Sets. 2008. National Renewable Energy Laboratory: Golden, CO. Report No. NREL/TP-581-43156 Rev. Available at < www.nrel.gov/docs/fy08osti/43156.pdf $>$ 
DOE developed estimates of the new construction floor space that correspond to each prototype/climate zone combination. It then used this data to develop the relative fraction of new construction floor space represented by building prototype and within the 15 climate zones. Using the EUI statistics from each building simulation and the corresponding relative fraction of new construction floor space, DOE developed floor-space-weighted national EUI statistics by fuel type for each building type and standard level. DOE then added these fuel-specific EUI estimates to obtain national site energy EUI by building type and standard level. DOE also applied national average fuel prices data and national average primary energy fuel conversion rates data to the fuel-specific EUI data to obtain estimates of national primary energy EUI and national energy cost intensity (ECI), again by building type and by Standard 90.1 level. DOE examined the national results by building prototype to determine which building types would show a reduction in energy use under Standard 90.1-2007.

Finally, DOE used the relative floor space data for each of the building types nationally to weight the EUI and ECI statistics by building type to arrive at national site EUI, primary energy EUI, and ECI values for buildings constructed under both versions of Standard 90.1. This quantitative assessment of the change in EUI/ECI by building type and nationally was used to support DOE's final determination of energy savings for Standard 90.1-2007

The approach taken is not comprehensive to all buildings. The analysis assesses the relative energy impact of the standard by simulation of prototypical examples of buildings of various types reflected in the overall building population. It is recognized that there will be specific requirements of the standard that will not be amenable to simulation within the scope of this analysis. For most of these specific requirements, any differences in requirements will suggest an obvious stringency change between the standards, and this has been explored in the qualitative analysis done in parallel to this quantitative assessment. 


\subsection{Building Types and Model Prototypes}

Fifteen DOE prototype buildings (Table 6.1) were used in the DOE final quantitative analysis. A $16^{\text {th }}$ DOE prototype or reference building model, supermarket, was not used for the final quantitative analysis because an extant benchmark was not available at the start of the Determination process. Each DOE reference building model building is defined as characteristic of a certain class of buildings, mostly corresponding to a classification scheme established in the 2003 DOE/Energy Information Administration (EIA) Commercial Building Energy Consumption Survey (CBECS). ${ }^{1}$ CBECS categorizes commercial buildings using variables principal building activity (PBA) and PBAplus for more specific activities, separating the commercial sector into 29 PBA categories and 51 further subcategories. DOE relied heavily on these classifications in determining the buildings to be represented by the set of reference building models. By mapping CBECS observations to each prototype, DOE also used the CBECS building characteristics data to develop reference buildings that could best typify the building stock represented by each. Multi-family housing buildings are not included in CBECS but are covered by Standard 90.1 if over three stories high. Consequently, DOE developed a mid-rise apartment building to add to the original reference building prototypes identified through the review of CBECS. The characteristics of the mid-rise multi-family were developed from data in a separate study by PNNL. ${ }^{2}$

In the case of office buildings, one of the largest PBA categories in terms of square footage of stock, DOE determined that the wide variation in building design and equipment use made determining a "typical" office design difficult. Consequently, DOE developed three sizes and form factors characteristic of small, medium, and large office buildings to reflect the wide variation of office building design.

Table 6.1. ASHRAE Commercial Reference Building Models

\begin{tabular}{lll}
\hline Building Type & \multicolumn{1}{c}{ Building Prototype } & \multicolumn{2}{c}{ Prototype Floor Area } \\
& & \multicolumn{2}{c}{$\mathrm{ft}^{2}$} \\
\hline Office & Small Office & 5,502 \\
& Medium Office & 53,628 \\
& Large Office & 498,588 \\
Retail & Stand-Alone Retail & 24,692 \\
& Strip Mall & 22,500 \\
Education & Primary School & 73,959 \\
& Secondary School & 210,887 \\
Healthcare & Outpatient Health Care & 40,946 \\
& Hospital & 241,501 \\
Lodging & Small Hotel & 43,202 \\
& Large Hotel & 122,120 \\
Warehouse & Non-Refrigerated Warehouse & 52,045 \\
Food Service & Fast Food Restaurant & 2,501 \\
& Sit-Down Restaurant & 5,502 \\
Apartment & Mid-Rise Apartment & 33,741 \\
\hline
\end{tabular}

1. U.S. Energy Information Administration. 2003 Commercial Buildings Energy Consumption Survey-Overview of Commercial Buildings Characteristics. (Last accessed March 31, 2010.)

$<\underline{\text { http://www.eia.doe.gov/emeu/cbecs/cbecs2003/introduction.html }>}$

2. Gowri, K., M. A. Halverson, and E. E. Richman. Analysis of Energy Saving Impacts of ASHRAE 90.1-2004 for New York. 2007. Pacific Northwest National Laboratory: Richland, WA. Report No. PNNL-16770. 
To keep the building set manageable, the basic form factor and equipment selection for each reference building was developed to be most typical of construction on a national basis. It is thus characteristic of a specific construction. Regional variation in form factor, size, or design differences such as equipment selection are not represented in the group of reference buildings.

As stated, the original basis of the building models used in the final quantitative analysis is the new construction set of reference building models posted by DOE that are believed to represent typical new building architectural program and design, and use ASHRAE 90.1-2004 as the basis for many construction specifics. Each of these DOE benchmark buildings was subsequently vetted through the ASHRAE Standard 90.1 subcommittee to clarify further construction and operation assumptions by building type and to confirm that the building models accurately reflect the requirements of Standard 90.1-2004. Because this review process resulted in some modification of assumptions from the original DOE reference building models, this revised second set of 15 prototypes actually used in the final quantitative analysis is referred to as the ASHRAE reference buildings (or the prototypes). ASHRAE's Standard 90.1 Standing Standards Product Committee (SSPC) is working with DOE to use this set of ASHRAE reference buildings to establish the energy benefits of ongoing addenda being considered for subsequent versions of Standard 90.1. DOE has posted both ASHRAE 90.1-2004 and ASHRAE 90.12007 compliant versions of these 15 reference buildings on the DOE website for the as background information for DOE's final determination at http://www.energycodes.gov/implement/determinations_90.1-2007.stm. The 90.1 SSPC reviews have already resulted in changes to some of the original DOE-developed reference buildings, and it is anticipated that further updates will result in a single set of reference building models.

The 15 building-type categories used in the final quantitative analysis together reflect approximately 80 percent of the total square footage of commercial construction, including multi-family buildings greater than three stories, covered under ASHRAE Standard 90.1. 


\subsection{Inclusion of Addenda by Building Type}

In the qualitative analysis, DOE identified nine specific addenda that would have a measurable impact using the simulation methodology and would be modeled. DOE examined each of the 44 addenda to 90.1 2004 and specifically identified which of the ASHRAE reference building models would be affected by the addenda and modified to reflect inclusion of the addenda for the final quantitative analysis. Where an addendum was believed to have no readily discernable energy impact, this was also identified. For certain addenda, DOE determined that while the addenda may have an impact on commercial building energy use, the analysis methodology could not readily capture that impact, usually because the energy using building feature impacted was not represented in any of the reference building models.

In addition, an underlying theme in the final quantitative analysis was that the quantitative analysis reflects real changes to building code requirements that would be expected to be either required by States, or whose impact on energy use be reflected in revised State building codes (since EPCA requirements for State building codes do not explicitly require adoption of 90.1 or specific addenda but rather that overall updated building code efficiency be equivalent to that of the last version of Standard 90.1 for which DOE issued a positive determination). This theme results in special treatment of addenda in two key areas; ventilation requirements and equipment efficiency changes.

\subsection{Ventilation}

The final quantitative analysis assumed the same base ventilation level for buildings constructed to Standard 90.1-2004 and Standard 90.1-2007. Neither edition of Standard 90.1 specifies minimum or maximum ventilation rates for commercial building construction. ASHRAE has a separate ventilation standard for commercial construction, ANSI/ASHRAE Standard 62.1, "Ventilation for Acceptable Indoor Air Quality." This ventilation standard is cited only in a few specific requirement exceptions within the mechanical sections of either ASHRAE 90.1-2004 or ASHRAE 90.1-2007, with each edition referencing a different version of Standard 62.1. ASHRAE 90.1-2004 lists ASHRAE 62.1-1999 in its table of references, and ASHRAE 90.1-2007 lists ASHRAE 62.1-2004 in its table of references. The most recent version of ASHRAE Standard 62.1 is now Standard 62.1-2007. ${ }^{1}$

Ventilation rates can have significant impact on the energy use of commercial buildings. States and local jurisdictions typically specify the ventilation requirements for buildings within their respective building codes and set these requirements independent of the energy code requirements. Because of the limited and oblique references to ventilation requirements (through exceptions to actual requirements) within either edition of ASHRAE 90.1, the requirements that States certify that their energy codes meet or exceed the latest version of ASHRAE 90.1 will in general not require modification of State ventilation code requirements. DOE recognizes that in many cases, State ventilation requirements can be traced back to requirements found in one or another version of ASHRAE Standard 62.1. For the quantitative analysis, DOE assumed ventilation rate for the simulation prototypes based on the requirements of ASHRAE 62.12004. DOE also performed a sensitivity analysis which calculated the quantitative impacts assuming a ventilation rate based on ASHRAE Standard 62.1-1999.

1. American Society of Heating, Refrigerating and Air-Conditioning Engineers, Inc. ASHRAE Standard: Ventilation for Acceptable Indoor Air Quality. 2002. ASHRAE: Atlanta, GA. ANSI/ASHRAE Addendum 62o to ANSI/ASHRAE Standard 62-2001. Available at

$<\underline{\text { http://www.ashrae.org/content/ASHRAE/ASHRAE/ArticleAltFormat/200377135714 347.pdf }>}$ 


\subsection{Equipment Efficiency and Mandatory Federal Efficiency Standards}

Both Standard 90.1-2004 and Standard 90.1-2007 contain specific tables of HVAC and service water heating equipment efficiency requirements. Most, but not all, of the equipment classes shown in these Standard 90.1 tables have minimum Federal efficiency standards applied to them. The overlap between Federal efficiency standards and the requirements shown in ASHRAE 90.1 as a model code result in specific complications for an analysis used to inform a DOE determination of energy savings. In some instances, a revised version of Standard 90.1 will adopt an existing Federal efficiency standard into its tabulated efficiency requirement, typically with the same effective date as provided by the Federal standard. Since that mandated equipment efficiency will be enforced as a manufacturing standard regardless of whether it is represented in Standard 90.1, the inclusion of the requirement in the ASHRAE standard has no real energy impact. DOE's quantitative analysis methodology includes any equipment efficiency improvements mandated by Federal equipment efficiency standards, either established by DOE or by legislation but not initiated by addenda to ASHRAE 90.1-2004 in the ASHRAE 90.1-2004 baseline. This prevents inclusion in the quantitative analysis energy savings that would occur in new building construction (due to these mandated equipment efficiency improvements) regardless of the use of Standard 90.1-2004 or Standard 90.1-2007 as the basis for State building codes and prevents an incorrect biasing of the quantitative analysis toward positive energy savings from federally mandated equipment efficiency improvements. Not including credit for these addenda in the quantitative analysis is consistent with the approach used in previous DOE determinations.

Historically, Standard 90.1 has provided for improved efficiency in mechanical equipment with primarily commercial applications, using effective dates that occur after the standard is published, typically 2 or 3 years after publication. It has done so primarily to give manufacturers time to make available higher efficiency equipment on the market for those States adopting the revised Standard 90.1 efficiency levels. For most of this commercial HVAC and service water heating equipment, revisions to ASHRAE also serve as a trigger for DOE to revise minimum manufacturing efficiency standards for this equipment. Revised minimum manufacturing standards set by DOE for this equipment are generally subject to a provision that they be no less efficient than those shown in the most recent version of ASHRAE 90.1; however, manufacturing standards generally will not be in effect for between 2 to 4 years after they are in effect in the ASHRAE standard. (42 U.S.C. 6291 et seq., as amended; EPCA)

For this reason, the publication of commercial equipment efficiency improvements in a revised Standard 90.1 results in improved efficiency in commercial buildings, particularly for States and jurisdictions that adopt Standard 90.1 efficiency requirements prior to these requirements being adopted as Federal manufacturing standards. In addition, because it serves as a trigger for a broader DOE rulemaking on Federal manufacturing standards, the publication in Standard 90.1 will eventually have an impact on efficiency of commercial buildings in all U.S. jurisdictions. However, a concern for the final determination is how to treat an addendum to Standard 90.1, which results in an increase in commercial equipment efficiency in the far future. In the case of Standard 90.1-2007, ASHRAE set the effective date of certain of these revised efficiency levels as far out as 2020, 13 years from the original publication date of Standard 90.1-2007. Because Standard 90.1 is currently revised in a 3-year cycle, DOE preliminarily determined that it would only include the effect of equipment efficiency changes in the Standard 90.12007 whose effective date in Standard 90.1 is within 3 years of the date of the publication of the revised standard. Efficiency improvements with effective dates greater than 3 years after publication will be 
considered in DOE's determinations about forthcoming editions of Standard 90.1. In the particular instance for the Standard 90.1-2007 Determination, Addenda 90.1-2004an establishes revised efficiency requirements for certain steam boilers for 2020. None of the ASHRAE reference building models used steam boilers, but even if they had, the impact of this efficiency improvement would not have been analyzed in the quantitative analysis according to this principle.

Table 7.1 identifies each of the Standard 90.1-2004 addenda and indicates which of the ASHRAE reference building buildings were modified to capture the impact of the addenda. Addenda judged to have no significant impact on the quantitative analysis are identified as no impact. Addendum with potential impact, but not addressed in the quantitative analysis, are also identified in the column titled "Savings Will Not be Captured." In some cases, where an addendum may impact the ECB compliance path in Standard 90.1, it is shown as having no impact on the quantitative analysis, but also that any savings will not be captured. 
Table 7.1. Addenda Included in Quantitative Analysis and Affected Building Models

\begin{tabular}{|c|c|c|c|c|c|c|c|c|c|c|c|c|c|c|c|c|c|c|c|}
\hline Addendum & $\begin{array}{l}\text { Section } \\
\text { Affected }\end{array}$ & Description & 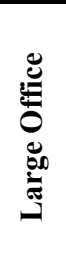 & 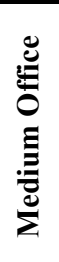 & 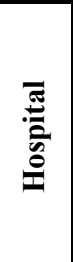 & 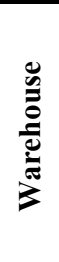 & 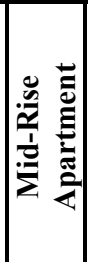 & 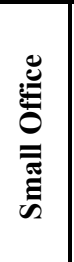 & 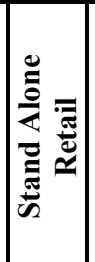 & 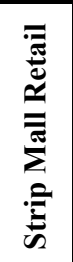 & 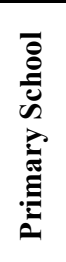 & 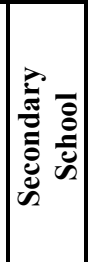 & 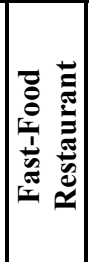 & $\mid \begin{array}{ll}0 \\
0 \\
0\end{array}$ & 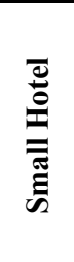 & 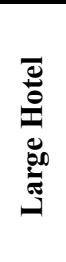 & 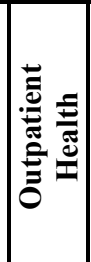 & 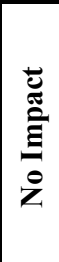 & 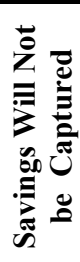 \\
\hline $90.1-04 a$ & Appendix G & $\begin{array}{l}\text { Clarifies window distribution, } \\
\text { treatment of un-insulated } \\
\text { assemblies, increases size range for } \\
\text { use of packaged VAV systems, and } \\
\text { provides more detail on hot water } \\
\text { system modeling. Also adds } \\
\text { reference to ASHRAE Standard } 140 .\end{array}$ & & & & & & & & & & & & & & & & $X$ & $\mathrm{X}$ \\
\hline $90.1-04 \mathrm{~b}$ & 6. HVAC & $\begin{array}{l}\text { Revises Table 6.8.1D and adds a } \\
\text { definition for single-package vertical } \\
\text { air-conditioner and single-package } \\
\text { vertical heat pump. }\end{array}$ & & & & & & & & & & & & & & & & & $\mathrm{X}$ \\
\hline $90.1-04 \mathrm{c}$ & 5. Envelope & $\begin{array}{l}\text { Revises the definition of building } \\
\text { entrance to include vestibules and } \\
\text { clarifies the requirements and } \\
\text { exceptions for vestibules in Section } \\
\text { 5.4.3.4. }\end{array}$ & & $\bar{X}$ & & $\bar{X}$ & $\bar{X}$ & $\mathrm{X}$ & $\mathrm{X}$ & $\mathrm{X}$ & $\mathrm{X}$ & $\mathrm{X}$ & $\mathrm{X}$ & $\mathrm{X}$ & $\bar{X}$ & & $\bar{X}$ & & \\
\hline $90.1-04 d$ & $\begin{array}{l}\text { 12. Normative } \\
\text { References }\end{array}$ & $\begin{array}{l}\text { Updates ASTM and National } \\
\text { Fenestration Rating Council (NFRC) } \\
\text { references. }\end{array}$ & & & & & & & & & & & & & & & & $X$ & \\
\hline $90.1-04 \mathrm{e}$ & 9. Lighting & $\begin{array}{l}\text { Recognizes that track and busway } \\
\text { type lighting systems can be limited } \\
\text { by circuit breakers and permanently } \\
\text { installed current limiters in Section } \\
\text { 9.1.4. }\end{array}$ & & & & & & & & & & & & & & & & $\mathrm{X}$ & \\
\hline $90.1-04 f$ & 6. HVAC & $\begin{array}{l}\text { Modifies Tables } 6.8 .1 \mathrm{~A} \text { and } 6.8 .1 \mathrm{~B} \\
\text { by raising minimum efficiency for } \\
\text { three-phase air-cooled central air } \\
\text { conditioners and heat pumps }< \\
65,000 \text { Btu/h to be consistent with } \\
\text { Federal minimum standards. } \\
\text { NO CREDIT GIVEN IN } \\
\text { DETERMINATION }\end{array}$ & & & & & & & & & & & & & & & & $\mathrm{X}$ & \\
\hline
\end{tabular}


Table 7.1. contd

\begin{tabular}{|c|c|c|c|c|c|c|c|c|c|c|c|c|c|c|c|c|c|c|c|}
\hline Addendum & $\begin{array}{c}\text { Section } \\
\text { Affected }\end{array}$ & Description & 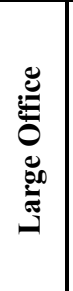 & 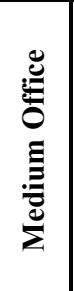 & 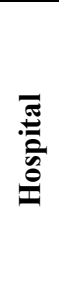 & 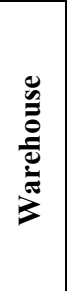 & 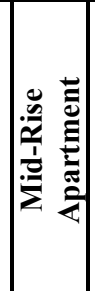 & 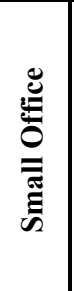 & 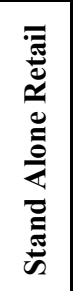 & 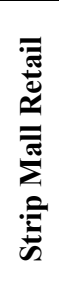 & 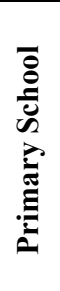 & 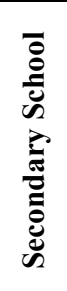 & 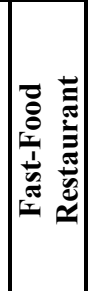 & 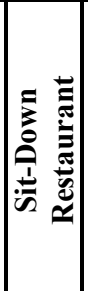 & 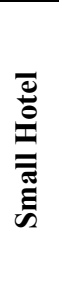 & 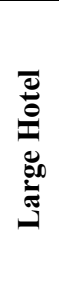 & 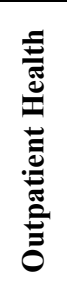 & $\begin{array}{l}\stackrel{\bar{U}}{\tilde{\Xi}} \\
\stackrel{\vec{z}}{\Xi} \\
\dot{z}\end{array}$ & 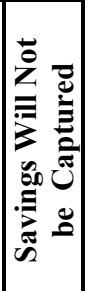 \\
\hline $90.1-04 \mathrm{~g}$ & 6. HVAC & $\begin{array}{l}\text { Amends minimum efficiency levels } \\
\text { of air-cooled air conditioners and } \\
\text { heat pumps } \\
>65,000 \mathrm{Btu} / \mathrm{h} \text { in Tables } 6.8 .1 \mathrm{~A} \text { and } \\
\text { 6.8.1B to be consistent with Federal } \\
\text { minimum standards. } \\
\text { NO CREDIT GIVEN IN } \\
\text { DETERMINATION }\end{array}$ & & & & & & & & & & & & & & & & $\mathrm{X}$ & \\
\hline $90.1-04 \mathrm{~h}$ & 6. HVAC & $\begin{array}{l}\text { Revises the exceptions to Sections } \\
\text { 6.4.3.1.2 and } 6.4 .3 .6 \text { by removing } \\
\text { data processing centers from } \\
\text { having specific exceptions on } \\
\text { temperature and humidification } \\
\text { dead bands. }\end{array}$ & & & & & & & & & & & & & & & & & $\mathrm{X}$ \\
\hline $90.1-04 \mathrm{i}$ & 9. Lighting & $\begin{array}{l}\text { Adds language to Section 9.1.4(b) } \\
\text { allowing flexibility in assigning } \\
\text { wattage to luminaires with multi- } \\
\text { level ballasts where other luminaire } \\
\text { components would restrict lamp } \\
\text { size. }\end{array}$ & & & & & & & & & & & & & & & & $\mathrm{X}$ & \\
\hline $90.1-04 j$ & 9. Lighting & $\begin{array}{l}\text { This addendum to Section 9.4.1.3 } \\
\text { allows additional flexibility in } \\
\text { complying with the controls } \\
\text { requirements by allowing } \\
\text { additional combinations of } \\
\text { commonly available control } \\
\text { equipment. }\end{array}$ & & & & & & & & & & & & & & & & $\mathrm{X}$ & \\
\hline $90.1-04 \mathrm{k}$ & $\begin{array}{c}\text { Normative } \\
\text { Appendix A. } \\
\text { Rated R-Value } \\
\text { of Insulation } \\
\text { and Assembly } \\
\text { U-, C-, and F- } \\
\text { Factor } \\
\text { Determinations } \\
\end{array}$ & $\begin{array}{l}\text { Adds U-factors for R-19 insulation } \\
\text { in screw down roofs. }\end{array}$ & & & & & & & & & & & & & & & & $\mathrm{X}$ & $\mathrm{X}$ \\
\hline
\end{tabular}


Table 7.1. contd

\begin{tabular}{|c|c|c|c|c|c|c|c|c|c|c|c|c|c|c|c|c|c|c|c|}
\hline Addendum & $\begin{array}{c}\text { Section } \\
\text { Affected }\end{array}$ & Description & 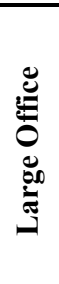 & 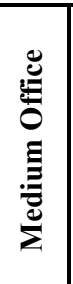 & 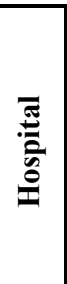 & 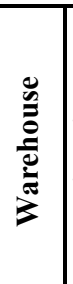 & $\mid \begin{array}{ll}0 \\
0 \\
0\end{array}$ & 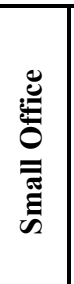 & 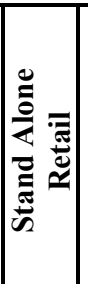 & 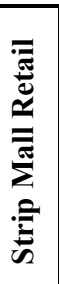 & 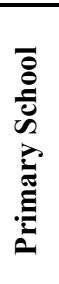 & 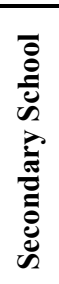 & 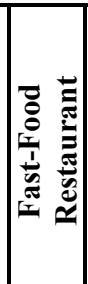 & 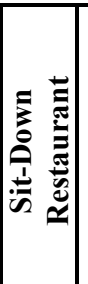 & 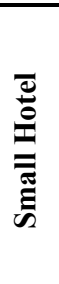 & 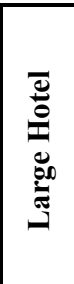 & 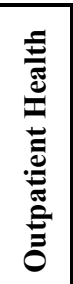 & 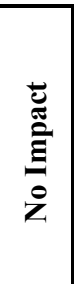 & 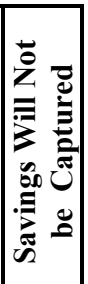 \\
\hline $90.1-041$ & $\begin{array}{l}\text { 12. Normative } \\
\text { References }\end{array}$ & $\begin{array}{l}\text { This addendum updates the } \\
\text { reference to ASHRAE Standard } \\
140 \text {. }\end{array}$ & & & & & & & & & & & & & & & & $\bar{X}$ & \\
\hline $90.1-04 n$ & 5. Envelope & $\begin{array}{l}\text { Revises Section 5.5.4.4.1 to provide } \\
\text { an exception to allow a user to take } \\
\text { credit for overhangs toward } \\
\text { compliance with maximum SHGC } \\
\text { requirements. }\end{array}$ & & & & & & & & & & & & & & & & $\bar{X}$ & \\
\hline $90.1-04 p$ & 9. Lighting & $\begin{array}{l}\text { This addendum modifies Exception } \\
\text { (g) to Section 9.2.2.3 to allow for } \\
\text { increased lighting for medical- and } \\
\text { age-related issues in addition to visual } \\
\text { impairment. }\end{array}$ & & & & & & & & & & & & & & & & $\mathrm{X}$ & \\
\hline $90.1-04 q$ & 6. HVAC & $\begin{array}{l}\text { Removes Exception (a) to Section } \\
\text { 6.4.3.2 for HVAC systems serving } \\
\text { hotel/motel rooms and guest rooms. }\end{array}$ & & & & & & & & & & & & & $\bar{X}$ & $\mathrm{X}$ & & & \\
\hline $90.1-04 \mathrm{r}$ & $\begin{array}{c}12 . \\
\text { Normative } \\
\text { References }\end{array}$ & $\begin{array}{l}\text { Updates reference to ARI Standard } \\
340 / 360 \text { from } 2000 \text { to } 2004 \text { edition. }\end{array}$ & & & & & & & & & & & & & & & & $\mathrm{X}$ & \\
\hline
\end{tabular}


Table 7.1. contd

\begin{tabular}{|c|c|c|c|c|c|c|c|c|c|c|c|c|c|c|c|c|c|c|c|}
\hline Addendum & $\begin{array}{l}\text { Section } \\
\text { Affected }\end{array}$ & Description & 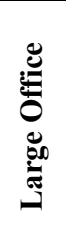 & 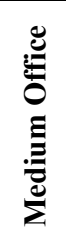 & 产 & 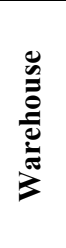 & 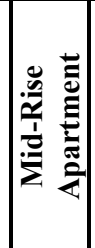 & 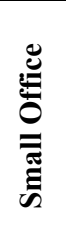 & 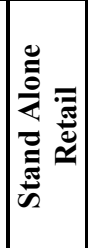 & 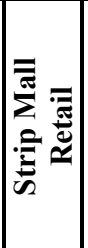 & 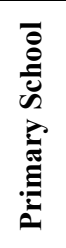 & 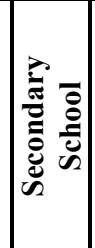 & 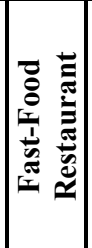 & 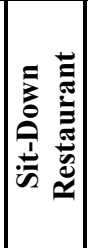 & 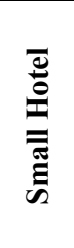 & 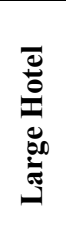 & 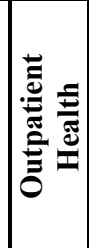 & 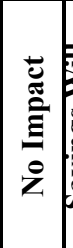 & 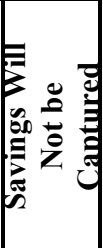 \\
\hline $90.1-04 \mathrm{~s}$ & $\begin{array}{l}\text { 6.HVAC and } \\
\text { 12. Normative } \\
\text { References }\end{array}$ & $\begin{array}{l}\text { Updates language in the standard } \\
\text { based on differences between } \\
\text { Standard 62-1999 and 62.1-2004. } \\
\text { The reference has also been updated. } \\
\text { NO CREDIT GIVEN IN } \\
\text { DETERMINATION }\end{array}$ & & & & & & & & & & & & & & & & $\mathrm{X}$ & \\
\hline $90.1-04 \mathrm{t}$ & $\begin{array}{l}\text { 6. HVAC and } \\
\text { 12. Normative } \\
\text { References }\end{array}$ & $\begin{array}{l}\text { Changes Table } 6.8 .1 \mathrm{~F} \text { to add an } \\
\text { additional requirement of } \\
\text { combustion efficiency to the current } \\
\text { requirement of thermal efficiency } \\
\text { for boilers, which will increase } \\
\text { minimum efficiency. The reference } \\
\text { in Section } 12 \text { has also been changed } \\
\text { to reflect the change in the table. }\end{array}$ & & & & & & & & & & & & & & & & \begin{tabular}{|l|}
$X$ \\
\end{tabular} & \\
\hline $90.1-04 u$ & $\begin{array}{l}\text { Informative } \\
\text { Appendix G }\end{array}$ & $\begin{array}{l}\text { Requires that systems } 1-4 \text { shall be } \\
\text { modeled with a system for each } \\
\text { thermal block and systems } 5-8 \text { shall } \\
\text { be modeled with a separate system } \\
\text { for each floor. }\end{array}$ & & & & & & & & & & & & & & & & $\mathrm{X}$ & \\
\hline $90.1-04 \mathrm{v}$ & 6. HVAC & $\begin{array}{l}\text { Modifies the provisions of Section } \\
\text { 6.4.3.8 to allow for demand control } \\
\text { ventilation. }\end{array}$ & & & & & & & & & $\mathrm{X}$ & $\mathrm{X}$ & & & & $\mathrm{X}$ & & & \\
\hline $90.1-04 x$ & $\begin{array}{l}\text { 12. Normative } \\
\text { References } \\
\text { and } \\
\text { Informative } \\
\text { Appendix G }\end{array}$ & $\begin{array}{l}\text { This addendum updates the } \\
\text { normative references in Section } 12 \\
\text { and Informative Appendix G for } \\
\text { ATM-02 to ATM- } 04 \text {. }\end{array}$ & & & & & & & & & & & & & & & & \begin{tabular}{|l|}
$X$ \\
\end{tabular} & \\
\hline $90.1-04 y$ & $\begin{array}{l}\text { 5. Envelope, } \\
\text { 12. Normative } \\
\text { References, } \\
\text { and Appendix } \\
\text { G }\end{array}$ & $\begin{array}{l}\text { Adds a reference and method of test } \\
\text { for deriving SRI (ASTM Test } \\
\text { Method E, 1980) for high albedo } \\
\text { roofs. The changes in the standard } \\
\text { were in both Section } 5 \text { and } \\
\text { Informative Appendix G. }\end{array}$ & & & & & & & & & & & & & & & & $\mathrm{X}$ & \\
\hline 90.1-04aa & 9. Lighting & $\begin{array}{l}\text { Modifies Section } 9.1 \text { to clarify some } \\
\text { lighting requirements. }\end{array}$ & & & & & & & & & & & & & & & & $\mathrm{X}$ & \\
\hline
\end{tabular}


Table 7.1. contd

\begin{tabular}{|c|c|c|c|c|c|c|c|c|c|c|c|c|c|c|c|c|c|c|c|}
\hline Addendum & $\begin{array}{l}\text { Section } \\
\text { Affected }\end{array}$ & Description & 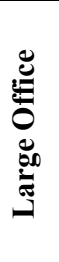 & 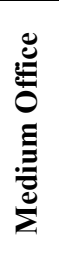 & 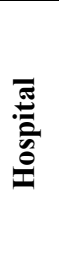 & 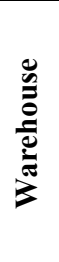 & 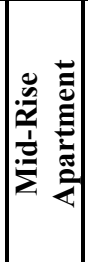 & 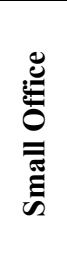 & 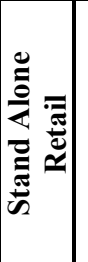 & 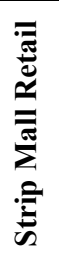 & 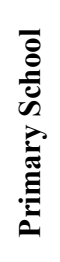 & 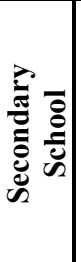 & 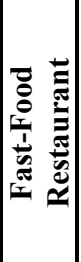 & 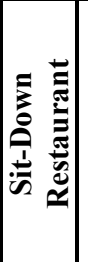 & 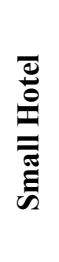 & 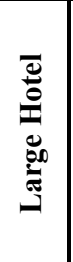 & 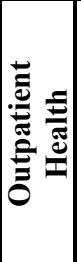 & $\begin{array}{l}\stackrel{\bar{E}}{\tilde{Z}} \\
\stackrel{\Xi}{\Xi} \\
\dot{0}\end{array}$ & 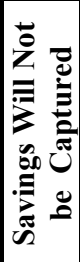 \\
\hline 90.1-04ab & $\begin{array}{c}11 \text { Energy } \\
\text { Cost Budget } \\
\text { Method and } \\
\text { Informative } \\
\text { Appendix G } \\
\text { Performance } \\
\text { Rating } \\
\text { Method } \\
\end{array}$ & $\begin{array}{l}\text { Changes references to lighting } \\
\text { sections and subsections to match } \\
\text { current standard. }\end{array}$ & & & & & & & & & & & & & & & & $\mathrm{X}$ & \\
\hline $90.1-04 \mathrm{ac}$ & $\begin{array}{l}\text { 6. HVAC and } \\
\text { 3. Definitions }\end{array}$ & $\begin{array}{l}\text { Modifies the fan power limitation } \\
\text { requirements in Section 6.5.3. }\end{array}$ & $\mathrm{X}$ & $\mathrm{X}$ & $\mathrm{X}$ & & & & $\mathrm{X}$ & $\mathrm{X}$ & $\mathrm{X}$ & $\mathrm{X}$ & & $\mathrm{X}$ & $\mathrm{X}$ & $\mathrm{X}$ & $\mathrm{X}$ & & \\
\hline 90.1-04ad & 5. Envelope & $\begin{array}{l}\text { Changes the exception to Section } \\
5.3 .1 .1 \text { to add a requirement that } \\
\text { values for solar reflectance and } \\
\text { thermal emittance be determined } \\
\text { by a laboratory accredited by a } \\
\text { nationally recognized organization } \\
\text { such as the Cool Roof Rating } \\
\text { Council. }\end{array}$ & & & & & & & & & & & & & & & & $\mathrm{X}$ & \\
\hline 90.1-04ae & $\begin{array}{l}\text { 11. Energy } \\
\text { Cost Budget } \\
\text { Method and } \\
\text { Informative } \\
\text { Appendix G } \\
\end{array}$ & $\begin{array}{l}\text { Clarifies that average LPD for each } \\
\text { thermal block should be modeled. }\end{array}$ & & & & & & & & & & & & & & & & $\mathrm{X}$ & $\mathrm{X}$ \\
\hline 90.1-04ag & $\begin{array}{c}\text { Informative } \\
\text { Appendix G } \\
\text { Performance } \\
\text { Rating } \\
\text { Method }\end{array}$ & $\begin{array}{l}\text { Clarifies that only HVAC fans that } \\
\text { provide outdoor air for ventilation } \\
\text { need to be modeled as running } \\
\text { continuously. }\end{array}$ & & & & & & & & & & & & & & & & $\mathrm{X}$ & \\
\hline 90.1-04ah & $\begin{array}{l}\text { 11 Energy } \\
\text { Cost Budget } \\
\text { Method }\end{array}$ & $\begin{array}{l}\text { Clarifies what to assume in budget } \\
\text { building model is condenser heat } \\
\text { recovery is required by Section } \\
6.5 .2\end{array}$ & & & & & & & & & & & & & & & & $\mathrm{X}$ & $\mathrm{X}$ \\
\hline 90.1-04ai & 9. Lighting & $\begin{array}{l}\text { Modifies the interior lighting } \\
\text { power requirements for retail } \\
\text { display lighting in Section 9.6.2. }\end{array}$ & & & & & & & & $\mathrm{X}$ & & & & & & & & & \\
\hline
\end{tabular}


Table 7.1. contd

\begin{tabular}{|c|c|c|c|c|c|c|c|c|c|c|c|c|c|c|c|c|c|c|c|}
\hline Addendum & $\begin{array}{c}\text { Section } \\
\text { Affected }\end{array}$ & Description & 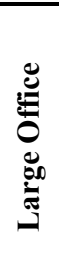 & 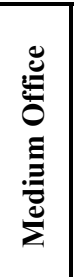 & 离 & 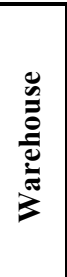 & 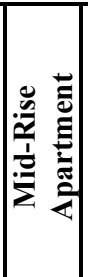 & 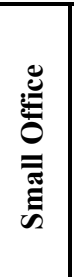 & 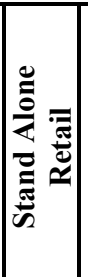 & 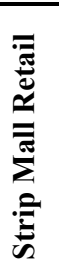 & 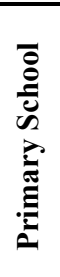 & 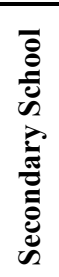 & 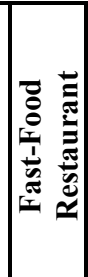 & 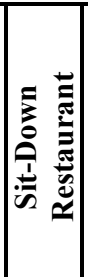 & 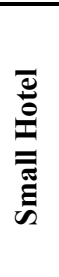 & 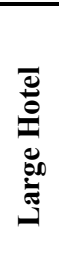 & 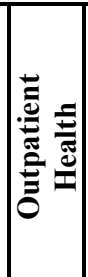 & 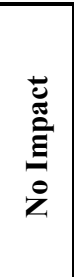 & 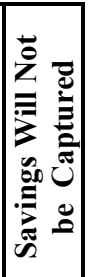 \\
\hline 90.1-04aj & 5. Envelope & $\begin{array}{l}\text { Modifies the exception to Section } \\
\text { 5.5.3.1 by adding the ASTM Test } \\
\text { Method E } 1980 \text { - Standard Practice } \\
\text { for Calculating SRI of Horizontal } \\
\text { and Low Sloped Opaque Surfaces. }\end{array}$ & & & & & & & & & & & & & & & & $\mathrm{X}$ & \\
\hline 90.1-04ak & 6. HVAC & $\begin{array}{l}\text { Changes Table } 6.2 .1 \mathrm{G} \text { to add } \\
\text { requirements for cooling towers to } \\
\text { be tested to CTI test procedures } \\
\text { and to update the corresponding } \\
\text { references in Section 6.2.1. }\end{array}$ & & & & & & & & & & & & & & & & $\mathrm{X}$ & \\
\hline $90.1-04 \mathrm{al}$ & \begin{tabular}{|c|} 
Normative \\
Appendix A. \\
Rated \\
R-Value of \\
Insulation and \\
Assembly \\
U-Factor, \\
C-Factor, and F- \\
Factor \\
Determinations
\end{tabular} & $\begin{array}{l}\text { Changes "metal spanning } \\
\text { members" to "metal roof panels" in } \\
\text { definition of metal building roofs, } \\
\text { includes mention of thermal spacer } \\
\text { blocks for standing seam roofs in } \\
\text { Table A2.3 and changes } \\
\text { description of "screw-down roofs" } \\
\text { to "thru-fastened roofs without } \\
\text { thermal spacer blocks." }\end{array}$ & & & & & & & & & & & & & & & & $\mathrm{X}$ & $\mathrm{X}$ \\
\hline 90.1-04am & \begin{tabular}{|c|}
11. Energy Cost \\
Budget Method \\
and Informative \\
Appendix G \\
Performance \\
Rating Method
\end{tabular} & $\begin{array}{l}\text { Changes the minimum flow } \\
\text { setpoints of VAV systems to } 0.4 \\
\text { cubic feet per minute }(\mathrm{cfm}) / \mathrm{ft}^{2} \text { of } \\
\text { floor area OR the minimum } \\
\text { ventilation rate, whichever is } \\
\text { larger. }\end{array}$ & & & & & & & & & & & & & & & & $\bar{X}$ & $\bar{X}$ \\
\hline 90.1-04an & 6. HVAC & $\begin{array}{l}\text { Modifies equipment efficiency } \\
\text { requirements for commercial } \\
\text { boilers in Table 6.8.1F. }\end{array}$ & $\mathrm{X}$ & & $\mathrm{X}$ & & & & & & & $\mathrm{X}$ & & & & $\mathrm{X}$ & & & \\
\hline
\end{tabular}


Table7.1. contd

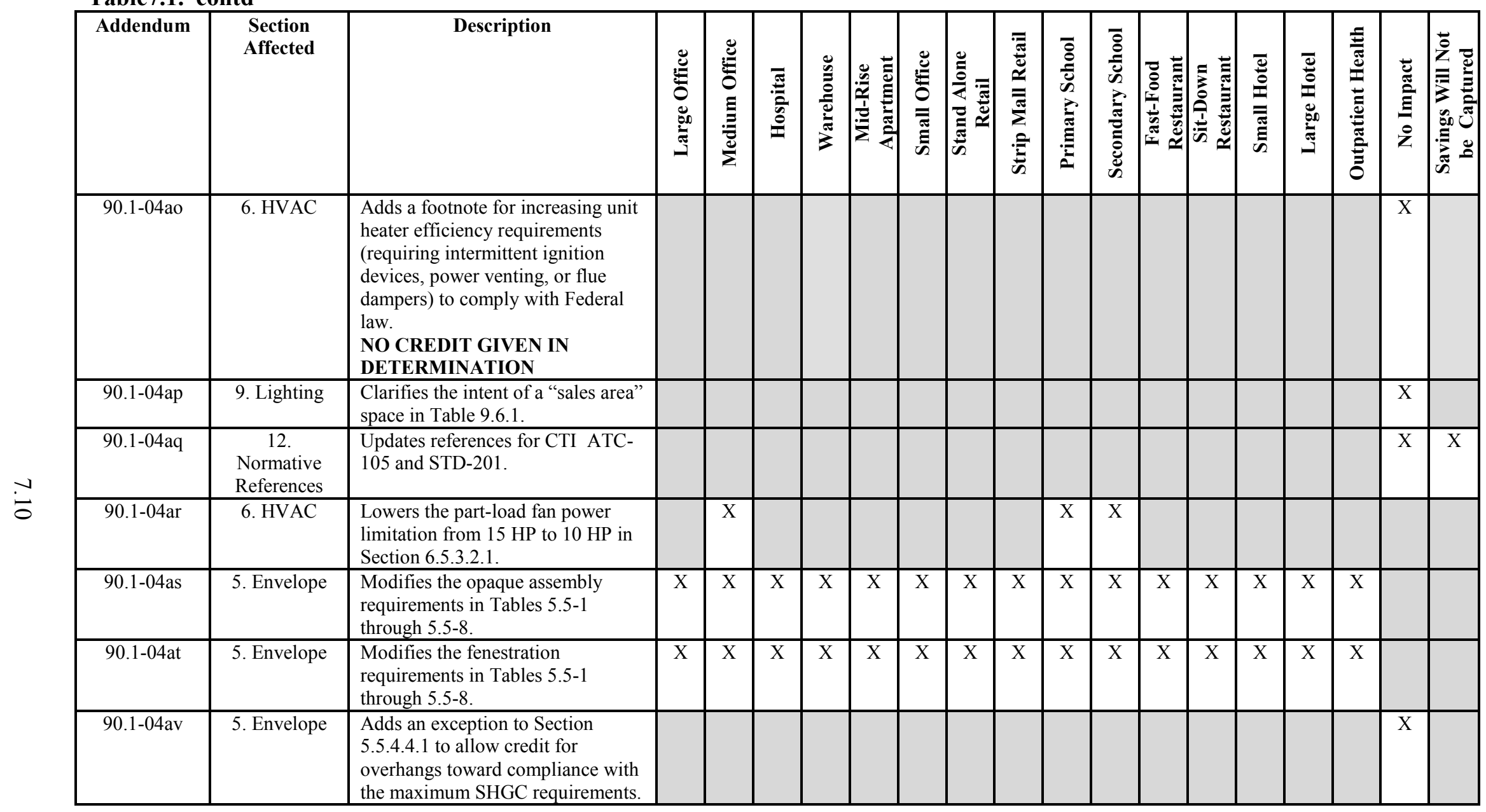




\subsection{Modeling of Specific Addenda}

A review of Table 7.1 shows that of the 44 addenda to Standard 90.1-2004, 9 are addressed in the quantitative analysis through impacts on one or more of the building prototypes: $90.1 \mathrm{c}, 90.1 \mathrm{q}, 90.1 \mathrm{v}$, 90.1 ac, 90.1 ai, 90.1 an, 90.1 ar, 90.1 as, and 90.1 at. Thirty-three addenda are considered to have little to no significant impact on commercial building energy use and are not modeled explicitly. Discussion of addenda identified as having no impact in Table 3 is provided in the qualitative analysis. Of these 32, 4 addenda (90.1-04f, 90.1-04g, 90.1-04s, 90.1-04ao) are not modeled due to the equipment efficiency and ventilation concerns addressed previously. Two more addenda (90.1-04b, 90.1-04h) are not modeled as they impact equipment not included in the reference building models but would be expected to improve energy efficiency in the building population as a whole. These last 6 addenda are shown in Table 8.1, with the reason for their not being included also shown.

Table 8.1. Special Consideration Addenda

\begin{tabular}{|c|c|}
\hline Addenda & Reason for Not Including in Quantitative Analysis \\
\hline $90.1-04 b$ & $\begin{array}{l}\text { No ASHRAE reference building model used single package vertical equipment. This is a niche } \\
\text { product application for which the ASHRAE standards have already been incorporated as national } \\
\text { manufacturing standards. }\end{array}$ \\
\hline 90.1-04f & $\begin{array}{l}\text { Addendum reflects previously enacted national manufacturing standards for three-phase air cooled } \\
\text { air conditioners and heat pumps and uses the same effective date as the national standards (see } \\
\text { previous discussion). }\end{array}$ \\
\hline $90.1-04 g$ & $\begin{array}{l}\text { Addenda reflects previously enacted national manufacturing standards for three-phase air cooled air } \\
\text { conditioners and heat pumps and uses same effective date (see previous discussion). }\end{array}$ \\
\hline 90.1-04h & $\begin{array}{l}\text { No ASHRAE reference building model specifically included computer data centers that would be } \\
\text { affected by this addendum. When considering all buildings in the general population which do } \\
\text { incorporate data centers, this addendum would be expected to result in some limited improvement } \\
\text { in energy efficiency. }\end{array}$ \\
\hline 90.1-04s & $\begin{array}{l}\text { Impact from change in referenced version of ASHRAE Standard } 62.1 \text { ventilation standard and } \\
\text { corresponding change in Standard } 90.1 \text { references to Standard } 62 \text { deemed to have little direct } \\
\text { impact on efficiency improvements from Standard } 90.1 \text { (see previous discussion). }\end{array}$ \\
\hline 90.1-04ao & $\begin{array}{l}\text { Addendum reflects previously enacted national manufacturing standards for unit heaters uses the } \\
\text { same effective date as the national standards (see previous discussion). }\end{array}$ \\
\hline
\end{tabular}

\subsection{Addendum 90.1-04c - Vestibules (almost all buildings)}

Addendum 90.1-04c revised the Standard 90.1-2004 definition of a "building entrance" and modifies Section 5.4.3.4 vestibules to both change when vestibules are required as well as explicitly requiring that the exterior envelope of a vestibule comply with envelope requirements of a conditioned space and that the interior envelope of a vestibule comply with envelope requirements for semi-heated space.

The discussion of envelope requirements for the outer wall of the vestibules and the adjoining wall between vestibule and interior building zone is more explicit than the language of Standard 90.1-2004, but this impact was not considered in the quantitative analysis as the impact was believed to be relatively minor. More significant are the treatment of the climate zones and building types for which vestibules would be required. Addendum 90.1-04c modified the section 5.4.3.4 exceptions such that vestibules would be required in many more buildings. In particular, Standard 90.1-2004 had an exception to vestibule requirements for buildings less than four stories high. This exception was modified such that it 
would apply only to buildings in climate zones 3 and 4 and then only when the building size was less than $10,000 \mathrm{ft}^{2}$. An additional exception was provided for all very small buildings (less than $1,000 \mathrm{ft}^{2}$ ) in all climate zones.

This impact of this addenda to Standard 90.1-2004 was modeled by first identifying which of the building prototypes would be affected, and if so, in which climates. For this analysis, building types not affected by the vestibule requirement were given the same defined level of infiltration calculated for each building in the 90.1-2004 baseline. Baseline infiltration was developed based on wind-driven models for exterior wall infiltration and an assumed air leakage rate of $1.8 \mathrm{cfm} / \mathrm{ft}^{2}$ of exterior envelope area at 0.30 in. wc (inches water column) pressure difference across the envelope. ${ }^{1}$ In general, buildings considered not affected by the Addenda 90.1-04c were tall buildings four stories or greater. Table 8.2 shows the vestibule requirements for each prototype in each climate zone for Standard 90.1-2004.

Table 8.3 shows the same information for Standard 90.1-2007.

The primary energy benefit of vestibules is to reduce infiltration in buildings during door openings. Infiltration rate for an open door was calculated for each building using a simplified method that takes into account design wind speed, door area, and building height to a neutral pressure plan (used to estimate the stack effect driven air pressure on the door) of one half the building height and a multiplication coefficient that is a function of door opening frequency.

Peak infiltration rates were first defined per unit door area for each prototype based on design day wind speeds of $15 \mathrm{mph}$, building height for each affected prototype, and average annual outdoor temperature, and defined based on study data for different building types. In addition, reduction in peak infiltration rates using vestibules were derived for buildings with vestibules and automatic doors based on an ASHRAE research project study as a function of door opening frequency. ${ }^{2}$ Door opening frequency was estimated for a "peak period" and an off-peak period for each building prototype. The hours defined by peak door opening frequency were based on the building occupancy schedule and identification of hours where occupancy (as a proxy for door use) was significantly high compared to the low unoccupied period for each particular building type.

Appendix A provides details of the modeling strategy for infiltration rates, door opening schedule development, and calculated peak and off-peak door infiltration rates by prototype.

1. Gowri, K., D. W. Winiarski, and R. E. Jarnagin. Infiltration Modeling Guidelines for Commercial Building Energy Analysis. 2009. Pacific Northwest National Laboratory: Richland, WA. Report No. PNNL-18898.

2. Yuill, G. K. Impact of High Use Automatic Doors on Infiltration.1996. ASHRAE: Atlanta, GA. Project 763-TRP. 
Table 8.2. ASHRAE 90.1-2004 Vestibule Requirement for All Prototypes in Each Zone*

\begin{tabular}{lcccccccc}
\hline \multicolumn{1}{c}{ Building Prototype } & \multicolumn{7}{c}{ Zone } \\
\cline { 2 - 9 } & $\mathbf{1}$ & $\mathbf{2}$ & $\mathbf{3}$ & $\mathbf{4}$ & $\mathbf{5}$ & $\mathbf{6}$ & $\mathbf{7}$ & $\mathbf{8}$ \\
\hline Large Office & No (a) & No (a) & Yes & Yes & Yes & Yes & Yes & Yes \\
Medium Office (b),(e) & No (a) & No (a) & No & No & No & No & No & No \\
Hospital & No (a) & No (a) & Yes & Yes & Yes & Yes & Yes & Yes \\
Warehouse (b),(e) & No (a) & No (a) & No & No & No & No & No & No \\
Mid-Rise Apartment (e) & No (a) & No (a) & No & No & No & No & No & No \\
Small Office (b),(e) & No (a) & No (a) & No & No & No & No & No & No \\
Strip Mall (b) & No (a) & No (a) & No & No & No & No & No & No \\
Stand-Alone Retail (b) & No (a) & No (a) & No & No & No & No & No & No \\
Primary School (b),(e) & No (a) & No (a) & No & No & No & No & No & No \\
Secondary School (b),(e) & No (a) & No (a) & No & No & No & No & No & No \\
Small Hotel (e) & No (a) & No (a) & No & No & No & No & No & No \\
Large Hotel & No (a) & No (a) & Yes & Yes & Yes & Yes & Yes & Yes \\
Outpatient Health Care (b) & No (a) & No (a) & No & No & No & No & No & No \\
Fast-Food Restaurant (b),(e) & No (a) & No (a) & No & No & No & No & No & No \\
Sit-Down Restaurant (b) & No (a) & No (a) & No & No & No & No & No & No \\
\hline
\end{tabular}

*The vestibule requirement exceptions in 90.1-2004 are shown in parentheses (see Appendix A for the description of exceptions).

Table 8.3. ASHRAE 90.1-2007 Vestibule Requirement for All Prototypes in Each Zone*

\begin{tabular}{|c|c|c|c|c|c|c|c|c|}
\hline \multirow[t]{2}{*}{ Building Prototype } & \multicolumn{8}{|c|}{ Zone } \\
\hline & 1 & 2 & 3 & 4 & 5 & 6 & 7 & 8 \\
\hline Large Office & No (d) & No (d) & Yes & Yes & Yes & Yes & Yes & Yes \\
\hline Medium Office & No (d) & No (d) & Yes & Yes & Yes & Yes & Yes & Yes \\
\hline Hospital & No (d) & No (d) & Yes & Yes & Yes & Yes & Yes & Yes \\
\hline Warehouse & No (d) & No (d) & Yes & Yes & Yes & Yes & Yes & Yes \\
\hline Mid-Rise Apartment & No (d) & No (d) & Yes & Yes & Yes & Yes & Yes & Yes \\
\hline Small Office & No (d) & No (d) & No (e) & No (e) & Yes & Yes & Yes & Yes \\
\hline Strip Mall & No $(d)$ & No (d) & Yes & Yes & Yes & Yes & Yes & Yes \\
\hline Stand-Alone Retail & No (d) & No (d) & Yes & Yes & Yes & Yes & Yes & Yes \\
\hline Primary School & No $(d)$ & No (d) & Yes & Yes & Yes & Yes & Yes & Yes \\
\hline Secondary School & No (d) & No (d) & Yes & Yes & Yes & Yes & Yes & Yes \\
\hline Small Hotel & No $(d)$ & No (d) & Yes & Yes & Yes & Yes & Yes & Yes \\
\hline Large Hotel & No (d) & No (d) & Yes & Yes & Yes & Yes & Yes & Yes \\
\hline Outpatient Health Care & No (d) & No (d) & Yes & Yes & Yes & Yes & Yes & Yes \\
\hline Fast-Food Restaurant & No (d) & No (d) & No (e) & No (e) & Yes & Yes & Yes & Yes \\
\hline Sit-Down Restaurant & No (d) & No (d) & No (e) & No (e) & Yes & Yes & Yes & Yes \\
\hline
\end{tabular}

*The vestibule requirement exceptions in 90.1-2007 are shown in parentheses (see Appendix A for the description of exceptions).

\subsection{Addendum 90.1-04q - Off-Hour Controls Exception for Hotel/Motel Removed}

Standard 90.1-2004 had requirements for off-hour controls (e.g., thermostat setback) that are required for most conditioned building spaces. An exception was provided for HVAC systems serving motel and hotel guest rooms. This original exception was based largely on the premise that such systems would not be cost effective because hotel and motel guest rooms are under control of the occupant and a controller could not be set up without prior knowledge of when a space would be unoccupied. Addendum 90.1-04q removed this exception, noting that there are controls specific to hotel/motel applications that can be 
incorporated to indicate when rooms are unoccupied (considered off-hour) and thus control certain HVAC functions, including thermostat set point.

To model the effect of Addendum 90.1-04q on hotels and motels, the occupied guestroom heating and cooling thermostat set points were modified from a constant $70^{\circ} \mathrm{F}$ indoor set point condition to a set point schedule that went to $66^{\circ} \mathrm{F}$ for heating and $74^{\circ} \mathrm{F}$ for cooling from 9 a.m. to 4 p.m. each day. This assumption was based on a similar analysis done for the DOE Advanced Energy Design Guide for Highway Lodging, with the basis discussed in the technical support document for that project. ${ }^{3}$

\subsection{Addendum 90.1-04v - Update for Demand-Controlled Ventilation Requirements}

Standard 90.1-2004 has specific ventilation requirements for high occupancy spaces that required a method to automatically reduce the ventilation rates when spaces are partially occupied (Section 6.4.3.8, Ventilation Controls for High Occupancy Areas). High occupancy areas for which these requirements existed were spaces with design occupancy of greater than 100 persons per $1,000 \mathrm{ft}^{2}$ floor area served by systems with greater than $3,000 \mathrm{cfm}$ of design outdoor air flow.

Addendum 90.1-04v modified the provisions of Section 6.4.3.8 by extending the requirement for demand controlled ventilation by setting a minimum size threshold for the spaces so that it would apply only to spaces larger than $500 \mathrm{ft}^{2}$ but lowering the design occupancy density threshold from 100 persons per $1,000 \mathrm{ft}^{2}$ to 40 persons per $1,000 \mathrm{ft}^{2}\left(100 \mathrm{~m}^{2}\right)$ of floor area.

The impact of this addendum was analyzed by first identifying buildings prototypes with spaces that would be considered high occupancy. High occupancy spaces were identified for three prototypes: primary school, secondary school, and large hotel.

For the primary and secondary schools, a demand controlled ventilation controller was implemented in the EnergyPlus model for the cafeteria space by modifying the minimum outdoor air schedule from a fixed minimum outdoor air to a controller-based outdoor air schedule with a minimum outdoor air level per square foot of floor area and an additional minimum ventilation rate per occupant. The outdoor air required by the space is the sum of the ventilation per square foot and the additional ventilation rate per occupant. For the secondary school, the auditorium space already fell under the demand controlled ventilation requirements in Standard 90.1-2004 and is modeled as demand controlled ventilation in both versions of Standard 90.1 using a similar strategy.

For the hotel, demand controlled ventilation controller was implemented in the following zones of the large hotel building: café-first floor, sixth-floor banquet room, and sixth-floor dining room. Each of the controllers are implemented by modifying the minimum outdoor air schedule in the Standard 90.1-2004 versions from a fixed minimum outdoor air to a controller based outdoor air schedule with a minimum outdoor air level per square foot of floor area and an additional minimum ventilation rate per occupant.

3. Jiang, W., R. E. Jarnagin, K. Gowri, M. McBride, and B. Liu. Technical Support Document: The Development of the Advanced Energy Design Guide for Highway Lodging Buildings. 2008. Pacific Northwest National Laboratory: Richland, WA. Report No. PNNL-17875. 


\subsection{Addendum 90.1-04ac - Fan Power Requirements}

Addendum 90.1-04ac is a significant update to the treatment of maximum fan power allowances in Standard 90.1-2004. ASHRAE Standard 90.1-2004 specifies maximum fan power allowances for fans systems with total fan power exceeding $5 \mathrm{hp} \mathrm{(3.73} \mathrm{kilowatts} \mathrm{[kW])} \mathrm{in} \mathrm{Section} \mathrm{6.5.3.} \mathrm{Addendum} \mathrm{90.1-04ac}$ strengthens stringency in fan power limitations for simple systems. It also expands the coverage for many complex systems to properly address complex exhaust fan systems associated with hospitals and laboratories, spaces for which it was possible to claim exemption in 90.1-2004 because the coverage of fans for these systems was not explicit and could be considered as exempt due to the overlap between fan system design and health and safety impacts for these type of buildings.

Addendum 90.1-04ac changes the fan power allowance structure to be based on a continuous curve for allowed horsepower as a function of design fan air volume (the Standard 90.1-2004 requirement had a step function in the allowed motor horsepower curve based on system air flow volume), but also providing two distinct compliance path options. The first path is similar to Standard 90.1-2004 in that it defines total allowable fan system nameplate motor horsepower based on system design air volume (with different curves provided for constant volume and variable volume systems). The second path defines the allowable fan system fan brake horsepower as a function of design fan volume and specific pressure drop adjustments for key system components. The latter path allows for higher fan power to be provided for, but only where it is actually needed due to the presence of specific system components such as fully ducted return and exhaust systems, high efficiency particulate filtration, air cleaners, and heat recovery devices. Because these components are widely used in hospitals and laboratories, this second path can be considered as providing a path that eliminates a need to exempt these applications.

The EnergyPlus program simulates fan power by considering three inputs: the design pressure drop through the fan, total fan efficiency, and the motor efficiency. For modeling of systems in accordance with a version of Standard 90.1 where the maximum fan power has been specified, the approach was to calculate a corresponding design pressure drop for each air system using the following equation:

Design Pressure Drop $=($ brake horsepower $\times$ fan efficiency $\times 6356) / \mathrm{cfm}$

where:

$$
\begin{aligned}
& \mathrm{cfm}=\quad \text { supply fan airflow as determined by EnergyPlus sizing runs, } \\
& \text { fan efficiency } \quad=\quad 65 \text { percent, based on assumptions used by the ASHRAE Standard } 90.1 \\
& \text { Committee while developing fan power requirements for the Standard, } \\
& \text { brake horsepower }=\text { allowed brake horsepower. }
\end{aligned}
$$

Once the brake horsepower is established for a fan system, the nameplate horsepower is calculated using a 10 percent over sizing factor (i.e., nameplate horsepower $=$ brake horsepower $\times 1.1$, as allowed under Standard 90.1). The nameplate motor horsepower is used in the calculation of the fan motor efficiency.

For comparing Standard 90.1-2004 and Standard 90.1-2007 versions, a rule set was established for determining fan system brake horsepower based on fan system type and system air volume and the fan efficiency. This rule set is shown in Table 8.4 and is based on the following assumptions. 
- Systems of less than or equal to five nameplate hp are not regulated by Section 6.5.3.1, Fan Power Limitation, in either version of Standard 90.1.

- Fan mechanical efficiency for the purpose of the calculations is set to 65 percent.

- Total static pressure assumption for constant volume fan systems less than 7,437 cfm is at $2.5 \mathrm{in}$. wc based on Small Retail Building Advanced Energy Design Guide Assumptions, ${ }^{4}$ 7,437 cfm at 2.5 in. wc total static pressure requires 4.5 brake hp or greater than 5 nameplate motor hp once motor efficiencies and safety factors have been accounted for.

- For constant air volume (CAV) fan systems, assume that if system air volume is greater than 7,437 $\mathrm{cfm}$, the fan power limitation applies.

- For VAV system, assume that if the design air volume is greater than 4,648 $\mathrm{cfm}$, the fan power limitation applies. This is based on an assumption of 4 in. we static pressure for small variable air volume systems.

- Unit heater total static pressure is equal to 0.2 in. wc and motor efficiency is assumed equal to 82.5 percent, based on review of manufacturers' catalog data. This is applied to all sizes of unit heater.

- The packaged terminal air conditioner (PTAC), packaged terminal heat pump (PTHP), and fan coil units (FCU) are assumed to have total static pressure of $1.33 \mathrm{in.} \mathrm{wc}$ based with fan motor efficiency set to 0.8 in. wc. This reflects total fan power for this equipment and is based on fan power assumptions used in Standard 90.1-2007, Informative Appendix G, Performance Rating Method, for modeling of fan systems for these types of equipment.

Table 8.4. Rules for Establishing Fan Power in Quantitative Analysis Simulations

\begin{tabular}{|c|c|c|c|}
\hline \multicolumn{4}{|c|}{ Fan Power Limitation Rule for 90.1-2004 } \\
\hline System & CFM Range & $\begin{array}{c}\text { TSP } \\
\text { in. } w c\end{array}$ & Fan Efficiency \\
\hline CAV & $<7,437$ & 2.50 & 0.65 \\
\hline VAV & $<4,648$ & 4.00 & 0.65 \\
\hline CAV & $\geq 7,437 \&<20,000$ & 4.46 & 0.65 \\
\hline CAV & $\geq 20,000$ & 4.09 & 0.65 \\
\hline VAV & $\geq 4,648 \&<20,000$ & 6.32 & 0.65 \\
\hline VAV & $\geq 20,000$ & 5.58 & 0.65 \\
\hline Unit Heater & All & 0.2 & 0.65 \\
\hline PTAC, PTHP, or FCUs & All & 1.33 & 0.65 \\
\hline CAV & $<7,437$ & 2.50 & 0.65 \\
\hline VAV & $<4,648$ & 4.00 & 0.65 \\
\hline CAV & $\geq 7,437$ & 4.09 & 0.65 \\
\hline VAV & $\geq 4,648$ & 5.58 & 0.65 \\
\hline Unit Heater & All & 0.2 & 0.65 \\
\hline PTAC, PTHP, or FCUs & All & 1.33 & 0.65 \\
\hline
\end{tabular}

4. Liu, B., R. E. Jarnagin, D. W. Winiarski, W. Jiang, M. F. McBride, and C. Crall. Technical Support Document: The Development of the Advanced Energy Design Guide for Small Retail Buildings. 2006. Pacific Northwest National Laboratory: Richland, WA. Report No. PNNL-16031. 
The last required input, motor efficiency, is taken directly from Table 10.8 of Standard 90.1- 2004 and reflects minimum Federal efficiency standards, based on motor nameplate size and assuming enclosed motors operating at $1,800 \mathrm{rpm}$.

\subsection{Addendum 90.1-04ai - Lighting in Retail Buildings}

ASHRAE 90.1-2004 defines maximum whole building interior lighting power using two possible compliance paths: (1) a tabulated whole building LPD, defined in units of maximum allowed installed lighting power per square foot of floor space by building type in what is called the building-area method compliance path and, (2) a more flexible approach to establishing the maximum allowed interior whole building lighting power based on the space-by-space method of calculating interior lighting power compliance path. The space-by-space method defines lighting power for individual spaces within a building and using the sum of the products of the allowed LPD by space and the square footage of each space type with a building, establishes an allowed whole building lighting power. In the space-by-space compliance path, additional lighting power allowances are provided for certain spaces where certain lighting design considerations exist.

Addendum 90.1-04ai modifies the additional lighting power requirements for retail display lighting found in Standard 90.1-2004, Section 9.6.2. Specifically, the addendum modifies the allowances provided for retail spaces by using four categories of retail merchandise in place of two, more general, merchandise categories found in Standard 90.1-2004. The new categorization is more precise in the description of merchandise in each category and provides new additional lighting power levels. In addition, it removes an additional lighting power allowance for spaces used with video display terminals. Standard 90.1-2004 and Standard 90.1-2007 both have additional lighting power allowances for decorative lighting, but these were not changed between the two versions of the Standard.

The building models used for the final quantitative analysis are specific building designs, in most cases with specific spaces defined within the prototype and with different lighting schedules for each space in accordance with its expected use. DOE chose to use the space-by-space method to establish the overall lighting power within these prototypes. In the case of one prototype, the strip mall retail building, DOE also included lighting power to reflect the typical values for additional lighting power allowances that would be allowed as display lighting under Standard 90.1-2004 and Standard 90.1-2007 based on the incorporation of Addendum 90.1-04ai and assuming the same display type and applicable display area in the strip mall prototype. For certain building prototypes where space type distinctions were not deemed as important or significant, the building area LPD numbers were used (e.g., office buildings).

The building area LPDs are identical for both Standard 90.1 versions. The base space-by-space LPDs tabulated by space type are also identical in both Standards. The additional lighting power for decorative lighting was not changed between standards and is not explicitly assumed in any building prototype. The additional lighting power for retail display lighting was modified to reflect the use of the four specific merchandise categories in ASHRAE 90.1-2007 from that calculated using the two general merchandise categories in Standard 90.1-2004. DOE collected limited information on display areas in a small sample of retail buildings and estimated that, for the strip mall prototype, approximately 13 percent of the entire building area might qualify for the display lighting power allowances. DOE assumed that the additional lighting power allowance for that display area was reduced from an average of 2.75 watts $(\mathrm{W}) / \mathrm{ft}^{2}$ (based on an average of the two additional lighting power display categories in Standard 90.1-2004) to 2.15 
$\mathrm{W} / \mathrm{ft}^{2}$ (based on an average of the middle two additional lighting power display categories in Standard 90.1-2007). This assumption resulted in a 4.6 percent reduction in whole building LPD for this prototype. DOE believes that this result is likely a conservative estimate of the energy savings from this additional lighting power change. See Appendix B for details on the development of additional lighting power for the strip mall prototype under both versions of Standard 90.1.

The use of the space-by-space lighting method is a deviation from previous ASHRAE Standard 90.1 Determinations, where less detailed building models were used in the quantitative analysis. However, since the base LPD values for either space-by-space or building area path did not change between Standard 90.1-2004 and Standard 90.1-2007 and the change in the additional lighting power allowance due to Addendum ai was small and considered for only one building type, the choice of compliance path was deemed not to affect significantly the determination of energy savings.

For each building type, Table 8.5 shows the lighting compliance path used for the quantitative analysis and the average LPD used in the building models. Once selected, the same compliance path was used for LPD assumptions in both Standard 90.1 editions being compared. For each building prototype, the ASHRAE Standard 90.1-2004 and 90.1-2007 building area LPDs are shown for comparison alongside the values used in the quantitative analysis.

The final space-by-space calculations used in the quantitative analysis yield LPDs that differ from the LPDs determined from the building area compliance paths. For all building models other than restaurants and the mid-rise apartment, the LPDs used are between 7 percent lower to 8 percent higher than LPD from the building area compliance path. The LPDs modeled for the two restaurant prototypes are 16 to 18 percent higher than the LPD from the building area compliance path in either standard, a direct result of the relative ratio of kitchen to dining areas used in these prototypes compared with that assumed in the development of the ASHRAE 90.1 building area LPD values. All else being equal, the higher LPD assumptions result in a somewhat greater cooling load and lower heating load in these prototypes.

Table 8.5. Internal Lighting Power Density Used in Building Models

\begin{tabular}{|c|c|c|c|c|c|c|}
\hline \multirow[t]{2}{*}{$\begin{array}{l}\text { Building } \\
\text { Type }\end{array}$} & \multirow[t]{2}{*}{$\begin{array}{l}\text { Reference Building } \\
\text { Prototype }\end{array}$} & \multirow{2}{*}{$\begin{array}{c}\text { Lighting } \\
\text { Compliance } \\
\text { Path used for } \\
\text { Quantitative } \\
\text { Analysis } \\
\end{array}$} & \multicolumn{2}{|c|}{$\begin{array}{c}\text { Quantitative Analysis } \\
\text { LPD } \\
W / f t^{2}\end{array}$} & \multicolumn{2}{|c|}{$\begin{array}{c}\text { Building Area LPD } \\
W / f t^{2}\end{array}$} \\
\hline & & & 90.1-2004 & $90.1-2007$ & $90.1-2004$ & $90.1-2007$ \\
\hline \multirow[t]{3}{*}{ Office } & Small Office & Building Area & 1.000 & 1.000 & 1.0 & 1.0 \\
\hline & Medium Office & Building Area & 1.000 & 1.000 & 1.0 & 1.0 \\
\hline & Large Office & Building Area & 1.000 & 1.000 & 1.0 & 1.0 \\
\hline \multirow[t]{2}{*}{ Retail } & Stand-Alone Retail & Space-by-Space & 1.548 & 1.548 & 1.5 & 1.5 \\
\hline & Strip Mall & Space-by-Space & 1.645 & 1.568 & 1.5 & 1.5 \\
\hline \multirow{2}{*}{ Education } & Primary School & Space-by-Space & 1.188 & 1.188 & 1.2 & 1.2 \\
\hline & Secondary School & Space-by-Space & 1.134 & 1.134 & 1.2 & 1.2 \\
\hline \multirow[t]{2}{*}{ Healthcare } & Outpatient Health Care & Space-by-Space & 1.094 & 1.094 & 1.0 & 1.0 \\
\hline & Hospital & Space-by-Space & 1.119 & 1.119 & 1.2 & 1.2 \\
\hline \multirow[t]{2}{*}{ Lodging } & Small Hotel & Space-by-Space & 0.968 & 0.968 & 1.0 & 1.0 \\
\hline & Large Hotel & Building Area & 1.000 & 1.000 & 1.0 & 1.0 \\
\hline Warehouse & $\begin{array}{l}\text { Non-Refrigerated } \\
\text { Warehouse }\end{array}$ & Space-by-Space & 0.810 & 0.810 & 0.8 & 0.8 \\
\hline \multirow{2}{*}{ Food Service } & Fast-Food Restaurant & Space-by-Space & 1.650 & 1.650 & 1.4 & 1.4 \\
\hline & Sit-Down Restaurant & Space-by-Space & 1.855 & 1.855 & 1.6 & 1.6 \\
\hline Apartment & Mid-Rise Apartment & Space-by-Space & 0.402 & 0.402 & 0.7 & 0.7 \\
\hline
\end{tabular}


The building average LPD modeled for the mid-rise apartment prototype is 43 percent lower than the tabulated building area LPD value shown in both versions of Standard 90.1. However, the lighting section in both versions states that lighting in living units (i.e., apartments within multi-family housing) is not within the scope of Standard 90.1, implying that the building area method value should be applied only to common space within multi-family buildings and would not be suitable for the modeling of building lighting power. To generate the LPD for the mid-rise apartment building, DOE used the space-by-space LPD allowances in Standard 90.1. The mid-rise apartment prototype consists of two defined space types: office-enclosed and corridors; and the individual apartment units. Standard 90.1 has space-by-space LPDs for the office and corridor spaces. DOE assumed a value of $0.36 \mathrm{~W} / \mathrm{ft}^{2}$ for the LPD inside the apartments based on the lighting power assumptions found in the DOE Residential Building America Research Benchmark $^{5}$.

\subsection{Addendum 90.1-04an - Boiler Efficiency Change}

Boiler efficiencies are provided in Table 6.8.1F of Standard 90.1-2004. This table was impacted by two addenda to that Standard. Addenda 90.1-04t modified the baseline efficiency requirements for certain classes of boilers by adding a requirement for thermal efficiency where only a requirement for combustion efficiency appears in Standard 90.1-2004. A DOE review of commercial boiler efficiency suggested that the level of thermal efficiency proposed by addenda 90.1-04t at 75 percent for boilers with a minimum 80 percent combustion efficiency would have no significant impact on products available or likely to become available in the market, and no credit has been given for this addendum in the quantitative analysis. $^{6}$

Addenda 90.1-04an improved the thermal efficiency requirements for most classes of commercial boilers. It did not address boilers with less than 300,000 Btu/h input capacity, which are covered as residential products. As the changes for gas boilers were to be effective in the ASHRAE Standard on March 2, 2010, within 3 years of the publication date of Standard 90.1-2007, DOE included the change in efficiency in the quantitative analysis. In the case of boilers with less than $300,000 \mathrm{Btu} / \mathrm{h}$ capacity, the efficiency requirement is actually expressed in terms of annual fuel utilization efficiency (AFUE), but which has been approximated as thermal efficiency for the EnergyPlus simulations. As this efficiency did not change between Standard versions, this was considered to be a reasonable approximation assumption for the quantitative analysis. For boilers with greater than 2,500 kilo British thermal units per hour $(\mathrm{kBtu} / \mathrm{h})$ capacity, the requirement in ASHRAE is expressed in terms of combustion efficiency; DOE converted this to a thermal efficiency by assuming a 0.007 percent difference between combustion and thermal efficiency for boilers in this size range. Table 8.6 shows the boiler assumptions used for commercial boilers in three size categories.

The following building models use commercial gas-fired hot water boilers for space heating: large office, hotel, hospital, secondary school, outpatient health care, and primary school. None of the

5. NREL (2005). Building America Research Benchmark Definition. Updated December 29, 2004. Golden, CO: National Renewable Energy Laboratory.

6. U.S. Department of Energy-Office of Energy Efficiency \& Renewable Energy. Energy Conservation Program for Certain Industrial Equipment: Test Procedures and Energy Conservation Standards for Commercial Heating, Air-Conditioning, and Water Heating Equipment Final Rule Technical Support Document. September 14, 2009. Washington, D.C. $<$ http://www1.eere.energy.gov/buildings/appliance standards/commercial/ashrae final rule.html $>$ 
prototypes used steam or oil-fired boilers. For each of these building models in each climate simulated, the buildings boilers were first sized using the design day sizing analysis, and the efficiency of boilers determined for both the 2004 and 2007 standards based on the following table. Where multiple boilers exist in a prototype, the total heating capacity was first calculated using the EnergyPlus design day sizing run and was divided by the number of boilers prior to establishing the thermal efficiency of each boiler.

Table 8.6. Boiler Efficiency Assumptions Used in Quantitative Analysis

\begin{tabular}{|c|c|c|}
\hline \multirow[t]{2}{*}{$\begin{array}{c}\text { Gas Hot Water Boiler (input) } \\
\text { Capacity }\end{array}$} & \multicolumn{2}{|c|}{$\begin{array}{c}\text { Thermal Efficiency Used in Prototype } \\
\text { Simulation }\end{array}$} \\
\hline & 90.1-2004 & $90.1-2007$ \\
\hline$<300 \mathrm{kBtu} / \mathrm{h}$ & $0.80^{*}$ & $0.80^{*}$ \\
\hline$\geq 300 \mathrm{kBtu} / \mathrm{h} \&<2,500 \mathrm{kBtu} / \mathrm{h}$ & 0.75 & 0.80 \\
\hline$>2,500 \mathrm{kBtu} / \mathrm{h}$ & 0.793 & 0.813 \\
\hline
\end{tabular}

\subsection{Addendum 90.1-04ar - Part Load Fan Power Limitation Modification}

Standard 90.1-2004, Section 6.5.3.2.1, Part Load Fan Power Limitation, required that individual VAV fan systems with motors $15 \mathrm{hp}$ or larger shall either: (A) be driven by a mechanical or electrical variable speed drive; (B) be a vane axial fan with variable pitch blades; or (C) shall have other controls or devices such that the fan motor demand be no more than 30 percent of design wattage at 50 percent of design air flow rate when the static pressure set point equals one third of total design static pressure, based on manufacturer's certified fan data. This requirement provided two prescriptive design options and one performance option to provide for acceptably low fan part load fan power for VAV fan systems.

Addendum 90.1-04ar reduced the fan motor size threshold in this section from $15 \mathrm{hp}$ to $10 \mathrm{hp}$, increasing the number of VAV fan systems that would have to meet one or another of the three prescribed options. This addendum was incorporated into the simulation routines by first calculating a total fan air volume for any VAV system based on the design day sizing, then calculating a brake horsepower requirement for that fan system using the methodology discussed previously under discussion of Addendum 90.1-04ac, and then using the required motor efficiency to calculate a motor input power in watts. Motor input power thresholds of 7,378 W (equivalent to $9.9 \mathrm{hp}$ of electrical power input) were deemed equivalent to $15 \mathrm{hp}$ or less name plate horsepower given nominal motor sizes available in this size range $(7.5,10,15,20 \mathrm{hp}$ ). Motor input power thresholds of 5,626 W (equivalent to $7.54 \mathrm{hp}$ of electrical power input) were deemed equivalent to $10 \mathrm{hp}$ or less name plate horsepower given nominal motor sizes available. If the motor input power was less than 7,378 W in Standard 90.1-2004 or less than 5,626 W in Standard 90.1-2007, VAV fan system part load curve A was used in the EnergyPlus simulation, effectively representing a VAV fan controlled using outlet dampers only. For motor input power greater than these thresholds, VAV fan system part load curve B was used in the EnergyPlus simulation, representative of a fan system curve complying with Option $\mathrm{C}$ of Section 6.5.3.2.1

EnergyPlus uses a fourth order polynomial curve which gives the fraction of full load power (PLF) of the supply fan as a function of flow fraction $(\mathrm{FF})$, which is the air mass flow rate divided by the maximum air mass flow rate (design maximum). The curve is of the form: 


$$
\mathrm{PLF}=\mathrm{C}_{1}+\mathrm{C}_{2} \times \mathrm{FF}+\mathrm{C}_{3} \times \mathrm{FF}^{2}+\mathrm{C}_{4} \times \mathrm{FF}^{3}+\mathrm{C}_{5} \times \mathrm{FF}^{4}
$$

Table 8.7 shows the coefficients $\mathrm{C}_{1}$ through $\mathrm{C}_{5}$ for both VAV fan performance curve $A$ and fan performance curve B.

Table 8.7. Coefficients for VAV Part-Load Curves

\begin{tabular}{lllllll}
\hline \multicolumn{1}{c}{ Coefficients } & \multicolumn{1}{c}{$\mathbf{C}_{\mathbf{1}}$} & \multicolumn{1}{c}{$\mathbf{C}_{\mathbf{2}}$} & \multicolumn{1}{c}{$\mathbf{C}_{\mathbf{3}}$} & $\mathbf{C}_{\mathbf{4}}$ & & $\mathbf{C}_{\mathbf{5}}$ \\
\hline Curve A & 0.18984763 & 0.31447014 & 0.49568211 & 0 & 0 & \\
Curve B & 0.0408 & 0.0880 & -0.0729 & 0.9437 & 0 & \\
\hline
\end{tabular}

While the implementation to capture the impact of Addendum 90.1-04ar was made in the simulation modeling scripts, none of the prototypes appeared to have VAV fan systems below $15 \mathrm{hp}$, in either the Standard 90.1-2004 or Standard 90.1-2007 simulations. Given this, none of the prototypes is actually impacted numerically by this addendum, although it is incorporated in the quantitative analysis methodology.

\subsection{Addendum 90.1-04as - Opaque Envelope U-Factors Updates}

Standard 90.1-2004 has specific envelope requirements, generally expressed in terms of maximum allowed U-factor for above ground opaque envelope components including roofs, walls, opaque doors, and floors exposed to the ambient, maximum allowed C-factor for exterior below grade walls, and F-factors for slab-on-grade floors. These factors are defined for three distinct space type categories: nonresidential, residential, and semi-heated spaces. Addendum 90.1-04as modified these requirements, increasing the stringency for many of them. A detailed overview of the requirements changes for this addendum as a function of space type, component type, and climate zone is discussed in the qualitative analysis, with tables showing the standard requirements for both 90.1-2004 and 90.1-2007 and highlighting changes between these versions. For modeling in EnergyPlus, the U-factors, C-factors, and F-factors corresponding to fundamental components descriptions used in the ASHRAE Benchmark prototypes (e.g., metal frame wall) were modified to reflect the minimum requirements under either Standard 90.1-2004 or 90.1-2007, as appropriate.

\subsection{Addendum 90.1-04at - Fenestration Solar Heat Gain Coefficient and U-Factor Updates}

Standard 90.1-2004 has requirements for fenestration solar heat gain coefficient (SHGC) and Ufactor, including requirements for glazed doors. As with the opaque envelope, these requirements are defined for the three space type categories (nonresidential, residential, and semi-heated spaces) and by climate zone, including providing values for the 15 U.S. climate zones used in this analysis. The prescriptive requirements for windows are provided as a function of percentage of wall area that is glazed (here referred to as window-to-wall ratio (WWR)) in five WWR bins up to a maximum for vertical fenestration of 50 percent WWR. WWR levels greater than 50 percent are not allowed in the prescriptive path; such buildings must use either the envelope tradeoff path found in Appendix C of Standard 90.1 or the performance path outlined in Chapter 11, Energy Cost Budget Method, of Standard 90.1-2004 to show compliance with the Standard. U-factor requirements are provided for two types of vertical glazing: fixed and operable. In general, U-factors for a given type of vertical glazing are the same for all WWR up 
to 40 percent. U-factor requirements for the 40 to 50 percent WWR bin are reduced compared to the 30 to 40 percent WWR bin. This reduction in U-factor for the highest WWR bin was originally developed by the Standard 90.1 committee using an energy tradeoff approach and was designed to provide roughly equal envelope energy impact for both 30 to 40 percent and 40 to 50 percent WWR bins.

SHGC requirements in Standard 90.1-2004 are also provided by WWR bin in general showing a reduction in allowed SHGC for higher WWR bins for nonresidential and residential space types. SHGC requirements do not exist for semi-heated space types. In addition, Standard 90.1-2004 provides different, generally higher SHGC allowances for north-facing fenestration.

Standard 90.1-2004 also provides maximum U-factor and minimum SHGC requirements for skylights as a function of fraction of roof area that is glazed (up to a maximum of 5 percent).

Addendum 90.1-04at modified the fenestration requirements in the following ways:

- Defined new types of vertical glazing — non-metal framing: all; metal frame: curtain wall/storefront; metal frame: entrance door; metal framing: all other. These replace the previous operable and fixed vertical glazing categories.

- Limited the WWR ratio to 40 percent in the prescriptive path.

- Eliminated the variation in SHGC by WWR bin by defining requirements to be the same for vertical fenestration from 0 to 40 percent WWR.

- Defined U-factors by each of the four new vertical glazing types defined.

- Defined a single maximum SHGC allowance for all vertical glazing types up to 40 percent WWR for nonresidential and residential space types.

Taken in concert, these changes result in a significantly different characterization of vertical fenestration requirements between Standard 90.1-2004 and Standard 90.1-2007. A tabulated comparison of these differences in SHGC and U-factor by climate zone and space type is provided in the qualitative analysis. For most climate zones, U-factors are approximately equivalent or a reduction in allowed Ufactor is provided in Standard 90.1-2007. Maximum SHGC allowances move up or down depending on building WWR assumed.

Regardless of the version of Standard 90.1, window requirements in the Standard are defined by bulk properties of U-factor and SHGC. EnergyPlus, however, requires that the thermal/optical properties be defined for the window assembly layer by layer.

To analyze these changes, DOE first established a method for selecting an actual window option, comprised of framing and selected glazing options that would as close as possible meet both the maximum U-factor and SHGC allowed for a particular combination of U-factor/SHGC requirement in either version of Standard 90.1. Hypothetical combinations of glazing layers were derived using WINDOW $5^{7}$ calculations to produce a match to the specified U-factor and SHGC outlined in Appendix B of Standard 90.1-2004. Glazing materials were collected into a single window object, and window frames

7. Lawrence Berkeley National Laboratory. WINDOW 5.2 Software Tool. 2009. Available at $<\underline{\mathrm{http}: / / \text { windows.lbl.gov/software/window/window.html }>}$ 
are neglected to reduce complexity in the EnergyPlus models and make the simulations run faster. The window performance was modeled as for the entire glazed area. U-factor and SHGC values were treated as whole-assembly values. A total of 587 different combinations of U-factor, SHGC, and VLT were created using material component data and constructions developed for use with the WINDOWS5 software tool. This was termed the theoretical window library. For the Standard 90.1 simulations, for each combination of U-factor and SHGC provided for in either Standard 90.1-2004 or Standard 90.1-2007, a corresponding window construction and component materials was developed and included in a separate partial-idf file for inclusion in the EnergyPlus building input descriptions. With this method, EnergyPlus window descriptions essentially meeting Standard 90.1 fenestration requirements but reflecting windows with real window materials and glazing properties were developed and used in the quantitative analysis. 



\subsection{Simulation of Prototypes and Extraction of Results}

Simulation of all 450 prototype/climate zones combinations was done using EnergyPlus. Each prototype is first simulated using a set of design-day runs based on ASHRAE design-day conditions. Certain specific data related to sizing of systems and equipment and necessary for determining the impact of addenda were extracted from the design day runs. Necessary updates to the input decks for each prototype type were made to correctly reflect the addenda, and an annual run was then performed for each of the prototype in each climate and at each standard level. Annual energy use for each annual simulation by fuel type (natural gas or electricity) was extracted for each simulation both by end use and at the whole building level. Data for each building prototype in each climate zone was extracted from the EnergyPlus simulations results using PERL scripting tools and the data incorporated into special purpose spreadsheets to weight to nationwide results. The energy use data was converted to EUI data by dividing by the building area for each prototype. This EUI data was then weighted using weighting factors discussed in the next section to provide nationally representative results. 



\subsection{Development of Weighting Factors}

For this weighting, weighting factors were developed based on 5 years of construction data purchased by DOE from McGraw Hill's FW DODGE dataset. Development of the weighting factors is discussed in a DOE/PNNL report. ${ }^{1}$ This report details weighting factors for 16 building prototypes, including a high rise apartment commercial reference building prototype planned by ASHRAE but not developed or available for use with the 90.1-2007 Determination. Weights for this building model were eliminated and the subsequent building weights rescaled to add to 100 percent for the development of relative weightings factors for use in the Determination. Rescaling was done based on the national sample weights for the high rise apartment building and for the other building prototypes reported in the cited paper, thus preserving the relative climate weights for any specific prototype. Table 10.1 shows the resulting rescaled weighting factors by climate and by building prototype used for each prototype in the Determination.

1. Jarnagin, R. E. and G. K. Bandyopadhyay. Weighting Factors for the Commercial Building Prototypes Used in the Development of ANSI/ASHRAE/IENSA Standard 90.1-2010. 2010. Pacific Northwest National Laboratory: Richland, WA. Report No. PNNL-19116. 
Table 10.1. Relative Construction Volume Weights for 15 ASHRAE Building Prototypes by Climate Zone

\begin{tabular}{|c|c|c|c|c|c|c|c|c|c|c|c|c|c|c|c|c|}
\hline ASHRAE & 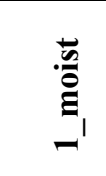 & 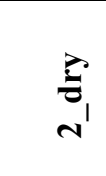 & 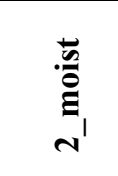 & $\begin{array}{l}\vec{b} \\
m_{1}\end{array}$ & 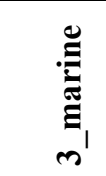 & 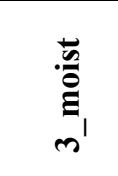 & $\begin{array}{l}\vec{B} \\
\nabla_{1}\end{array}$ & 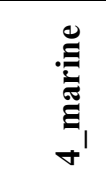 & 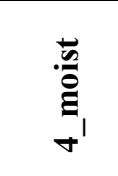 & $\begin{array}{l}\underbrace{}_{1} \\
n\end{array}$ & 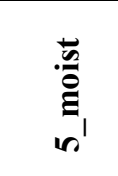 & $\begin{array}{l}\vec{E} \\
\sigma_{1}\end{array}$ & 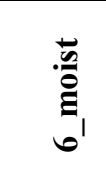 & $r$ & $\infty$ & 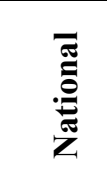 \\
\hline & \multicolumn{16}{|c|}{$\%$} \\
\hline Large Office & 0.112 & 0.067 & 0.358 & 0.313 & 0.128 & 0.489 & 0.000 & 0.169 & 1.243 & 0.133 & 0.486 & 0.000 & 0.146 & 0.012 & 0.000 & 3.655 \\
\hline Medium Office & 0.142 & 0.321 & 0.893 & 0.786 & 0.149 & 0.841 & 0.040 & 0.215 & 1.307 & 0.376 & 1.164 & 0.038 & 0.328 & 0.036 & 0.008 & 6.643 \\
\hline Small Office & 0.092 & 0.318 & 1.169 & 0.522 & 0.085 & 1.057 & 0.052 & 0.135 & 1.028 & 0.353 & 1.010 & 0.033 & 0.265 & 0.036 & 0.005 & 6.160 \\
\hline Standalone Retail & 0.246 & 0.556 & 2.439 & 1.373 & 0.210 & 2.621 & 0.131 & 0.471 & 2.796 & 0.870 & 3.767 & 0.100 & 1.042 & 0.119 & 0.015 & 16.757 \\
\hline Strip Mall & 0.151 & 0.278 & 1.088 & 0.687 & 0.114 & 1.121 & 0.025 & 0.117 & 1.108 & 0.221 & 1.123 & 0.018 & 0.168 & 0.008 & 0.001 & 6.228 \\
\hline Primary School & 0.070 & 0.180 & 1.025 & 0.490 & 0.052 & 1.037 & 0.033 & 0.103 & 0.983 & 0.246 & 1.011 & 0.041 & 0.185 & 0.026 & 0.004 & 5.486 \\
\hline Secondary School & 0.176 & 0.252 & 1.673 & 0.900 & 0.120 & 2.080 & 0.069 & 0.266 & 2.211 & 0.481 & 2.506 & 0.094 & 0.456 & 0.083 & 0.014 & 11.382 \\
\hline Hospital & 0.044 & 0.105 & 0.526 & 0.299 & 0.043 & 0.514 & 0.024 & 0.116 & 0.676 & 0.240 & 0.892 & 0.026 & 0.243 & 0.037 & 0.001 & 3.788 \\
\hline $\begin{array}{l}\text { Outpatient } \\
\text { Health Care }\end{array}$ & 0.041 & 0.147 & 0.623 & 0.302 & 0.067 & 0.638 & 0.026 & 0.199 & 0.898 & 0.239 & 1.163 & 0.037 & 0.376 & 0.043 & 0.002 & 4.801 \\
\hline Restaurant & 0.010 & 0.027 & 0.116 & 0.052 & 0.006 & 0.122 & 0.006 & 0.011 & 0.140 & 0.034 & 0.157 & 0.004 & 0.034 & 0.004 & 0.000 & 0.725 \\
\hline $\begin{array}{l}\text { Fast-Food } \\
\text { Restaurant }\end{array}$ & 0.009 & 0.022 & 0.101 & 0.069 & 0.008 & 0.112 & 0.006 & 0.016 & 0.098 & 0.028 & 0.141 & 0.003 & 0.028 & 0.004 & 0.000 & 0.644 \\
\hline Large Hotel & 0.119 & 0.137 & 0.682 & 0.871 & 0.116 & 0.698 & 0.041 & 0.135 & 1.053 & 0.219 & 1.010 & 0.063 & 0.249 & 0.042 & 0.004 & 5.439 \\
\hline Small Hotel/Motel & 0.011 & 0.033 & 0.316 & 0.125 & 0.024 & 0.294 & 0.022 & 0.043 & 0.346 & 0.098 & 0.400 & 0.034 & 0.117 & 0.023 & 0.004 & 1.890 \\
\hline $\begin{array}{l}\text { Non-Refrigerated } \\
\text { Warehouse }\end{array}$ & 0.384 & 0.638 & 2.846 & 2.525 & 0.169 & 3.259 & 0.075 & 0.478 & 2.687 & 0.756 & 3.932 & 0.054 & 0.512 & 0.047 & 0.002 & 18.362 \\
\hline Mid-Rise Apartment & 0.282 & 0.103 & 1.201 & 0.947 & 0.286 & 0.906 & 0.024 & 0.407 & 1.861 & 0.350 & 1.232 & 0.062 & 0.344 & 0.036 & 0.000 & 8.042 \\
\hline Totals & 1.890 & 3.185 & 15.055 & 10.260 & 1.578 & 15.789 & 0.574 & 2.881 & 18.433 & 4.645 & 19.995 & 0.608 & 4.492 & 0.554 & 0.061 & $\begin{array}{l}100.00 \\
0\end{array}$ \\
\hline
\end{tabular}




\subsection{Results}

Table 11.1 and Table 11.2 show the national EUI by building type for the 15 building prototypes analyzed and on an aggregated national basis for the 2004 and 2007 editions, respectively, based on the weighting factors discussed previously. For each edition of Standard 90.1, the national building floor area weight used to calculate the national impact on building EUI or building ECI is presented. The national average electricity and gas building EUI is presented separately for each building prototype analyzed, electricity being the predominant energy usage in all prototypes. National-average site EUIs range from over $500 \mathrm{Btu} / \mathrm{ft}^{2}$ annually for the fast-food prototype to approximately $28 \mathrm{Btu} / \mathrm{ft}^{2}$ annually for the nonrefrigerated warehouse type.

Table 11.1. Estimated Energy Use Intensity by Building Type - 2004 Edition

\begin{tabular}{|c|c|c|c|c|c|c|c|}
\hline \multirow[t]{2}{*}{$\begin{array}{l}\text { Building } \\
\text { Type }\end{array}$} & \multirow[t]{2}{*}{$\begin{array}{l}\text { Building } \\
\text { Prototype }\end{array}$} & \multirow{2}{*}{$\begin{array}{c}\text { Building } \\
\text { Type Floor } \\
\text { Area Weight } \\
\%\end{array}$} & \multicolumn{5}{|c|}{$\begin{array}{l}\text { Whole Building EUI Data for Building Population } \\
\qquad k B t u / f t^{2}-y r\end{array}$} \\
\hline & & & $\begin{array}{l}\text { Electric } \\
\text { EUI }\end{array}$ & $\begin{array}{l}\text { Gas } \\
\text { EUI }\end{array}$ & $\begin{array}{l}\text { Site } \\
\text { EUI }\end{array}$ & $\begin{array}{c}\text { Source } \\
\text { EUI }\end{array}$ & $\begin{array}{c}\mathbf{E C I} \\
\$ / f t^{2}-y r\end{array}$ \\
\hline \multirow[t]{3}{*}{ Office } & Small Office & 6.16 & 35.6 & 3.6 & 39.2 & 117.8 & $\$ 1.11$ \\
\hline & Medium Office & 6.64 & 42.1 & 4.2 & 46.3 & 139.2 & $\$ 1.31$ \\
\hline & Large Office & 3.65 & 34.4 & 5.7 & 40.1 & 116.2 & $\$ 1.09$ \\
\hline \multirow{2}{*}{ Retail } & Stand-Alone Retail & 16.76 & 56.1 & 15.0 & 71.1 & 195.7 & $\$ 1.84$ \\
\hline & Strip Mall & 6.23 & 55.2 & 20.1 & 75.2 & 198.3 & $\$ 1.86$ \\
\hline \multirow[t]{2}{*}{ Education } & Primary School & 5.49 & 47.9 & 23.5 & 71.4 & 178.9 & $\$ 1.68$ \\
\hline & Secondary School & 11.38 & 43.7 & 19.5 & 63.1 & 160.9 & $\$ 1.51$ \\
\hline \multirow[t]{2}{*}{ Healthcare } & $\begin{array}{l}\text { Outpatient Health } \\
\text { Care }\end{array}$ & 4.80 & 106.7 & 54.7 & 161.4 & 400.8 & $\$ 3.76$ \\
\hline & Hospital & 3.79 & 96.3 & 57.6 & 153.9 & 370.9 & $\$ 3.48$ \\
\hline \multirow[t]{2}{*}{ Lodging } & Small Hotel & 1.89 & 48.3 & 26.1 & 74.3 & 182.8 & $\$ 1.71$ \\
\hline & Large Hotel & 5.44 & 68.5 & 84.4 & 152.9 & 311.0 & $\$ 2.91$ \\
\hline Warehouse & $\begin{array}{l}\text { Non-Refrigerated } \\
\text { Warehouse }\end{array}$ & 18.36 & 14.5 & 10.7 & 25.2 & 58.1 & $\$ 0.54$ \\
\hline \multirow{2}{*}{$\begin{array}{l}\text { Food } \\
\text { Service }\end{array}$} & Fast-Food & 0.64 & 226.5 & 326.1 & 552.6 & 1080.0 & $\$ 10.10$ \\
\hline & $\begin{array}{l}\text { Restaurant } \\
\text { Sit-Down } \\
\text { Restaurant }\end{array}$ & 0.72 & 179.3 & 202.1 & 381.4 & 794.0 & $\$ 7.43$ \\
\hline Apartment & $\begin{array}{l}\text { Mid-Rise } \\
\text { Apartment }\end{array}$ & 8.04 & 32.5 & 10.1 & 42.7 & 115.1 & $\$ 1.08$ \\
\hline National & & 100 & 48.1 & 24.2 & 72.3 & 180.3 & $\$ 1.69$ \\
\hline
\end{tabular}


Table 11.2. Estimated Energy Use Intensity by Building Type - 2007 Edition

\begin{tabular}{|c|c|c|c|c|c|c|c|}
\hline \multirow[t]{2}{*}{$\begin{array}{l}\text { Building } \\
\text { Type }\end{array}$} & \multirow[t]{2}{*}{$\begin{array}{l}\text { Building } \\
\text { Prototype }\end{array}$} & \multirow{2}{*}{$\begin{array}{c}\text { Building } \\
\text { Type Floor } \\
\text { Area Weight } \\
\%\end{array}$} & \multicolumn{5}{|c|}{$\begin{array}{l}\text { Whole Building EUI Data for Building Population } \\
k B t u / f t^{2}-y r\end{array}$} \\
\hline & & & Electric & Gas & Site & Source & $\underset{\$ / f t^{2}-y r}{\mathbf{E C I}}$ \\
\hline \multirow[t]{3}{*}{ Office } & Small Office & 6.16 & 35.3 & 3.3 & 38.6 & 116.6 & $\$ 1.10$ \\
\hline & Medium Office & 6.64 & 40.2 & 4.3 & 44.5 & 133.2 & $\$ 1.25$ \\
\hline & Large Office & 3.65 & 34.3 & 4.6 & 38.9 & 114.7 & $\$ 1.08$ \\
\hline \multirow[t]{2}{*}{ Retail } & Stand-Alone Retail & 16.76 & 51.4 & 13.3 & 64.7 & 178.9 & $\$ 1.68$ \\
\hline & Strip Mall & 6.23 & 52.3 & 16.9 & 69.2 & 185.8 & $\$ 1.74$ \\
\hline \multirow{2}{*}{ Education } & Primary School & 5.49 & 46.7 & 19.9 & 66.6 & 171.1 & $\$ 1.61$ \\
\hline & Secondary School & 11.38 & 42.5 & 16.6 & 59.1 & 154.2 & $\$ 1.45$ \\
\hline \multirow[t]{2}{*}{ Healthcare } & $\begin{array}{l}\text { Outpatient Health } \\
\text { Care }\end{array}$ & 4.80 & 102.1 & 52.8 & 154.9 & 384.3 & $\$ 3.60$ \\
\hline & Hospital & 3.79 & 95.8 & 56.2 & 152.0 & 367.7 & $\$ 3.45$ \\
\hline \multirow[t]{2}{*}{ Lodging } & Small Hotel & 1.89 & 46.5 & 24.7 & 71.2 & 175.7 & $\$ 1.65$ \\
\hline & Large Hotel & 5.44 & 69.1 & 79.1 & 148.2 & 307.3 & $\$ 2.88$ \\
\hline Warehouse & $\begin{array}{l}\text { Non-Refrigerated } \\
\text { Warehouse }\end{array}$ & 18.36 & 14.5 & 10.6 & 25.2 & 58.0 & $\$ 0.54$ \\
\hline \multirow{3}{*}{$\begin{array}{l}\text { Food } \\
\text { Service }\end{array}$} & Fast-Food & 0.64 & 222.1 & 319.5 & 541.6 & 1058.7 & $\$ 9.90$ \\
\hline & Restaurant & & & & & & \\
\hline & $\begin{array}{l}\text { Sit-Down } \\
\text { Restaurant }\end{array}$ & 0.72 & 177.5 & 200.0 & 377.6 & 785.9 & $\$ 7.35$ \\
\hline Apartment & $\begin{array}{l}\text { Mid-Rise } \\
\text { Apartment }\end{array}$ & 8.04 & 31.8 & 9.0 & 40.8 & 111.7 & $\$ 1.05$ \\
\hline National & & 100 & 46.5 & 22.5 & 69.0 & 173.3 & $\$ 1.63$ \\
\hline
\end{tabular}

DOE's prototypes reflect the use of two fuel types, electricity and natural gas. Using the weighting factors, DOE was able to establish an estimate of the relative reduction in building energy use, as determined by a calculated reduction in weighted average site EUI for each building prototype. Site energy refers to the energy consumed at the building site. In a corresponding fashion, DOE was also able to calculate a reduction in terms of weighted average primary EUI and in terms of weighted average energy cost intensity (ECI) in $\$$ sq. $\mathrm{ft}$. of building floorspace. Primary energy as used here refers to the energy required to generate and deliver energy to the site. To estimate primary energy, all electrical energy use intensities were first converted to primary energy using a factor of 10,918 Btus primary energy per kWh (based on the 2010 estimated values reported in Table 2 of the EIA 2010 Annual Energy Outlook, release date December 2009, available at http://www.eia.doe.gov/oiaf/archive/aeo10/aeoref tab.html).

The conversion factor of 10,918 was calculated from Table 2 by summing the commercial electricity value of 4.62 quads with the electricity losses value of 10.17 quads and then dividing that sum by the commercial value. $((4.62+10.17) / 4.62=3.2)$ This yields an electricity ratio of 3.2 for converting how much primary (source) electricity is required per unit of site required electricity. This ratio of 3.2 is then multiplied by 3,412 Btu per $\mathrm{kWh}$, producing a value of 10,918 Btus primary energy per $\mathrm{kWh}$ of site energy. Natural Gas EUIs in the prototypes were converted to primary energy using a factor of 1.090 Btus primary energy per Btu of site natural gas use (based on the 2010 national energy use estimated shown in Table 2 of the AEO 2010). This natural gas source energy conversion factor was calculated by dividing the natural gas subtotal of 23.15 quads (sum of all natural gas usage, including usage for natural gas field production, leases, plant fuel, and pipeline (compression) supply) by the delivered natural gas total of 21.23 quads (sum of four primary energy sectors (residential, commercial, industrial, and transportation). 
To estimate the reduction in energy cost index, DOE relied on national average commercial building energy prices of $\$ 0.1027$ / $\mathrm{kWh}$ of electricity and $\$ 10.06$ per 1000 cubic feet $(\$ 0.9796 /$ therm) of natural gas, based on EIA statistics for 2010 (the last complete year of data available in Table 5.3 Average Retail Price of Electricity to Ultimate Consumers: Total by End-Use Sector for the commercial sector available from EIA at http://www.eia.doe.gov/cneaf/electricity/epm/table5_3.html and for 2009 (the last complete year of data available from the EIA Natural Gas Annual Summary for the commercial sector available at http://tonto.eia.doe.gov/dnav/ng/ng_pri_sum_dcu nus_a.htm.) DOE recognizes that actual fuel costs will vary somewhat by building type within a region, and will in fact vary more across regions. Nevertheless, DOE believes that the use of simple national average figures illustrates whether there will be energy cost savings sufficient for the purposes of the DOE determination.

Resulting EUI statistics by fuel type and site or primary energy are shown in Table 11.1 and Table 11.2 for Standard 90.1-2004 and Standard 90.1-2007, respectively, and using ASHRAE Standard 62.1-2004 ventilation assumptions for both sets of buildings. In terms of energy expenditures per square foot per year, ECI statistics are provided as well in these tables.

Table 11.3 presents the estimated percent energy savings (based on change in EUI) between the 2004 and 2007 editions. Considering those differences that can be reasonably quantified, the 2007 edition will increase the energy efficiency of commercial buildings. The values shown in Table 11.3 represent percent energy savings; thus, negative numbers represent increased energy use. Overall, the quantitative analysis projects a decrease in gas EUI for all building types except medium office. This decrease in gas EUI represents the majority of the national site energy savings from the 2007 edition. There is a decrease in electrical EUI for all building prototypes except for large hotel.

Table 11.3. Estimated Percent Energy Savings with 2007 Edition - by Building Type

\begin{tabular}{|c|c|c|c|c|c|c|c|}
\hline \multirow[t]{2}{*}{$\begin{array}{l}\text { Building } \\
\text { Type }\end{array}$} & \multirow[t]{2}{*}{ Building Prototype } & \multirow{2}{*}{$\begin{array}{c}\text { Building Type } \\
\text { Floor Area } \\
\text { Weight } \\
\%\end{array}$} & \multicolumn{5}{|c|}{$\begin{array}{c}\text { Savings in Whole Building EUI } \\
\%\end{array}$} \\
\hline & & & Electric & Gas & Site & Source & $\overline{\mathrm{ECl}}$ \\
\hline \multirow[t]{3}{*}{ Office } & Small Office & 6.16 & 0.8 & 9.0 & 1.5 & 1.0 & 1.0 \\
\hline & Medium Office & 6.64 & 4.6 & -2.3 & 3.9 & 4.3 & 4.4 \\
\hline & Large Office & 3.65 & 0.3 & 18.0 & 2.8 & 1.3 & 1.3 \\
\hline \multirow{2}{*}{ Retail } & Stand-Alone Retail & 16.76 & 8.3 & 11.2 & 9.0 & 8.6 & 8.6 \\
\hline & Strip Mall & 6.23 & 5.2 & 15.6 & 8.0 & 6.3 & 6.3 \\
\hline \multirow[t]{2}{*}{ Education } & Primary School & 5.49 & 2.5 & 15.4 & 6.8 & 4.4 & 4.3 \\
\hline & Secondary School & 11.38 & 2.6 & 14.8 & 6.3 & 4.2 & 4.2 \\
\hline \multirow[t]{2}{*}{ Healthcare } & Outpatient Health Care & 4.80 & 4.2 & 3.4 & 4.0 & 4.1 & 4.1 \\
\hline & Hospital & 3.79 & 0.6 & 2.3 & 1.2 & 0.9 & 0.9 \\
\hline \multirow[t]{2}{*}{ Lodging } & Small Hotel & 1.89 & 3.6 & 5.2 & 4.2 & 3.9 & 3.9 \\
\hline & Large Hotel & 5.44 & -1.0 & 6.3 & 3.0 & 1.2 & 1.2 \\
\hline Warehouse & $\begin{array}{l}\text { Non-Refrigerated } \\
\text { Warehouse }\end{array}$ & 18.36 & 0.0 & 0.7 & 0.3 & 0.2 & 0.2 \\
\hline Food & Fast Food Restaurant & 0.64 & 1.9 & 2.0 & 2.0 & 2.0 & 2.0 \\
\hline Service & Sit-Down Restaurant & 0.72 & 1.0 & 1.0 & 1.0 & 1.0 & 1.0 \\
\hline Apartment & Mid-Rise Apartment & 8.04 & 2.1 & 11.5 & 4.3 & 3.0 & 3.0 \\
\hline National & & 100 & 3.4 & 6.9 & 4.6 & 3.9 & 3.9 \\
\hline
\end{tabular}




\subsection{Ventilation Assumption Sensitivity}

Sensitivity to ventilation rate assumption was modeled by using ASHRAE Standard 62.1-1999 ventilation rates for both Standard 90.1-2004 and Standard 90.1-2007. For most building types, Standard 62.1-1999 had similar or somewhat higher ventilation levels than Standard 62.1-2004. Table 11.4, Table 11.5, and Table 11.6 show similar EUI data as discussed previously, but under the assumption that ventilation levels were at the Standard 62.1-1999 levels. Under this ventilation assumption, national savings were estimated at 4.4 percent primary energy, 5.6 percent site energy. The calculated change in the ECI was 4.5 percent.

Table 11.4. Estimated Energy Use Intensity by Building Type - 2004 Edition (62.1-1999 Vent.)

\begin{tabular}{|c|c|c|c|c|c|c|c|}
\hline \multirow[t]{2}{*}{$\begin{array}{c}\text { Building } \\
\text { Type }\end{array}$} & \multirow[t]{2}{*}{$\begin{array}{l}\text { Building } \\
\text { Prototype }\end{array}$} & \multirow{2}{*}{$\begin{array}{c}\text { Building } \\
\text { Type Floor } \\
\text { Area Weight } \\
\% \\
\end{array}$} & \multicolumn{5}{|c|}{$\begin{array}{l}\text { Whole Building EUI Data for Building Population } \\
\qquad k B t u / f t^{2}-y r\end{array}$} \\
\hline & & & Electric & Gas & Site & Source & $\begin{array}{c}\mathbf{E C I} \\
\$ / f t^{2}-y r\end{array}$ \\
\hline \multirow[t]{3}{*}{ Office } & Small Office & 6.16 & 35.7 & 3.8 & 39.5 & 118.4 & $\$ 1.11$ \\
\hline & Medium Office & 6.64 & 42.1 & 4.7 & 46.8 & 139.9 & $\$ 1.32$ \\
\hline & Large Office & 3.65 & 34.4 & 6.2 & 40.6 & 116.8 & $\$ 1.10$ \\
\hline \multirow[t]{2}{*}{ Retail } & Stand-Alone Retail & 16.76 & 56.4 & 19.7 & 76.1 & 201.9 & $\$ 1.90$ \\
\hline & Strip Mall & 6.23 & 55.6 & 24.6 & 80.2 & 204.5 & $\$ 1.92$ \\
\hline \multirow[t]{2}{*}{ Education } & Primary School & 5.49 & 48.7 & 27.0 & 75.7 & 185.2 & $\$ 1.74$ \\
\hline & Secondary School & 11.38 & 45.7 & 25.4 & 71.0 & 173.8 & $\$ 1.63$ \\
\hline \multirow[t]{2}{*}{ Healthcare } & Outpatient Health Care & 4.80 & 107.1 & 56.4 & 163.6 & 404.2 & $\$ 3.79$ \\
\hline & Hospital & 3.79 & 97.6 & 56.7 & 154.3 & 374.1 & $\$ 3.51$ \\
\hline \multirow[t]{2}{*}{ Lodging } & Small Hotel & 1.89 & 48.9 & 29.2 & 78.1 & 188.3 & $\$ 1.77$ \\
\hline & Large Hotel & 5.44 & 69.9 & 94.8 & 164.7 & 326.9 & $\$ 3.06$ \\
\hline Warehouse & $\begin{array}{l}\text { Non-Refrigerated } \\
\text { Warehouse }\end{array}$ & 18.36 & 14.5 & 10.7 & 25.2 & 58.1 & $\$ 0.54$ \\
\hline Food & Fast-Food Restaurant & 0.64 & 220.2 & 337.9 & 558.1 & 1072.6 & $\$ 10.02$ \\
\hline Service & Sit-Down Restaurant & 0.72 & 180.2 & 217.8 & 398.0 & 813.8 & $\$ 7.61$ \\
\hline Apartment & Mid-Rise Apartment & 8.04 & 32.5 & 10.2 & 42.7 & 115.1 & $\$ 1.08$ \\
\hline National & & 100 & 48.6 & 27.1 & 75.7 & 185.0 & $\$ 1.74$ \\
\hline
\end{tabular}


Table 11.5. Estimated Energy Use Intensity by Building Type - 2007 Edition (62.1-1999 Vent)

\begin{tabular}{|c|c|c|c|c|c|c|c|}
\hline \multirow[t]{2}{*}{$\begin{array}{l}\text { Building } \\
\text { Type }\end{array}$} & \multirow[t]{2}{*}{$\begin{array}{l}\text { Building } \\
\text { Prototype }\end{array}$} & \multirow{2}{*}{$\begin{array}{c}\text { Building } \\
\text { Type Floor } \\
\text { Area Weight } \\
\% \\
\end{array}$} & \multicolumn{5}{|c|}{$\begin{array}{l}\text { Whole Building EUI Data for Building Population } \\
\qquad k B t u / f t^{2}-y r\end{array}$} \\
\hline & & & Electric & Gas & Site & Source & $\underset{\$ / f t^{2}-y r}{\mathbf{E C I}}$ \\
\hline \multirow[t]{3}{*}{ Office } & Small Office & 6.16 & 35.4 & 3.5 & 38.9 & 117.1 & $\$ 1.10$ \\
\hline & Medium Office & 6.64 & 40.2 & 4.8 & 45.0 & 133.9 & $\$ 1.26$ \\
\hline & Large Office & 3.65 & 34.3 & 5.1 & 39.4 & 115.2 & $\$ 1.08$ \\
\hline \multirow[t]{2}{*}{ Retail } & Stand-Alone Retail & 16.76 & 51.7 & 18.0 & 69.7 & 185.0 & $\$ 1.74$ \\
\hline & Strip Mall & 6.23 & 52.7 & 21.3 & 74.0 & 191.7 & $\$ 1.80$ \\
\hline \multirow{2}{*}{ Education } & Primary School & 5.49 & 47.3 & 20.8 & 68.1 & 173.9 & $\$ 1.63$ \\
\hline & Secondary School & 11.38 & 44.6 & 19.7 & 64.3 & 164.2 & $\$ 1.54$ \\
\hline \multirow[t]{2}{*}{ Healthcare } & Outpatient Health Care & 4.80 & 102.6 & 54.6 & 157.2 & 387.8 & $\$ 3.64$ \\
\hline & Hospital & 3.79 & 97.2 & 55.4 & 152.6 & 371.4 & $\$ 3.48$ \\
\hline \multirow[t]{2}{*}{ Lodging } & Small Hotel & 1.89 & 46.3 & 27.4 & 73.7 & 178.0 & $\$ 1.67$ \\
\hline & Large Hotel & 5.44 & 70.0 & 82.5 & 152.5 & 313.9 & $\$ 2.94$ \\
\hline Warehouse & $\begin{array}{l}\text { Non-Refrigerated } \\
\text { Warehouse }\end{array}$ & 18.36 & 14.5 & 10.6 & 25.1 & 58.0 & $\$ 0.54$ \\
\hline Food & Fast-Food Restaurant & 0.64 & 215.7 & 332.0 & 547.7 & 1052.0 & $\$ 9.83$ \\
\hline Service & Sit-Down Restaurant & 0.72 & 178.4 & 216.0 & 394.4 & 806.1 & $\$ 7.54$ \\
\hline Apartment & Mid-Rise Apartment & 8.04 & 31.9 & 9.0 & 40.9 & 111.7 & $\$ 1.05$ \\
\hline National & & 100 & 46.9 & 24.6 & 71.5 & 176.9 & $\$ 1.66$ \\
\hline
\end{tabular}

Table 11.6. Estimated Percent Energy Savings with 2007 Edition - by Building Type (62.1-1999 Vent)

\begin{tabular}{|c|c|c|c|c|c|c|c|}
\hline \multirow[t]{2}{*}{$\begin{array}{l}\text { Building } \\
\text { Type }\end{array}$} & \multirow[t]{2}{*}{ Building Prototype } & \multirow{2}{*}{$\begin{array}{c}\text { Building } \\
\text { Type Floor } \\
\text { Area Weight } \\
\% \\
\end{array}$} & \multicolumn{5}{|c|}{ Savings in Whole Building EUI } \\
\hline & & & $\begin{array}{c}\text { Electric } \\
\text { EUI }\end{array}$ & Gas EUI & Site EUI & $\begin{array}{c}\text { Source } \\
\text { EUI }\end{array}$ & ECI \\
\hline \multirow[t]{3}{*}{ Office } & Small Office & 6.16 & 0.8 & 8.9 & 1.6 & 1.1 & 1.1 \\
\hline & Medium Office & 6.64 & 4.6 & -2.7 & 3.8 & 4.3 & 4.3 \\
\hline & Large Office & 3.65 & 0.4 & 16.8 & 2.9 & 1.3 & 1.3 \\
\hline \multirow[t]{2}{*}{ Retail } & Stand-Alone Retail & 16.76 & 8.3 & 8.9 & 8.5 & 8.4 & 8.4 \\
\hline & Strip Mall & 6.23 & 5.2 & 13.3 & 7.7 & 6.3 & 6.2 \\
\hline \multirow[t]{2}{*}{ Education } & Primary School & 5.49 & 2.9 & 22.9 & 10.0 & 6.1 & 6.0 \\
\hline & Secondary School & 11.38 & 2.4 & 22.3 & 9.5 & 5.5 & 5.5 \\
\hline \multirow[t]{2}{*}{ Healthcare } & Outpatient Health Care & 4.80 & 4.2 & 3.2 & 3.9 & 4.1 & 4.1 \\
\hline & Hospital & 3.79 & 0.4 & 2.3 & 1.1 & 0.7 & 0.7 \\
\hline \multirow{2}{*}{ Lodging } & Small Hotel & 1.89 & 5.3 & 6.3 & 5.7 & 5.5 & 5.5 \\
\hline & Large Hotel & 5.44 & -0.1 & 12.9 & 7.4 & 4.0 & 3.9 \\
\hline Warehouse & $\begin{array}{l}\text { Non-Refrigerated } \\
\text { Warehouse }\end{array}$ & 18.36 & 0.0 & 0.8 & 0.3 & 0.2 & 0.2 \\
\hline Food & Fast Food Restaurant & 0.64 & 2.0 & 1.8 & 1.9 & 1.9 & 1.9 \\
\hline Service & Sit-Down Restaurant & 0.72 & 1.0 & 0.8 & 0.9 & 1.0 & 1.0 \\
\hline Apartment & Mid-Rise Apartment & 8.04 & 2.1 & 11.5 & 4.3 & 3.0 & 3.0 \\
\hline National & & 100 & 3.5 & 9.3 & 5.6 & 4.4 & 4.4 \\
\hline
\end{tabular}





\section{Appendix A}

\section{Vestibule Requirement and Door Infiltration Modeling}





\section{Appendix A - Vestibule Requirement and Door Infiltration Modeling}

\section{A.1 Introduction}

The purpose of this study is to develop a modeling strategy to capture the energy saving impacts from Addendum c to 90.1-2004 and Addendum q to 90.1-2007. These addenda require vestibules in buildings in certain climate zones to reduce the infiltration through the building entrance doors.

Building entrance door infiltration can be an important factor to estimate an overall infiltration value of a whole building when door-opening frequency is high. When doors are used infrequently, door infiltration can be estimated based on air leakage through cracks between door and frame. Many commercial buildings, such as restaurants, strip-malls, retail stores, supermarkets, offices, and hospitals, are likely to have high door-opening frequency at certain time periods of day. Vestibules or revolving doors are often considered to reduce the air leakage when doors are used frequently. This appendix presents a proposed method to estimate door-infiltration rate with and without vestibules for the purpose of the estimating the impact of addendum to 90.1-2004. The estimated values for the prototype models are presented. The values are also used as EnergyPlus inputs to estimate end-use energy reduction for each prototype by installing vestibules.

\section{A.2 General Assumption}

In this analysis, doors in each prototype are assumed to be automatic doors (i.e., air flow through a door for each use is assumed to be constant). The main reason for this assumption is that currently we are unable to find any method to estimate airflow through manual doors. However, a method to estimate airflow through automatic doors is available from ASHRAE Fundamental Handbook. Since automatic doors often stay open longer with each use than manual doors, this assumption may result in overestimates of infiltration rates through building entrance doors when doors are open.

\section{A.3 ASHRAE 90.1 Vestibule Requirements}

In this section, each building prototype is identified for the vestibule requirement. The prototype model characteristics to determine vestibule requirements are described in Table A.1. The vestibule requirements for both Standard 90.1-2004 standard and 90.1-2007 (reflecting addendum 'c' to 90.1-2004) are below.

\section{A.3.1 ASHRAE 90.1-2004 Requirement}

5.4.3.4 Vestibules. A door that separates conditioned space from the exterior shall be protected with an enclosed vestibule, with all doors opening into and out of the vestibule equipped with self-closing devices. Vestibules shall be designed so that in passing through the vestibule it is not necessary for the interior and exterior doors to open at the same time. Interior and exterior doors shall have a minimum distance between them of not less than $7 \mathrm{ft}$ when in the closed position. 


\section{Exceptions to 5.4.3.4:}

a. Doors in buildings in climate zones 1 and 2 .

b. Doors in buildings less than four stories above grade.

c. Doors not intended to be used as a building entrance door, such as mechanical or electrical equipment rooms.

d. Doors opening directly from dwelling unit.

e. Doors that open directly from a space less than $3000 \mathrm{ft}^{2}$ in area.

f. Doors in building entrances with revolving doors.

g. Doors used primarily to facilitate vehicular movement or material handling and adjacent personnel doors.

\section{A.3.2 ASHRAE 90.1-2007 requirement (addenda 'c' to ASHRAE 90.1-2004)}

5.4.3.4 Vestibules. A door that separates conditioned space from the exterior shall be protected with an enclosed vestibule, with all doors opening into and out of the vestibule equipped with self-closing devices. Vestibules shall be designed so that in passing through the vestibule it is not necessary for the interior and exterior doors to open at the same time. Interior and exterior doors shall have a minimum distance between them of not less than $7 \mathrm{ft}$ when in the closed position. The exterior envelope of conditioned vestibules shall comply with the requirements for a conditioned space. The interior and exterior envelope of unconditioned vestibules shall comply with the requirements for a semiheated space.

Exceptions:

a. Building entrances with revolving doors.

b. Doors not intended to be used as a building entrance.

c. Doors opening directly from dwelling unit.

d. Building entrances in buildings located in climate zone 1 or 2 .

e. Building entrances in buildings located in climate zone 3 or 4 that are less than four stories above grade and less than $10,000 \mathrm{ft} 2$ in area.

f. Building entrances in buildings located in climate zone 5, 6, 7, or 8 that are less than 1,000 ft2 in area.

g. Doors that open directly from a space that is less than $3000 \mathrm{ft} 2$ in area and is separate from the building entrance.

In Table A.2 and Table A.3, all the prototypes in each climate zone are identified for the vestibule requirement for each version of Standard 90.1. From Tables A.2 and A.3, we can identify that large office, large hotel, high-rise apartment and hospital prototypes require vestibules in 90.1-2004 and in 90.1-2007 except in zones 1 and 2. Therefore, these buildings are assumed to have no savings by vestibule requirements in this study. 
Table A.1. Prototype Model Characteristics to Determine Vestibule Requirements

\begin{tabular}{|l|l|l|l|l|l|}
\hline Building Prototype & $\begin{array}{l}\text { Gross Floor } \\
\text { Area }\left(\mathrm{ft}^{2}\right)\end{array}$ & $\begin{array}{l}\text { Number of } \\
\text { stories }\end{array}$ & $\begin{array}{l}\text { Floor Footprint } \\
\text { Area }\left(\mathrm{ft}^{2}\right)\end{array}$ & $\begin{array}{l}\text { Entrance Zone } \\
\text { Area* }\left(\mathrm{ft}^{2}\right)\end{array}$ & $\begin{array}{l}\text { Building } \\
\text { Height }\left(\mathrm{ft}^{2}\right)\end{array}$ \\
\hline Large Office & 498,600 & 12 & 38,400 & 3,373 & 156 \\
\hline Medium Office & 54,000 & 3 & 17,876 & 2,232 & 39 \\
\hline Hospital & 241,410 & 5 & 40,250 & 15,875 & 78 \\
\hline Warehouse & 49,500 & 1 & 49,500 & 2,550 & 28 \\
\hline Mid-rise Apartment & 33,700 & 4 & 8,436 & 836 & 40 \\
\hline Small Office & 5,500 & 1 & 5,500 & 1,221 & 10 \\
\hline Strip Mall & 22,500 & 1 & 22,500 & $3,750 / 1,875$ & 17 \\
\hline Stand-alone Retail & 24,695 & 1 & 24,695 & 17,227 & 20 \\
\hline Primary School & 73,960 & 1 & 73,960 & 1,840 & 13 \\
\hline Secondary School & 210,900 & 2 & 128,242 & 2,260 & 26 \\
\hline Small Hotel & 43,200 & 4 & 10,800 & 1,755 & 38 \\
\hline Large Hotel & 122,130 & 6 & 21,300 & 14,081 & 71 \\
\hline Outpatient Health Care & 40,950 & 3 & 13,650 & 1096 & 30 \\
\hline Fast Food Restaurant & 2,500 & 1 & 2,500 & 1,250 & 10 \\
\hline Sit-down Restaurant & 5,500 & 1 & 5,500 & 4,002 & 10 \\
\hline
\end{tabular}

* Entrance zone area is a space where the entrance doors are located.

Table A.2. ASHRAE 90.1 - 2004 Vestibule Requirement for All Prototypes in Each Zone

\begin{tabular}{|l|l|l|l|l|l|l|l|l|}
\hline Building Prototype & Zone 1 & Zone 2 & Zone 3 & Zone 4 & Zone 5 & Zone 6 & Zone 7 & Zone 8 \\
\hline Large Office & No (a) & No (a) & Yes & Yes & Yes & Yes & Yes & Yes \\
\hline Medium Office (b),(e) & No (a) & No (a) & No & No & No & No & No & No \\
\hline Hospital & No (a) & No (a) & Yes & Yes & Yes & Yes & Yes & Yes \\
\hline Warehouse (b),(e) & No (a) & No (a) & No & No & No & No & No & No \\
\hline Mid-rise Apartment (e) & No (a) & No (a) & No & No & No & No & No & No \\
\hline Small Office (b),(e) & No (a) & No (a) & No & No & No & No & No & No \\
\hline Strip Mall (b) & No (a) & No (a) & No & No & No & No & No & No \\
\hline Stand-alone Retail (b) & No (a) & No (a) & No & No & No & No & No & No \\
\hline Primary School (b),(e) & No (a) & No (a) & No & No & No & No & No & No \\
\hline Secondary School (b),(e) & No (a) & No (a) & No & No & No & No & No & No \\
\hline Small Hotel (e) & No (a) & No (a) & No & No & No & No & No & No \\
\hline Large Hotel & No (a) & No (a) & Yes & Yes & Yes & Yes & Yes & Yes \\
\hline Outpatient Health Care (b) & No (a) & No (a) & No & No & No & No & No & No \\
\hline Fast Food Restaurant (b),(e) & No (a) & No (a) & No & No & No & No & No & No \\
\hline Sit-down Restaurant (b) & No (a) & No (a) & No & No & No & No & No & No \\
\hline
\end{tabular}

Note: The vestibule requirement exceptions are shown in parenthesis. 
Table A.3. ASHRAE 90.1 - 2007 Vestibule Requirement for All Prototypes in Each Zone (Addendum 'c' to $90.1-2004)$

\begin{tabular}{|l|l|l|l|l|l|l|l|l|}
\hline Building Prototype & Zone 1 & Zone 2 & Zone 3 & Zone 4 & Zone 5 & Zone 6 & Zone 7 & Zone 8 \\
\hline Large Office & No (d) & No (d) & Yes & Yes & Yes & Yes & Yes & Yes \\
\hline Medium Office & No (d) & No (d) & Yes & Yes & Yes & Yes & Yes & Yes \\
\hline Hospital & No (d) & No (d) & Yes & Yes & Yes & Yes & Yes & Yes \\
\hline Warehouse & No (d) & No (d) & Yes & Yes & Yes & Yes & Yes & Yes \\
\hline Mid-rise Apartment & No (d) & No (d) & Yes & Yes & Yes & Yes & Yes & Yes \\
\hline Small Office & No (d) & No (d) & No (e) & No (e) & Yes & Yes & Yes & Yes \\
\hline Strip Mall & No (d) & No (d) & Yes & Yes & Yes & Yes & Yes & Yes \\
\hline Stand-alone Retail & No (d) & No (d) & Yes & Yes & Yes & Yes & Yes & Yes \\
\hline Primary School & No (d) & No (d) & Yes & Yes & Yes & Yes & Yes & Yes \\
\hline Secondary School & No (d) & No (d) & Yes & Yes & Yes & Yes & Yes & Yes \\
\hline Small Hotel & No (d) & No (d) & Yes & Yes & Yes & Yes & Yes & Yes \\
\hline Large Hotel & No (d) & No (d) & Yes & Yes & Yes & Yes & Yes & Yes \\
\hline High-rise Apartment & No (d) & No (d) & Yes & Yes & Yes & Yes & Yes & Yes \\
\hline Outpatient Health Care & No (d) & No (d) & Yes & Yes & Yes & Yes & Yes & Yes \\
\hline Fast Food Restaurant & No (d) & No (d) & No (e) & No (e) & Yes & Yes & Yes & Yes \\
\hline Sit-down Restaurant & No (d) & No (d) & No (e) & No (e) & Yes & Yes & Yes & Yes \\
\hline
\end{tabular}

Note: The vestibule requirement exceptions are shown in parenthesis

\section{A.4 Modeling Strategy for Door-Infiltration With and Without Vestibules}

Door infiltration can be determined based on the information of the type and use of building and of outdoor wind speed and building pressure differentials. Since air flow through a door for each use is assumed to be constant in this analysis, the number of people using a door per hour can be identified as an important parameter to estimate air flow through doors for different type of buildings. The pressure difference across a door in a building is one of driven factors in the air flow calculation. This pressure difference depends on pressure difference due to stack effect and wind-induced surface pressure to static pressure. The ASHRAE design values [1] for the square root of the pressure difference across the door can be used in the door-airflow calculation.

Following the method introduced in the ASHRAE handbook [1], the infiltration rate through the automatic door can be determined by

$$
Q=C_{A} A R_{p}
$$

where $\mathrm{Q}$ is airflow rate $(\mathrm{cfm}), \mathrm{C}_{\mathrm{A}}$ is air flow coefficient $\left(\mathrm{cfm} / \mathrm{ft}^{2}\right.$-(in. of water) $\left.{ }^{0.5}\right), \mathrm{A}$ is area of the door opening $\left(\mathrm{ft}^{2}\right)$, and $\mathrm{R}_{\mathrm{p}}$ is pressure factor (in. of water ${ }^{0.5}$ ).

The air flow coefficient $\mathrm{C}_{\mathrm{A}}$ with and without vestibules, as shown in Figure A.1, can be expressed as a function of the door-opening frequency (i.e., the number of people using a door per hour). Note that Figure A.1 was developed by ASHRAE research project RP-763 [6] to simplify the airflow calculation 
through automatic doors with the following assumptions: (a) the wind velocity on the design day is assumed to be at $15 \mathrm{mph}$; (b) the neutral pressure plane is assumed to be at the mid-height of the building; and (c) the draft coefficient in the building is 0.9. Assumption (b) is conservative since the neutral pressure would be lower than mid-point if the door is open.

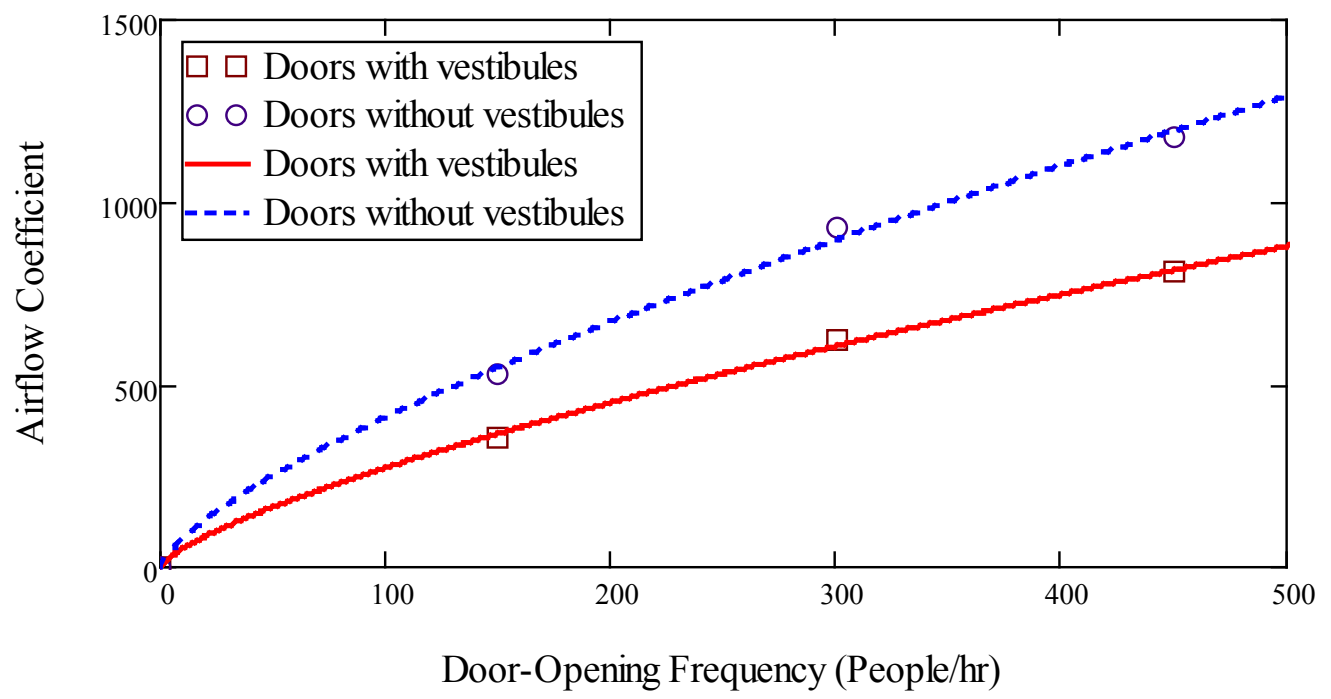

Figure A.1. Air Flow Coefficient vs. Door-Opening Frequency (interpreted using data in [1])

The pressure factor $R_{p}$, which is a design value and represents the pressure difference across the door, can be obtained using Figure A.2. This value remains the same regarding the presence of vestibules.

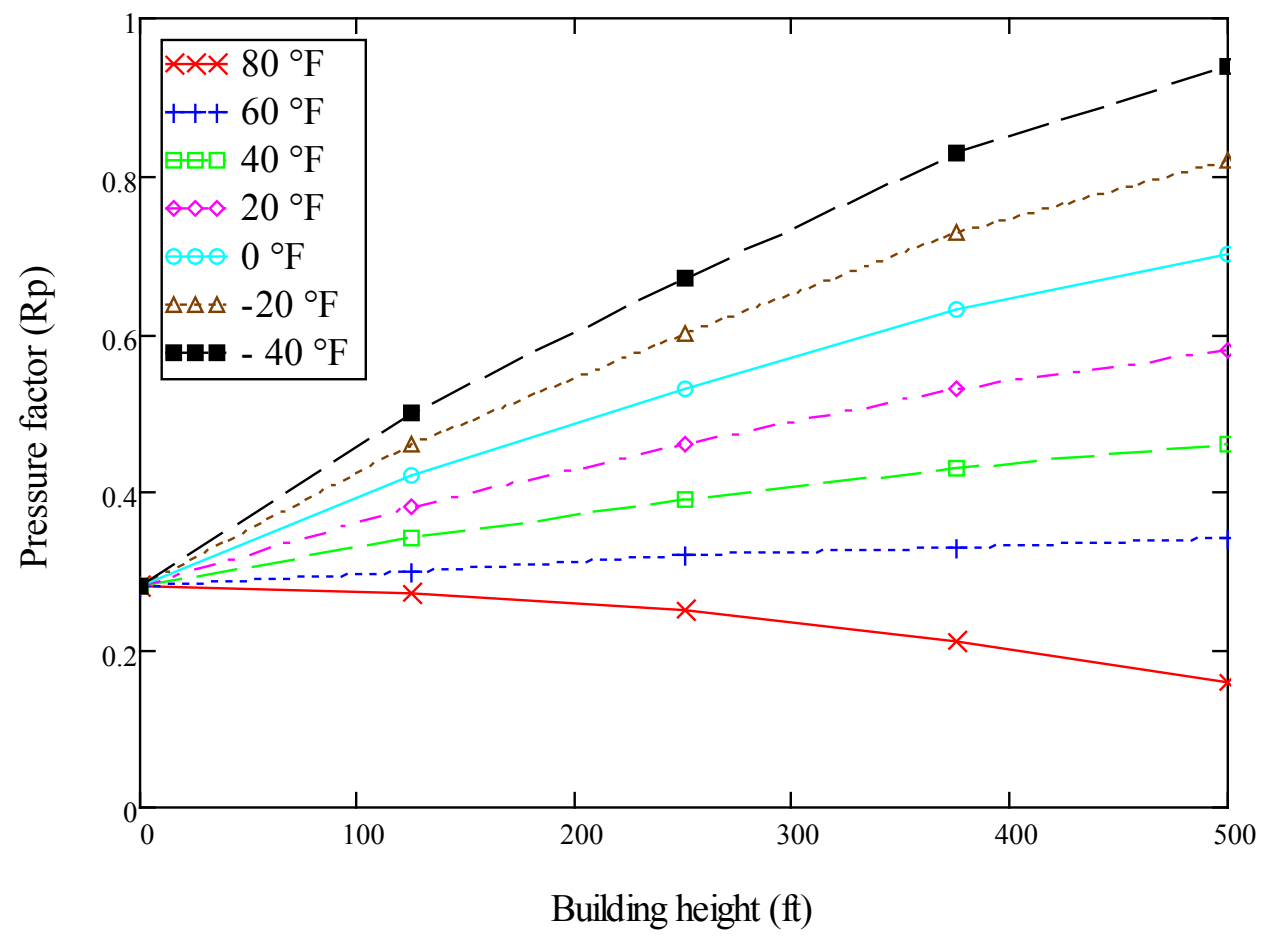

Figure A.2. Pressure Factor vs. Building Height at Different Outdoor Air Temperatures (interpreted using data in [1]) 


\section{A.5 Estimation of Door-Opening Frequency}

Estimating reasonable values of door-opening frequency for different types of buildings is significantly important to calculate the airflow rate through doors. Door-opening frequency can be determined by field observations, but it is a costly and time-consuming work. It can also be determined by estimating occupancy information in buildings. In the analysis, occupancy field data was used for some prototype buildings if the data is available in the literature. Otherwise the number of occupancy in each prototype building is estimated to determine the door-opening frequency. The detailed method to estimate the number of occupancy for each prototype is described in the following.

\section{A.5.1 Small Office, Medium Office, and Warehouse}

The number of occupancy (workers) for small office, medium office, and warehouse is estimated based on the occupancy survey data collected from Commercial Buildings Energy Consumption Survey (CBECS) by Energy Information Administration (EIA) [2]. From the 2003 CBECS data, the numbers of workers for small office, medium office, and warehouse are determined to be 9,105 , and 5, respectively.

\section{A.5.2 Stand-Alone Retail and Strip Mall}

The average door-opening frequency for stand-alone retail stores is obtained directly from the field observation data collected by Yuill [6]. The total number of 52 data sets was collected in different locations. The average door-opening frequency is then calculated to be 153 (people/hour). Note that this value is used for the number of people in the store during peak hours. The strip mall prototype is assumed to have the same number of people $\left(\mathrm{N}_{\text {retail }}\right)$ per entrance zone area $\left(\mathrm{A}_{\text {retail }}\right)$. The entrance zone area of the stand-alone retail prototype $\left(\mathrm{A}_{\text {retail }}\right)$ is $17,227 \mathrm{ft}^{2}$ (see Table 1$)$. Then the area occupied per person $\left(\mathrm{O}_{\text {retail }}\right)$ for the retail prototype is determined as

$$
\mathrm{O}_{\text {retail }}=\mathrm{A}_{\text {retail }} / \mathrm{N}_{\text {retail }}=112.6 \mathrm{ft}^{2}
$$

In the strip mall prototype, there are two different sizes of stores: two stores with $3,750 \mathrm{ft}^{2}$ and eight stores with $1,875 \mathrm{ft}^{2}$. Then the number of occupancy of the strip mall prototype $\left(\mathrm{N}_{\text {strip }}\right)$ for each zone size can be estimated as

$$
\begin{aligned}
& \text { Large store: Nstrip }=3,750 \mathrm{ft}^{2} / \mathrm{O}_{\text {retail }} \approx 33 \\
& \text { Small store: Nstrip }=1,875 \mathrm{ft}^{2} / \mathrm{Or}_{\text {etail }} \approx 17
\end{aligned}
$$

\section{A.5.3 Primary and Secondary Schools}

The total number of occupancy in schools consists of the number of staffs including teachers and the number of students. The number of staffs for primary school and secondary school are estimated to be 64 and 115, respectively, from the CBECS data [2]. Then the number of students is estimated based on the national averages of teacher-to-staff ratio $\left(\mathrm{R}_{\mathrm{t} 2 \mathrm{sf}}\right)$ and student-to-teacher ratio $\left(\mathrm{R}_{\mathrm{s} 2 \mathrm{t}}\right)$ :

$$
\begin{aligned}
& \text { Number of teachers }=\text { Number of staffs } X R_{t 2 s f} \\
& \text { Number of students }=\text { Number of teachers } X R_{s 2 t}
\end{aligned}
$$


where the national average of teacher-to-staff ratio is 0.512 in 2005 [3] and the national average of student-to-teacher ratio is 15.7 in 2005 [4]. The total number of occupancy is the sum of the number of students and staffs. Finally the total number of occupancy can be estimated to be 580 for the primary school prototype and 1,041 for the secondary school prototype.

\section{A.5.4 Fast-Food and Sit-Down Restaurants}

The number of customers for fast-food and sit-down restaurant prototype buildings is determined according the field study conducted by Claar et al. [5]. The average daily number of customers was reported as 898 for a fast-food restaurant and 284 for a sit-down restaurant. It is assumed that a half of customers for a fast-food restaurant use drive-through. If we assume that the customers evenly visit during 5 hours of peak time, the number of customers can be estimated as $90(=898 / 2 / 5)$ for the fast-food restaurant model and $57(=284 / 5)$ for the sit-down restaurant model.

\section{A.5.5 Outpatient Health Care}

The average door-opening frequency for outpatient health care is directly obtained from the field observation data collected by Yuill [6]. The total number of 16 data sets was collected in different locations. The average door-opening frequency is calculated to be 123 (people/hour). This value is used for the peak hour door-opening frequency.

\section{A.5.6 Small Hotel and Mid-Rise Apartment}

For small hotel, mid-rise apartment, and high-rise apartment prototypes, the number of rooms/units is used to estimate the number of occupancy. In the small hotel prototype, 77 rooms are available for customers. According to the 2007 Lodging Industry Profile report [7], the average occupancy rate was 63.3 percent for the lodging industry in 2006 and there is usually one person in a business room and two persons in a leisure room. Based on this information, it is assumed that 65 percent of the guest rooms are occupied and 1.5 people stay in each rented room. From the CBECS data [2], the average number of workers in small hotels is given by 15 . Then the total number of occupancy in the hotel prototype can be determined as $90(\approx 77 \times 0.65 \times 1.5+15)$. There are 23 apartment units available for residence in the mid-rise apartment prototype. It is been assumed that an average of two people live in each apartment. Then the total numbers of residence are estimated to be $46(=23 \mathrm{X} 2)$ for the mid-rise apartment.

The estimated values of the number of occupancy and door-opening frequency are listed in Table A.4. The door-opening frequency for peak-hour is assumed to be equal to the number of occupancy in a building. The values for off-peak-hour are estimated by one tenth of the values for peak-hour. 
Table A.4. Door-Opening Frequency Estimation

\begin{tabular}{|c|c|c|c|}
\hline \multirow{2}{*}{ Building Type } & \multirow{2}{*}{$\begin{array}{c}\text { Number of } \\
\text { occupancy }\end{array}$} & \multicolumn{2}{|c|}{ Door-opening frequency (number of people/hour) } \\
\cline { 3 - 4 } & & Peak & Off-peak \\
\hline Small office & 9 & 9 & 1 \\
\hline Medium office & 105 & 105 & 10 \\
\hline Warehouse & 23 & 23 & 2 \\
\hline Stand-alone retail & 153 & 153 & $3 / 2$ \\
\hline Strip mall & $33 / 17$ & $33 / 17$ & 58 \\
\hline Primary school & 580 & 580 & 104 \\
\hline Secondary school & 1041 & 1041 & 9 \\
\hline Fast food restaurant & 90 & 90 & 12 \\
\hline Sit-down restaurant & 57 & 57 & 9 \\
\hline Outpatient health care & 123 & 123 & 5 \\
\hline Small hotel & 90 & 90 & 46 \\
\hline Mid-rise apartment & 46 & & \\
\hline
\end{tabular}

In Table A.5, the door-opening schedule for each prototype is estimated based on the occupancy schedule in the benchmark building models. Note that the cells highlighted in yellow indicate the off-peak hours while the cells highlighted in green indicate the peak hours. For the restaurants, the fractions values of the peak hour door-opening frequency are used and presented in Table A.5. 
Table A.5. Door-Opening Schedule

\begin{tabular}{|c|c|c|c|c|c|c|c|c|c|c|c|c|c|c|c|c|c|c|c|c|}
\hline & & $12-6 a$ & $6-7 \mathrm{a}$ & $7-8 \mathrm{a}$ & $8-9 a$ & $9-10 \mathrm{a}$ & $\begin{array}{l}10- \\
11 \mathrm{a}\end{array}$ & \begin{tabular}{|l|}
$11 \mathrm{a}-$ \\
$12 \mathrm{p}$
\end{tabular} & $12-1 p$ & $1-2 p$ & $2-3 p$ & $3-4 p$ & $4-5 p$ & $5-6 p$ & $6-7 p$ & $7-8 p$ & $8-9 p$ & $9-10 p$ & $\begin{array}{l}10- \\
11 \mathrm{p}\end{array}$ & $\begin{array}{l}11- \\
12 a\end{array}$ \\
\hline \multirow{2}{*}{ Small Office } & Week Day & & & & & & & & & & & & & & & & & & & \\
\hline & Weekend & & & & & & & & & & & & & & & & & & & \\
\hline \multirow{2}{*}{ Medium Office } & Week Day & & & & & & & & & & & & & & & & & & & \\
\hline & Weekend & & & & & & & & & & & & & & & & & & & \\
\hline \multirow{2}{*}{ Warehouse } & Week Day & & & & & & & & & & & & & & & & & & & \\
\hline & Weekend & & & & & & & & & & & & & & & & & & & \\
\hline Strip mall & All & & & & & & & & & & & & & & & & & & & \\
\hline \multirow{2}{*}{ Primary school } & Week Day & & & & & & & & & & & & & & & & & & & \\
\hline & Weekend & & & & & & & & & & & & & & & & & & & \\
\hline \multirow{2}{*}{$\begin{array}{l}\text { Secondary } \\
\text { school }\end{array}$} & Week Day & & & & & & & & & & & & & & & & & & & \\
\hline & Weekend & & & & & & & & & & & & & & & & & & & \\
\hline $\begin{array}{l}\text { Fast food } \\
\text { restaurant }\end{array}$ & Weekend & & 0.144 & 0.558 & 0.558 & 0.462 & 0.258 & 0.462 & 0.558 & 0.558 & 0.462 & 0.363 & 0.363 & 0.363 & 0.74 & 0.915 & 0.74 & 0.65 & 0.558 & 0.363 \\
\hline \multirow{2}{*}{$\begin{array}{l}\text { Sit-down } \\
\text { restaurant }\end{array}$} & Week Day & & 0.144 & 0.462 & 0.462 & 0.462 & 0.258 & 0.558 & 0.829 & 0.74 & 0.462 & 0.258 & 0.363 & 0.558 & 0.829 & 0.829 & 0.829 & 0.558 & 0.363 & 0.258 \\
\hline & Weekend & & 0.144 & 0.558 & 0.558 & 0.462 & 0.258 & 0.462 & 0.558 & 0.558 & 0.462 & 0.363 & 0.363 & 0.363 & 0.74 & 0.915 & 0.74 & 0.65 & 0.558 & 0.363 \\
\hline \multirow{2}{*}{$\begin{array}{l}\text { Outpatient } \\
\text { health care }\end{array}$} & Week Day & & & & & & & & & & & & & & & & & & & \\
\hline & Weekend & & & & & & & & & & & & & & & & & & & \\
\hline Small Hotel & All & & & & & & & & & & & & & & & & & & & \\
\hline $\begin{array}{c}\text { Mid-rise } \\
\text { Apartment }\end{array}$ & All & & & & & & & & & & & & & & & & & & & \\
\hline
\end{tabular}

\section{A.6 Estimation of Door Infiltration Rate}

Using the method described in Section A.4 and the door-opening frequency information in Section A.5, the door-infiltration rates for each prototype are estimated. In the estimation, the outdoor temperature is assumed to be $60^{\circ} \mathrm{F}$ and the door area is assumed to be $21 \mathrm{ft}^{2}(=7 \mathrm{ft} \times 3 \mathrm{ft}$ ). The estimated values with and without vestibules are presented in Table A.6.

Table A.6. Door Infiltration Rate With and Without Vestibules

\begin{tabular}{|c|c|c|c|c|}
\hline \multirow{2}{*}{ Building Type } & \multicolumn{2}{|c|}{$\begin{array}{c}\text { Door infiltration rate (cfm) with a } \\
\text { vestibule }\end{array}$} & $\begin{array}{c}\text { Door infiltration rate (cfm) without a } \\
\text { vestibule }\end{array}$ \\
\cline { 2 - 5 } & Peak & Off-peak & Peak & Off-peak \\
\hline Small office & 162 & 21 & 275 & 40 \\
\hline Medium office & 1,438 & 188 & 2,210 & 318 \\
\hline Warehouse & 374 & 49 & 612 & 88 \\
\hline Stand-alone retail & 1,986 & 260 & 3,006 & 432 \\
\hline Strip mall & $511 / 285$ & $67 / 37$ & $824 / 471$ & $118 / 68$ \\
\hline Primary school & 6,423 & 840 & 9,205 & 1,323 \\
\hline Secondary school & 10,837 & 1,417 & 15,161 & 2,179 \\
\hline Fast food restaurant & 1,237 & 162 & 1,913 & 275 \\
\hline Sit-down restaurant & 826 & 108 & 1,302 & 187 \\
\hline Outpatient health care & 1,646 & 215 & 2,513 & 361 \\
\hline Small hotel & 1,254 & 164 & 1,940 & 279 \\
\hline Mid-rise apartment & 694 & 91 & 1,103 & 159 \\
\hline
\end{tabular}




\section{A.7 References}

1. 2009 ASHRAE Handbook - Fundamentals, "Commercial and Institutional Air Leakage”, pp. 16.2516.27 .

2. Energy Information Administration, 2003 Commercial Buildings Energy Consumption Survey, http://www.eia.doe.gov/emeu/cbecs/

3. U.S. Department of Education, National Center for Education Statistics, Digest of Education Statistics 2007, Table 78: Staff employed in public elementary and secondary school systems, by type of assignment and state or jurisdiction: Fall 2005. Accessed at: http://nces.ed.gov/programs/digest/d07/tables/dt07 078.asp

4. U.S. student to teacher ratios for Fall 2005 - U.S. Department of Education, National Center for Education Statistics, Digest of Education Statistics 2007, Table 63: Teachers, enrollment, and pupil/teacher ratios in public elementary and secondary schools, by state or jurisdiction: Fall 2005. Accessed at http://nces.ed.gov/programs/digest/d07/tables/dt07 063.asp

5. Claar, C.N., Mazzucchi, R.P. and Heidell, J.A., 1985, "The Project on Restaurant Energy Performance - End-use Monitoring and Analsysis," PNL-5462, Pacific Northwest National Laboratory, Richland, WA

6. Yuill, G.K., 1996, "Impact of High Use Automatic Doors on Infiltration", Project 763-TRP, ASHRAE, Atlanta, GA

7. American Hotel \& Lodging Association, 2007, "The 2007 Lodging Industry Profile", Washington, D.C., Accessed on December 14, 2009 at http://www.ahla.com/content.aspx?id=4214 
Appendix B

Development of Additional Lighting Power for the Strip Mall Prototype 



\section{Appendix B - Development of Additional Lighting Power for the Strip Mall Prototype}

\section{B.1 Introduction}

The purpose of this study is to develop a modeling strategy to capture the energy saving impacts from addendum ai to 90.1-2004. This addendum modifies the allowed additional lighting power for display lighting found in ASHRAE 90.1-2004.

\section{B.2 General Methodology}

The general methodology used was to adjust prototype Standard 90.1-2004 LPDs from the original DOE reference building prototype to create an explicit LPD mapping for space-by-space lighting power and consistent with values being used for the ASHRAE 90.1-2007 Determination and the original DOE reference building prototypes. This includes adding explicit additional lighting power allowance for display lighting in two of the three store types in the prototype. Underlying this is an assumption that the display area available for additional lighting power is 25 percent of total retail store area in order to approximately equal current prototype LPDs for each of three store types.

The ASHRAE strip mall reference building prototype is assumed to have 10 stores: 2 larger stores and 8 smaller stores. These stores and the subsequent total store area were grouped using the Standard 90.1-2004 additional lighting power allowance based on the type of merchandise sold as shown in Table B-1. It is important to note that the additional lighting power allowed in Standard 90.1-2004 was confined to the area of the specific display, not the retail area; however, DOE believes that this distinction was often missed in practice due to the difficult in defining the display area (for instance, the display area can be on the wall of the building, can include counter top area, etc). For this analysis it is assumed that the overall floor area allocated to the additional lighting power was the same under both Standard 90.1 versions.

Table B.1. Strip Mall Area Fraction by Store Groups

\begin{tabular}{|c|c|c|}
\hline $\begin{array}{c}\text { Strip Mall Reference } \\
\text { Prototype Stores }\end{array}$ & $\begin{array}{c}\text { Additional Display or } \\
\text { Accent Lighting Allowed } \\
\text { under Standard 90.1- } \\
\mathbf{2 0 0 4}\end{array}$ & $\begin{array}{c}\text { Total Fraction of Strip } \\
\text { Mall Area in Specific } \\
\text { Store Groupings }\end{array}$ \\
\hline LGstore 1, Smstore 1 & No Accent Lighting & $50 \%$ \\
\hline $\begin{array}{c}\text { SMstore 2, SMstore 3, } \\
\text { SMstore 4 }\end{array}$ & $\begin{array}{c}\text { Accent at } 1.6 \mathrm{w} / \mathrm{ft}^{2} \text { times } \\
\text { area of specific display }\end{array}$ & $25 \%$ \\
\hline $\begin{array}{c}\text { LGstore 2, SMstore 5, } \\
\text { SMStore 6, SMstore 7, } \\
\text { SMstore 8 }\end{array}$ & $\begin{array}{c}\text { Accent at 3.9 } \mathrm{w} / \mathrm{ft}^{2} \text { times } \\
\text { the area of specific display }\end{array}$ & $25 \%$ \\
\hline
\end{tabular}

The relative fraction of stores with these allowed additional lighting power densities reflects the assumptions used in the original DOE commercial reference building prototypes. 
Within the building groupings, the fraction of building floor area devoted to each space type and the corresponding base LPD by space type is developed under Standard 90.1-2004 and is shown in Table B.2. In addition, the base lighting power density for the building groups using the space-by-space LPDs, but without any additional lighting power allowance, is calculated and shown. Finally, the additional lighting power density allowed for each the building groups is shown, and the resulting building weighted average LPD including the additional lighting power allowances is calculated based on 25 percent of the floor area in each group utilizing the allowed additional lighting power.

Table B.2. Calculation of Lighting Power Densities for Building Groups in Strip Mall- Standard 90.12004

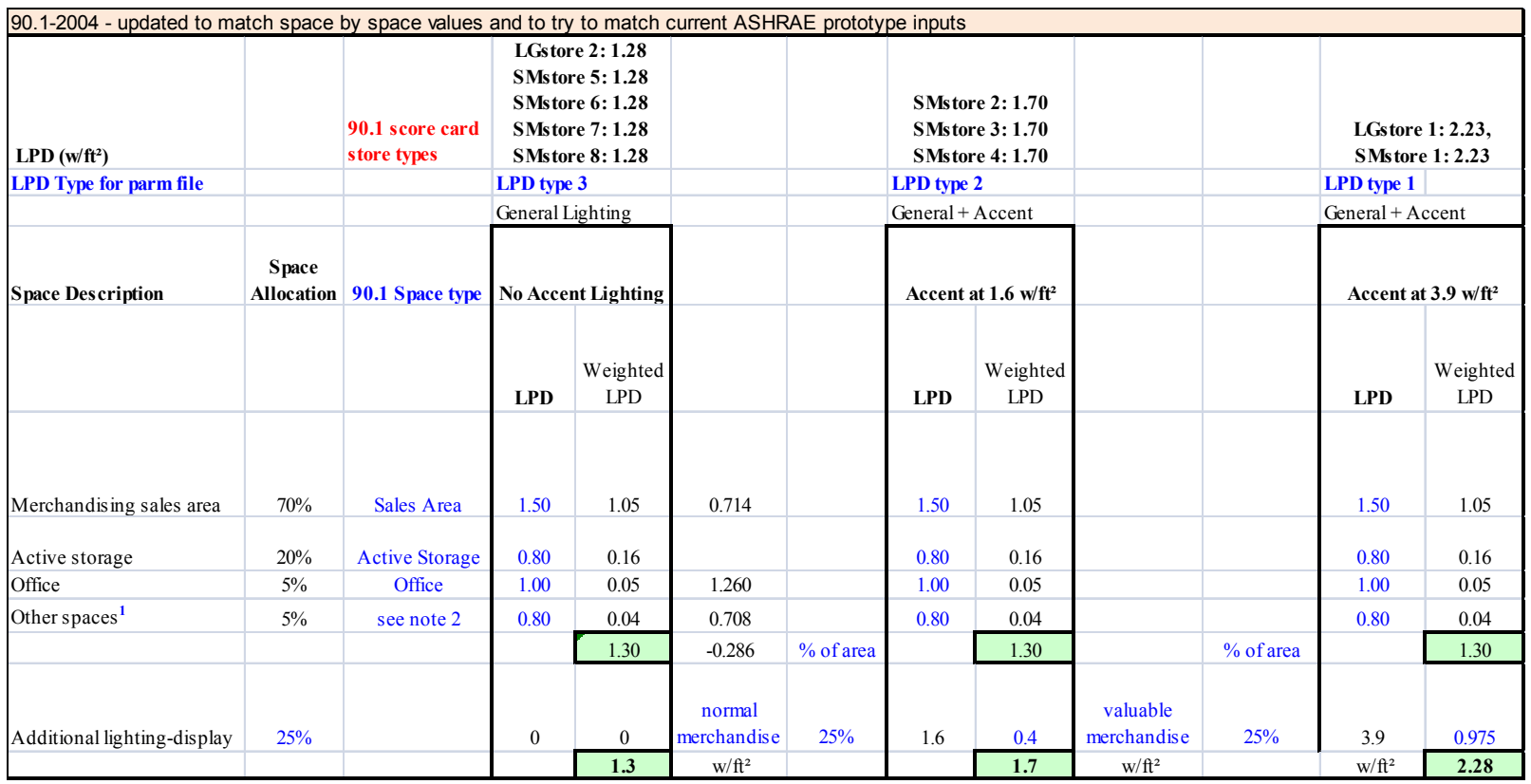

Once the Standard 90.1-2004 lighting levels were developed, they were modified to reflect addendum 90.1-2004 ai using the following assumptions:

- For buildings in which no accent lighting was provided in Standard 90.1-2004, no accent lighting was assumed in Standard 90.1-2007.

- For buildings in which the first tier of additional display lighting power (1.6 W/ft ${ }^{2}$ of specific display area) was assumed in Standard 90.1-2004, the merchandise was assumed to be best represented by retail area type 2 in Standard 90.1-2007 (e.g., sporting goods, small electronics). This provides for $1.7 \mathrm{~W} / \mathrm{ft}^{2}$ additional lighting power over the assumed 25 percent of floor area for display of these products.

- For buildings in which the second tier of additional display lighting power $\left(3.9 \mathrm{~W} / \mathrm{ft}^{2}\right)$ was assumed in Standard 90.1-2004, the merchandise was assumed to be best represented by retail area type 3 in Standard 90.1-2007 (e.g., clothing, furniture, cosmetics, and artwork). This provides for $2.6 \mathrm{~W} / \mathrm{ft}^{2}$ additional lighting power over the assumed 25 percent of floor area for display of these products.

Note that for buildings in the second group, these assumptions result in an increase in allowed additional lighting power. However, for buildings in the third group, a lower additional lighting power 
allowance is assumed for Standard 90.1-2007. The additional lighting power allowance of $3.9 \mathrm{~W} / \mathrm{ft}^{2}$ of specific display area in Standard 90.1-2004 is described in that Standard as intended for "valuable merchandise, such as jewelry, fine apparel and accessories, china and silver, art, and similar items where detailed display and examination of merchandise is important." In practice, however, the use of the term "valuable" in the description allows for a broader spectrum of merchandise to be considered, and in particular apparel and accessories may make up the bulk of actual retail area considered for use in this category.

The corresponding Standard 90.1-2007 retail area category for clothing, furniture, cosmetics, and artwork was chosen to represent the merchandise that would make up the bulk of the floor area that could be categorized with an additional lighting power allowance of $3.9 \mathrm{~W} / \mathrm{ft}^{2}$ in Standard 90.1-2004. The highest allowed additional lighting power in Standard 90.1-2007 (retail area category 4) is explicitly reserved to display of jewelry, crystal, and china, and none of the floor space in the strip mall was mapped to this category.

Table B.3 shows the development of the lighting power density under Standard 90.1-2007 additional lighting power assumptions. The different additional lighting power assumptions are shown highlighted in yellow for comparison with Table B.1.

The overall whole building lighting power for the strip mall reference prototype is then calculated using the assumed floor area percentages devoted to each of the original building type/additional lighting power groupings as shown in Table B.1. The resulting LPD for buildings by store type is $1.645 \mathrm{~W} / \mathrm{ft}^{2}$ under Standard 90.1-2004 and 1.568 W/ $\mathrm{ft}^{2}$ under Standard 90.1-2007.

Table B.3. Calculation of Lighting Power Densities for Building Groups in Strip Mall- Standard 90.12007 (Addendum ai)

\begin{tabular}{|c|c|c|c|c|c|c|c|c|c|c|c|c|}
\hline $\operatorname{LPD}\left(\mathbf{w} / \mathbf{f t}^{2}\right)$ & & $\begin{array}{l}90.1 \text { score card } \\
\text { store types }\end{array}$ & $\begin{array}{l}\text { LGst } \\
\text { SMst } \\
\text { SMst } \\
\text { SMst } \\
\text { SMst }\end{array}$ & $\begin{array}{l}2: 1.28 \\
5: 1.28 \\
6: 1.28 \\
7: 1.28 \\
8: 1.28\end{array}$ & & & \multirow{2}{*}{\multicolumn{2}{|c|}{$\begin{array}{r}\text { SMs tore 2: } 1.70 \\
\text { SMs tore 3: } 1.70 \\
\text { SMs tore 4: } 1.70 \\
\text { LPD type 2 }\end{array}$}} & & & \multicolumn{2}{|c|}{$\begin{array}{l}\text { LGstore 1: 2.23, } \\
\text { SMstore 1:2.23 }\end{array}$} \\
\hline \multirow[t]{2}{*}{ LPD Type for parm file } & & & LPD ty & & & & & & & & LPD type 1 & \\
\hline & & & General & ighting & & & \multicolumn{2}{|c|}{ General + Accent } & & & \multicolumn{2}{|c|}{ General + Accent } \\
\hline \multirow[t]{2}{*}{ Space Description } & $\begin{array}{c}\text { Space } \\
\text { Allocation }\end{array}$ & 90.1 Space type & \multicolumn{2}{|c|}{ No Accent Lighting } & & & \multicolumn{2}{|c|}{ Accent at $1.6 \mathrm{w} / \mathrm{ft}^{2}$} & & & \multicolumn{2}{|c|}{ Accent at $3.9 \mathrm{w} / \mathbf{f t}^{2}$} \\
\hline & & & LPD & $\begin{array}{l}\text { Weighted } \\
\text { LPD }\end{array}$ & & & LPD & $\begin{array}{l}\text { Weighted } \\
\text { LPD }\end{array}$ & & & LPD & $\begin{array}{l}\text { Weighted } \\
\text { LPD }\end{array}$ \\
\hline Merchandising sales area & $70 \%$ & Sales Area & 1.5 & 1.05 & & & 1.5 & 1.05 & & & 1.5 & 1.05 \\
\hline Active storage & $20 \%$ & Active Storage & 0.8 & 0.16 & & & 0.8 & 0.16 & & & 0.8 & 0.16 \\
\hline Office & $5 \%$ & Office & 1 & 0.05 & & & 1 & 0.05 & & & 1 & 0.05 \\
\hline \multirow[t]{2}{*}{ Other spaces ${ }^{1}$} & $5 \%$ & see note 2 & 0.8 & 0.04 & & & \multirow[t]{2}{*}{0.8} & 0.04 & & & \multirow[t]{2}{*}{0.8} & 0.04 \\
\hline & & & & 1.3 & & $\%$ of area & & 1.3 & & $\%$ of area & & 1.3 \\
\hline \multirow[t]{2}{*}{ Additional lighting-display } & $25 \%$ & & 0 & 0 & $\begin{array}{c}\text { Retail area } \\
\text { type } 2 \text { (for } \\
\text { electronics) }\end{array}$ & $25 \%$ & \multirow[t]{2}{*}{1.7} & 0.425 & $\begin{array}{l}\text { Retail area } \\
\text { type } 3 \text { (for } \\
\text { sporting } \\
\text { goods) }\end{array}$ & $25 \%$ & \multirow{2}{*}{$\begin{array}{c}2.6 \\
\mathrm{w} / \mathrm{ft}^{2}\end{array}$} & 0.65 \\
\hline & & & & 1.3 & $\mathrm{w} / \mathrm{ft}^{2}$ & & & 1.73 & $\mathrm{w} / \mathrm{ft}^{2}$ & & & 1.95 \\
\hline
\end{tabular}






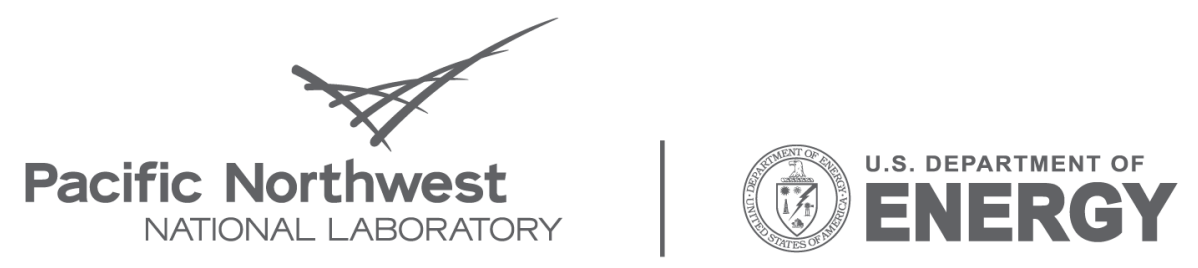

Proudly Operated by Battelle Since 1965

902 Battelle Boulevard

P.O. Box 999

Richland, WA 99352

1-888-375-PNNL (7665)

www.pnl.gov 